\title{
Recent Developments in Treating Cognitive Impairment Associated with
} Schizophrenia

Robert A. Bittner ${ }^{1,2^{*}}$, Catherine V. Barnes-Scheufler ${ }^{1}$, Meike D. Hettwer ${ }^{1,3}$, Andreas Reif $^{1}$, Mishal Qubad ${ }^{1}$

${ }^{1}$ Department of Psychiatry, Psychosomatic Medicine, and Psychotherapy, University Hospital Frankfurt, Goethe University, Frankfurt, Germany

${ }^{2}$ Ernst Strüngmann Institute for Neuroscience in Cooperation with Max Planck Society, Frankfurt am Main, Germany

${ }^{3}$ Max Planck School of Cognition, Max Planck Institute for Human Cognitive and Brain Sciences (MPI CBS), Leipzig, Germany

${ }^{*}$ Corresponding author. Department of Psychiatry, Psychosomatic Medicine and Psychotherapy, University Hospital Frankfurt, Goethe University, Heinrich-Hoffmann-

Str. 10, D-60528 Frankfurt am Main, Germany.

Phone: +49696301 84713. Fax: +4969630181775.

Email: robert.bittner@med.uni-frankfurt.de

Total number of words in abstract: 199/200

Total number of words in text: 11708 


\section{ORCID IDs}

R.A.B.: orcid.org/0000-0003-2021-0358

C.V.B.-S.: orcid.org/0000-0002-4730-1981

M.D.H.: orcid.org/0000-0002-7973-6752

A.R.: orcid.org/0000-0002-0992-634X

M.Q.: orcid.org/0000-0002-9291-5739 


\section{ABSTRACT}

Pervasive and wide-ranging cognitive deficits are a core feature of schizophrenia and an important determinant of long-term functional outcome. The lack of sufficiently effective treatments for cognitive impairment associated with schizophrenia (CIAS) represents a major unmet need and a central roadblock towards recovery. This is partly due to the current therapeutic focus on clinical symptoms, and the relative neglect of cognitive impairments despite their functionally disabling effects. Furthermore, effective treatment is impeded by our limited knowledge of the complex pathophysiology, which gives rise to perturbed information processing. Here, we review mechanisms and effectiveness of available pharmacological and nonpharmacological treatments for CIAS. Current evidence indicates, that while techniques which broadly enhance neural plasticity show the greatest therapeutic potential, effect sizes are at best moderate. Among other reasons, this is due to a considerable heterogeneity of responses to individual interventions. Furthermore, we discuss how recent conceptual advances in operationalizing cognitive impairments based on cognitive neuroscience have the potential to address these issues and facilitate the development of novel treatment strategies for CIAS. This includes more clearly elucidating pathophysiological mechanisms in both humans and animal models, identifying new treatment targets as well as establishing biomarkers for a better prediction of treatment responses.

\section{KEYWORDS}

Schizophrenia, cognitive dysfunction, neural plasticity, inflammation, cognitive imaging biomarker, pharmacological treatment, cognitive remediation, aerobic exercise, brain stimulation 


\section{Introduction}

"I have no common thread in my thinking. I take so much information into my consciousness, but I cannot process it. I cannot structure the whole flood of information, which is in my head, and sort it according to importance. Dividing a task into small individual steps and then working through them in a structured manner is sometimes an impossibility. I have a hard time focusing. I was preparing a presentation with my fellow students and my head would just shut down again and again."

These words by a patient suffering from schizophrenia succinctly summarize the considerable functional burden resulting from the wide-ranging and pervasive cognitive disturbances, which constitute a central feature of the disorder. Currently, the lack of broadly effective and durable treatment options for CIAS constitutes one of the greatest therapeutic challenges and a major unmet need [1-3]. In this review we summarize recent conceptual advances aiming to reduce translational obstacles on the way towards addressing this important issue. We examine current efforts to expand both pharmacological and non-pharmacological cognitive enhancement approaches and discuss mechanistic similarities. Finally, we outline important areas for future research, which should facilitate the development of novel and more effective procognitive interventions.

\section{Section I: Schizophrenia - a disorder of impaired information processing}

The cognitive phenotype

On average, patients with schizophrenia consistently score about two standard deviations lower than healthy controls in a wide variety of cognitive domains including attention, executive function, verbal fluency, working and long-term memory [4-12]. 
Indeed, schizophrenia is first and foremost an information processing disorder [13-16]. Largely due to this characteristic, it is one of the potentially most severe and chronic forms of mental illness, which consistently ranks among the top ten most frequent causes of disability in developed countries [17]. Yet, the current diagnostic criteria of schizophrenia continue to emphasize almost exclusively its clinical symptom dimensions [18,19], which comprise positive symptoms such as hallucinations and delusions, negative symptoms like anhedonia, avolition and social withdrawal as well as thought disorder but do not include concomitant cognitive deficits. This omission of cognitive dysfunction is a key factor contributing to its relative disregard in routine treatment efforts $[1,18,20]$. The inclusion of a cognitive impairment qualifier for schizophrenia in ICD-11 is a first tentative step toward addressing this issue. It will require clinicians to rate the global degree of cognitive deficits along with other symptom dimensions [21].

Importantly, despite its severity and contrary to early conceptual critiques [22], cognitive dysfunction does not result from a global, generalized cognitive deficit $[23,24]$ or an overall reduction in intelligence [25]. This is underscored by evidence for areas of preserved cognitive function [24], whose delineation requires sufficiently refined cognitive models and experimental paradigms [23].

\section{The dysconnection syndrome}

Schizophrenia has a clear neurodevelopmental background with a pathophysiological trajectory spanning multiple decades [26]. Compared to other neurodevelopmental disorders such as autism spectrum disorder (ASD) and attention deficit hyperactivity disorder (ADHD) it has a late onset typically during adolescence or early adulthood [27]. Illness onset is preceded by multiple "hits" triggering 
pathophysiological cascades at several crucial stages of brain development $[26,28]$. There is converging evidence that these processes lead to the emergence of a widespread dysconnection syndrome [29,30], which results in increasing cognitive impairment. Widespread dysconnection on the micro- and macrocircuit level is also a parsimonious explanation for most findings in the vast functional neuroimaging literature on the neurophysiological basis of impaired information processing in schizophrenia [31]. Although a more detailed account of this literature is beyond the scope of this review, this should by no means diminish the vital importance of functional neuroimaging for this field of research.

One central mechanism underlying this dysconnection syndrome appears to be synaptic dysfunction [32]. There is evidence for an enrichment of schizophrenia risk variants in genes related to synaptic function [33-37]. Furthermore, post-mortem studies have also consistently reported synaptic abnormalities [33,38]. An important consequence of synaptic dysfunction are disturbances of synaptic plasticity and other aspects of neural plasticity, which likely contribute to cortical microcircuit dysfunction [38-40]. Together, these mechanisms are widely considered to be a central pathophysiological pathway of schizophrenia and a major point of pathophysiological convergence $[41,42]$.

\section{E/l imbalance}

Recently, one central aspect of microcircuit dysfunction has emerged as an important research focus. Computation in the brain relies crucially on the interplay of cortical excitatory pyramidal cells and inhibitory interneurons, which sets a ratio of excitation and inhibition (E/I balance). Reciprocal excitatory-inhibitory microcircuits are essential for the generation of neural oscillations in the gamma frequency range $(\sim 30$ 
- $200 \mathrm{HZ}$ ) [43]. Gamma oscillations play an important role for a many key cognitive functions including perception, attention, working memory and executive control [4447]. A growing body of evidence of attenuated gamma oscillations in schizophrenia engaged in a variety of cognitive tasks supports the notion that disturbances of gamma oscillations are a major pathophysiological mechanism contributing to CIAS [48-50]. Importantly, a disruption of E/I balance appears to be an important factor underlying disturbed gamma oscillations [51]. Specifically, the break in $E / l$ balance in schizophrenia has been attributed to neurobiological alterations and functional abnormalities of cortical GABAergic inhibitory interneurons [51,52]. Among the different classes of GABAergic interneurons, parvalbumin (PV) expressing neurons have most consistently been implicated [53,54]. PV neurons are recruited by phasic NMDA receptor mediated input from pyramidal neurons and provide recurrent GABAA a1 receptor mediated perisomatic inhibitory feedback $[55,56]$. Recurrent inhibition of excitatory pyramidal cells by PV neurons is a central element of excitatory-inhibitory loops. Importantly, the causal role of PV neurons and other subclasses of interneurons for the generation of high-frequency oscillations has been firmly established by optogenetic experiments $[57,58]$. Abnormalities in PV neurons in schizophrenia include lower messenger RNA and protein levels of the glutamic acid decarboxylase $67 \mathrm{kD}$ isoform (GAD67), a main GABA synthesizing enzyme [52]. Conversely, cortical PV neuron density appears to be unaltered [52]. As a consequence of decreased GAD67 levels in PV neuron terminals inhibitory inputs onto pyramidal neurons are likely reduced, contributing to $\mathrm{E} / \mathrm{I}$ imbalance. These changes appear to form the neurobiological basis for a decreased power of gamma oscillation in schizophrenia [52]. Together, these findings underscore the significance of the altered $E / l$ balance 
and disturbed neural oscillations for understanding the pathophysiology of CIAS and also provide important clues for novel therapeutic avenues [59].

\section{The neurodevelopmental gradient hypothesis}

Schizophrenia is not the only neurodevelopmental disorder with a late onset. Based on converging neuroimaging and genetic evidence of considerable overlap between clinical and especially cognitive symptoms, there appears to be a connection between schizophrenia and bipolar disorder [60], with bipolar disorder having seemingly less neurodevelopmental anomalies connecting with higher functional capacity [61]. Similarly, first episode patients with bipolar disorder have similar but less severe deficits in neurocognition as compared to first episode patients with schizophrenia [62] despite normal pre-morbid cognitive functioning. These findings demonstrate that cognitive deficits in mental disorders are not excusive to schizophrenia. Furthermore, findings from genetic studies have led to the conceptualization of a neurodevelopmental gradient [63]. Accordingly, the gradient of increasing neurodevelopmental and cognitive impairment starts with bipolar disorder having the least impairment, followed by ADHD, schizophrenia, ASD, and intellectual disability [64].

In line with the neurodevelopmental origin of schizophrenia, subtle cognitive deficits can already be detected in children of patients during early adolescence [65]. The first clear indications of cognitive dysfunction can typically be observed during the prodromal phase [66-69] and prior to the manifestation of the first clinical symptoms [70-72]. The largest degree of cognitive decline appears to occur during the early stages of illness before the first full-blown psychotic episode and the initiation of antipsychotic treatment $[73,74]$, leading to a largely stable deficit throughout 
subsequent illness phases [75,76]. Thus, cognitive deficits cannot be considered being a consequence of psychopharmacological interventions. Notably, cognitive deficits are also present in patients with schizophrenia spectrum disorders to a lesser degree $[77,78]$. Subtle disturbance of information processing can also be observed in patients' siblings, especially in first-degree relatives [79-82]. However, cognitive impairment is clearly linked to firmly established common and rare genetic variants conferring risk to schizophrenia [83-87].

The clear link to the emerging genetic architecture, the early onset years before any other overt signs of mental illness, the presence in unaffected relatives and the persistence over the course of the illness independent of medication status [88] clearly indicate that cognitive impairments are not secondary sequelae of the disorder. Rather, they are now widely regarded as a direct consequence of abnormal brain function and a primary correlate of the pathophysiology of schizophrenia $[16,29,89]$.

This conceptual shift is not limited to schizophrenia but applies to most major psychiatric disorders [90]. Accordingly, it is also the basis of the research domain criteria (RDoC) initiative, which was launched by the National Institute of Mental Health (NIMH) in order to characterize mental disorders based on biological mechanisms, rather than the traditional clinically operationalized diagnostic categories [91]. The dimensional RDoC framework is founded on three major premises: mental illnesses can be conceptualized as brain disorders, clinical neuroscience measurements can reliably asses the underlying neural circuit dysfunction, and genetic and clinical neuroscience data can generate "biosignatures" across conventional diagnostic boundaries that lead to considerable improvements in uncovering basic neurobiological mechanisms and hence diagnosis and treatment of mental disorders $[92,93]$. Accordingly, essential cognitive systems comprising the constructs perception, 
attention, working memory, cognitive control, declarative memory as well as language are a crucial element of the RDoC matrix. This highlights their importance for braincircuit-based conceptualizations of mental disorders and should also facilitate a greater focus on treating cognitive dysfunction.

\section{The functional consequences of cognitive dysfunction}

The necessity for a change of focus from clinical to cognitive symptoms in the treatment of schizophrenia is underscored by the lack of a correlation between psychotic symptoms and functional outcome [94]. In fact, the treatment of positive symptoms does not seem to improve cognitive deficits to a relevant degree [95]. Conversely, a clear connection has been demonstrated between current cognitive deficits and later levels of community functioning, which strongly depends on patients' general functional capacity $[2,96]$.

Cognitive deficits strongly affect key aspects of patients' life including social relationships, living independently and employment $[1,97,98]$, severely impeding their ability to return into successful lives. Furthermore, the diagnosis of schizophrenia is correlated to high incidence rates of homelessness $[99,100]$. These factors contribute substantially to the enormous societal impact and indirect costs of schizophrenia [101]. This significant societal cost of schizophrenia pose a heavy economic burden of healthcare costs and productivity loss [102]. The toll on patients is also reflected by reduced reproductive and marital rates [103].

Importantly, the degree of cognitive impairment is a strong indicator of occupational functioning with more deficits correlating with less employment [104]. With more employment success, patients are able to live independently, significantly increasing their quality of life $[105,106]$. Accordingly, vocational rehabilitation programs 
with supported employment show effectiveness in employment rates and improvements in cognition [107-109]. Overall, the close relationship between cognition and long-term functional outcome is possibly the single most important rationale for treating cognitive dysfunction [2] (Figure 1).

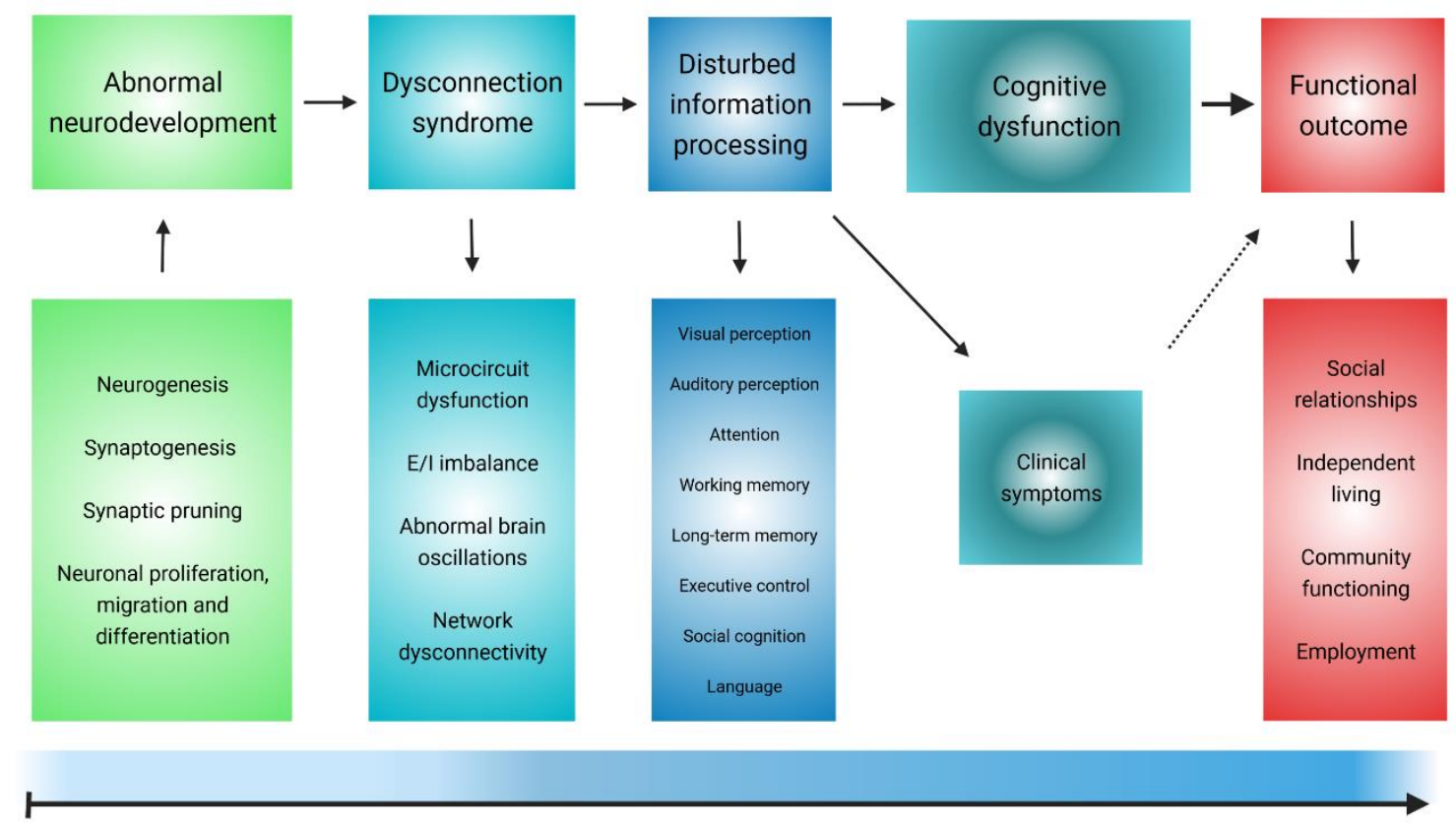

Figure 1

\section{Figure 1: Cognitive dysfunction and the pathophysiology of schizophrenia}

Schizophrenia is a neurodevelopmental disorder leading to a dysconnection syndrome and inducing disturbed information processing. Impaired information processing is the basis of both cognitive dysfunction and clinical symptoms. With respect to patients' functional outcome cognitive dysfunction is of particular relevance.

Operationalizing and assessing cognitive dysfunction 
Important prerequisites for treating cognitive deficits are the definition and operationalization of relevant cognitive domains and the possibility of their reliable and repeated assessment in patient populations. An important concerted effort in this direction was the "Measurement and Treatment Research to Improve Cognition in Schizophrenia" (MATRICS) initiative. It resulted in the creation of the MATRICS cognitive consensus battery (MCCB), a battery of cognitive tasks for the explicit purpose of evaluating the effectiveness of pharmacological and non-pharmacological cognitive enhancement interventions [110]. It includes ten tests probing seven distinct cognitive domains: speed of processing, attention/vigilance, working memory, verbal and visual learning, reasoning and problem solving as well as social cognition. Thus, MATRICS also provided a widely accepted framework of cognitive constructs in order to achieve greater harmonization of research in this field. Yet, MATRICS drew mainly upon tasks from clinical neuropsychology.

Conversely, the "Cognitive Neuroscience Treatment Research to Improve Cognition in Schizophrenia" [111-113] initiative - while building on MATRICS followed a translational research strategy primarily informed by basic cognitive neuroscience. It utilized concepts and constructs firmly established by cognitive neuroscience to study brain systems closely involved in crucial cognitive processes with the goal of identifying mechanisms, which could improve their function in schizophrenia [114]. To this end, CNTRICS aimed to encompass both research in animal models as well as psychophysical and functional neuroimaging research in healthy cohorts and patients. The cognitive domains and constructs deemed to have the greatest translational potential were visual perception, working memory, attention, executive control, long-term memory, and social cognition. 
The design and selection process for cognitive tasks probing these domains for use in future clinical trials followed a number of evaluation criteria. These comprised good construct validity and psychometric characteristics, correlation with functional outcome, clear links to neural systems, neuropsychopharmacology and cognitive mechanisms, good suitability for human neuroimaging studies and availability of animal models [115]. The last criterion was motivated by the parallel initiative to further develop comparable tasks for rodent models [116].

The subsequent and still ongoing "Cognitive Neuroscience Test Reliability And Clinical applications for Schizophrenia" (CNTRACS) initiative continued the evaluation and optimization of the most promising tasks for use in clinical settings and as potential endpoints for treatment development research $[117,118]$. Importantly, the overall research strategy underlying MATRICS, CNTRICS and CNTRACS provides a detailed blueprint for the systematic translational investigation of cognitive impairments for cognitive domains and disorders beyond the original scope of these initiatives.

\section{Central cognitive deficits in schizophrenia}

While CNTRICS focused on cognitive constructs with the greatest immediate translational potential, this selection is by no means exclusive. The following section provides an overview over important aspects of the most important cognitive domains, which to our view also include auditory perception and language function (Figure 2). 

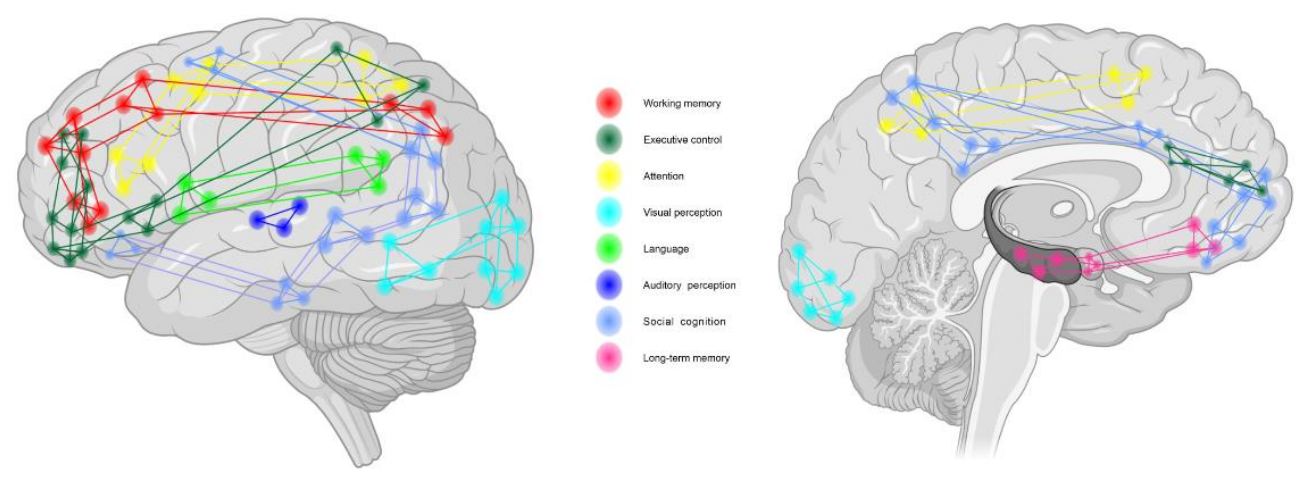

Figure 2

\section{Figure 2: Central cognitive domains impaired in schizophrenia}

Cognitive dysfunction emerges from disturbed information processing and affects a number of key cognitive domains, whose underlying cerebral networks are disturbed by the dysconnection syndrome.

\section{$\underline{\text { Visual perception }}$}

The profoundness of impaired information processing in schizophrenia is perhaps best exemplified by basic perceptual disturbances. Visual impairments have been extensively characterized at multiple processing levels $[119,120]$. They include early deficits in visual acuity and contrast sensitivity as well as impairments in numerous facets of perceptual organization such as spatial and object discrimination.

Disturbed perceptual organization reflects an intermediate level impairment, which encompasses aberrant processing in both the ventral and dorsal visual pathways [121-125]. Ventral and dorsal visual stream dysfunction in turn contributes 
to perturbed processing in subsequent cognitive nodes such as the prefrontal cortex (PFC).

Downstream effects of aberrant visual processing can therefore impact higherorder cognitive functions that are dependent on perceptual information, including object recognition $[121,124]$, social cognition $[126,127]$ and working memory $[128,129]$. Moreover, visual distortions and difficulties in merging visual inputs into a coherent percept contribute to visual hallucinations [120,130-132]. Living with such abnormal visual representations and their consequences thus appears to be related to both cognitive deficits as well as the emergence of psychotic symptoms.

\section{Auditory perception}

Similar to visual dysfunction, patients with schizophrenia also experience deficits in the auditory domain, which encompass multiple levels of processing and can have downstream cognitive, psychosocial and clinical consequences [119]. That is, effects of aberrant auditory processing range from issues during every-day social interactions to auditory-verbal hallucinations [133]. They primarily emerge from auditory cortex dysfunction linked to imprecise basic auditory processing such as tonal discrimination [134-136]. Consequently, patients with schizophrenia may experience difficulties in extracting relevant information [137]. This in turn promotes delusional thinking and auditory hallucinations [138-143]. Along with its clinical implications, auditory dysfunction has fundamental consequences for psychosocial functioning [119]. Impaired processing of prosodic information during social interactions impedes the perception of context beyond semantic information, such as emotional and attitudinal tone and emphasis of words. An inability to detect prosodic information, indicating e.g. sarcasm or sadness, hinders functional social interactions and thus 
negatively impacts social and role function [133]. Therefore, it constitutes a central mechanism by which auditory dysfunction and consequential processing deficits affect daily functioning in schizophrenia.

\section{Attention}

The term attention refers to the ability to select information to be focused on and eventually stored in memory or used for other higher cognitive processes. As multiple items compete for limited processing in visual attention, the dynamic interplay of selecting relevant and ignoring irrelevant information is crucial for the successful control of attention [144,145]. The control of attention appears to be specifically disturbed in schizophrenia, i.e., the endogenous guidance of attention to specific items, which is distinct from the actual implementation of selection [146]. For instance, patients require more time to guide attention to target stimuli in an array of similar objects [147].

Furthermore, patients have an attentional bias toward highly salient information [148], which can have both positive [149] and negative cognitive consequences [148] depending of the relevance of this information. In this context, it is also important to note that attending to irrelevant information and adding significance to such stimuli is an essential mechanism underlying delusions and other positive symptoms $[150,151]$. This attribution of abnormal salience appears to be caused primarily by disturbances of mesolimbic dopaminergic neurotransmission, which form the final common pathway of psychosis [152]. Yet, this phenomenon also demonstrates the close connection between abnormal attentional processing and the clinical symptoms of schizophrenia.

However, not all components of attention are affected in schizophrenia. In addition to the implementation of attentional selection, the ability to ignore visual distractors is 
intact, as well as input selection, and the fast allocation of attention [149,153,154]. The use of exogenous cues to guide attention also appears to be intact [155].

\section{Working Memory}

Working memory is a sub-process of short-term memory and allows to hold in information temporarily accessible for further cognitive operations. It is considered to be an essential determinant of cognitive functioning [156], and is a crucial mediator of cognitive development and learning $[157,158]$. Working memory deficits in patients with schizophrenia have been reported across all stages of the illness [148,149,159$164]$, including the prodromal phase $[165,166]$.

Working memory comprises three essential component processes, the encoding, maintenance and retrieval of information. Psychophysical and neurophysiological evidence indicates that the encoding phase is primarily impaired in schizophrenia $[49,128,129,167]$. The component process model of working memory dysfunction is especially relevant because of the differential dopaminergic modulation of these processes in the PFC $[168,169]$. Furthermore, the consolidation of information in working memory also appears to be disturbed [164]. However, other aspects of working memory seem to be preserved, including successfully removing irrelevant information from memory, and the utilization of top-down and bottom-up visual cues to select information to be encoded $[170,171]$. In addition to data indicative of an overall reduction of working capacity in terms of the number of stored items [172] there is also clear evidence for a reduced precision of working memory representations [173]. Reduced working memory capacity is a robust predictor of general cognitive as well as functional impairment $[172,174]$. These findings indicate that improving working 
memory dysfunction should have wide-ranging pro-cognitive and pro-functional effects.

\section{Long-term memory}

Long-term memory in schizophrenia is disturbed on multiple levels, showing possibly the largest effect sizes among cognitive impairments [175]. The most pronounced deficits have been observed in episodic memory, a substrate of declarative memory resposible for recalling specific events $[175,176]$. Converging evidence points to specific memory deficits in schizophrenia, which limit deep encoding into episodic memory under high levels of processing demand [177-180]. Specifically, relational encoding is clearly compromised, while item-specific encoding is relatively unimpaired. More automatic learning and memory mechanisms also appear to be mostly intact [178]. Conversely, conscious recollection and autobiographical memory have also seem to be disturbed [181]. Impairments in another important substrate of declarative memory, semantic memory, have also been repeatedly demonstrated [182].

Notably, there is also evidence that working memory and long term memory are tightly intertwined. Successful long-term memory encoding and retrieval depends upon efficient control of information processing during working memory [183]. It has also been demonstrated that these interactions between working and long-term memory are disrupted in schizophrenia [184]. This indicates that working memory dysfunction might contribute to long-term memory deficits and that these might be improved by ameliorating working memory impairments.

\section{Executive functioning}


Deficits in executive control seem to be more prominent in schizophrenia than in other psychiatric disorders [185]. They have been reported across all phases of the illness as well as in high risk individuals and first degree relatives [186,187]. Traditionally, a number of core executive control processes have been defined including updating (information updating and monitoring), inhibition (of prepotent responses), shifting (mental set shifting) and divided attention (coordinating dual tasks) [188]. Deficits in schizophrenia have been reported across all four domains of executive function $[187,189]$. Furthermore, rule generation and selection - processes crucial for using endogenous or exogenous cues to activate task-related goals or rules and actively representing and maintaining them in a highly accessible state in order to bias and constrain attention and response selection - has been implicated as an essential executive control deficit in schizophrenia $[190,191]$. Dynamic adjustments in control - processes crucial for detecting conflict or errors in ongoing processing, identifying the required type of control adjustments and recruiting additional control processes - have similarly been implicated $[190,191]$.

Executive function is clearly linked to functional outcome [192], and independent living in patients [193]. Impaired executive functioning has been specifically connected to poorer functional outcome due to lack of illness insight and lower medication adherence [193]. Also, higher ratings of positive and negative symptoms tend to correlate with executive function deficits [194].

\section{Social cognition}

Patients with schizophrenia experience difficulties performing mental operations required for perceiving, interpreting and reacting to social information $[195,196]$. These deficits are thought to arise from cascades of disturbed information processing 
streams. There is evidence for impairments related to bottom-up processing, including processing of speech prosody [197-199] and facial expressions [119,200-207]. Furthermore top-down components such as attentional control and expectation biases $[119,208]$ are also affected. As a consequence, they impede societal integration, promote social withdrawal [196] and also contribute to paranoid thinking through misinterpretation of the social intent of others $[209,210]$.

Impaired social cognition itself constitutes a major predictor of poor functional outcome in schizophrenia [211]. However, it also acts as a mediator, such that neurocognitive deficits to a large degree exert their deleterious effect on daily functioning through their impact on social cognition [212-216]. Yet, not all subprocesses of social cognition are equally affected. An influential conceptualization [217] proposes that social cognitive deficits are primarily observed in reflective social processes which require active cognitive engagement, i.e. mental state attribution, emotion regulation and social cue perception. Conversely, reflexive social processes such as experience sharing and emotion experience, which require less mental processing, appear to be largely intact $[218,219]$.

\section{Language}

Difficulties during social interactions are not only the result of social cognitive deficits but are also promoted by altered use of language in patients with schizophrenia. Due to disorganized speech and auditory-linguistic hallucinations, disturbed language production and language processing also pose a prominent clinical issue [18]. Language abnormalities can reflect both aberrant linguistic processing as a distinct domain as well as the expression of disordered thought in speech [220-222]. Similar to other clinical symptoms, language abnormalities can be classified into 
positive language symptoms such as neologisms, idiosyncratic semantic associations and word approximation [223-225] and negative language symptoms such a poverty of speech and simplification of grammar [226-228]. Notably, they also comprise difficulties to convey content, illogicality, perseveration, over-inclusion and overabstraction as well derailment from the intended topic [223]. To a certain degree, this has been linked to a loss of voluntary control over trains of thought, which are directly transferred to spoken language. Linguistically, patients' speech is mainly characterized by unusual lexical access, as exemplified by stilted speech and neologisms, flattened intonation (i.e. aprosody) and pitch as well as distorted pragmatics [223,229-231]. Distorted pragmatics describes the relationship between language and context, which is often disturbed due to patients presuming information that is not actually available or using indirect references to people or objects that are not clear to the listener $[232,233]$. Together, language impairments add another level of difficulty to social interactions and represent a domain of higher-level cognitive disturbances that is particularly perceivable to the outside world [133].

\section{Section II: Pharmacological treatment of cognitive dysfunction}

Over the last two decades, increasing awareness regarding the significance of cognitive dysfunction has prompted a growing number of efforts to identify pharmacological compounds with robust pro-cognitive efficacy.

\section{Antipsychotic and antidepressant medication}

The effects of first- (FGA) and second-generation antipsychotics [234] on cognitive dysfunction have been studied extensively [234]. Overall, these studies reported at most a modest effect on cognitive deficits with some evidence for greater 
efficacy of SGAs [235,236]. However, data from the "Clinical Antipsychotic Trials of Intervention Effectiveness“ (CATIE) study showed no difference between FGA and SGA [237]. Data from first-episode patients also indicates that their cognitive improvements are comparable in magnitude with practice effects observed in healthy controls, which likely have confounded the results of many methodologically less sound studies [238].

Cognitive improvements have also been attributed to reduced psychopathology [239] and generally improving function [240]. Overall, the pro-cognitive effects of FGA and SGA in stable patients appear to be comparable and are not regarded as clinically relevant [241]. Conversely, evidence in antipsychotic-naïve patients indicates that even relatively low doses of a D2-recpetor antagonist, risperidone, lead to a measurable worsening of spatial working memory [242]. Moreover, extrapyramidal and metabolic side effects as well as of concurrent anticholinergic medication might also worsen existing cognitive deficits [243,244].

The cognitive effects of antidepressant augmentation of antipsychotics have also been studied repeatedly. In contrast to the beneficial effects of this strategy on negative and depressive symptoms [245], there is no evidence for a clinically meaningful improvement in any cognitive domain [246].

\section{Direct modulation of major neurotransmitter systems}

For the pharmacological treatment of cognitive deficits, scientists have focused on the dopamine (DA), $5 \mathrm{HT}$ (serotonin) and Glu (glutamate) neurotransmitter systems and to a lesser extent on NE (norepinephrine) and $\mathrm{ACH}$ (acetylcholine). All appear to play a crucial role in the pathogenesis of various clinical and cognitive symptoms [247249]. Furthermore, they all share one important property, namely a Yerkes Dodson 
inverted U-shaped function that regulates their effects on networks involved in cognitive processes. This concept can be easily illustrated by looking at D1 receptors and pyramidal cells in the dorsolateral prefrontal cortex (DLPFC). Optimal, intermediated levels of DA stimulating these receptors reduce neural noise and thus enhance cognitive function. Low levels of D1 receptor stimulation increase NMDAreceptor mediated neural firing - leading to comparably more noise and thus impairing cognitive processes such as working memory. On the other hand, high levels of D1 receptor stimulation largely suppress NMDA receptor mediated neural firing, also impacting cognition negatively $[250,251]$. This implies an optimum middle range of dopaminergic stimulation while either too little or too much DA impairs the tuning of prefrontal pyramidal neurons and impairs cognition, which has been demonstrated in a variety of species [252].

This notion is also supported by genetic studies on COMT, the major enzyme catabolizing DA in PFC [253] although these have mixed findings. Neuroimaging studies have shown that genetic variants with high COMT activity are positioned to the left, those with lower activity nearer the optimum of the inverted $U$ curve. This position predicts nonlinear response to amphetamine stimulation [254] as well as interactions between dopamine synthesis and prefrontal response [255]. Task-related and taskunrelated prefrontal functions respond in opposite ways to genetic variation in dopamine synthesis, suggesting a tuning mechanism [255]. Additionally, interacting genetic variants in COMT have also been found to affect PFC in an inverted $U$ fashion [256].

Importantly, an inverted U-shaped pattern is also described for noradrenergic neurons originating from the locus coeruleus (LC) [257]. Neural activity in the LC is characterized by tonic and phasic firing that leads to tonic and phasic NE release, 
respectively. Tonic firing is stimulus-independent while phasic-firing is stimulusdependent [258]. Very low tonic firing represents drowsiness and distractibility thus impeding cognitive performance. Very high tonic firing leads to stress that in turn again impedes performance. Therefore, moderate tonic firing facilitates prominent phasic firing [259]. A crucial region impacted by NE is the PFC. Here, again both deficient as well as excessive NE-mediated signaling leads to deficits in working memory [260262]. An optimal firing mode is needed for an advantageous function of the frontoparietal network which is involved in attention and working-memory processes [249].

Similarly, for the alpha-7-nAChR within the DLPFC benefits are evident in lower doses and decrease in higher doses which was observed using the agonist PHA543613 [263]. In rhesus macaques, Castner et al. observed improvements in working memory performance using the compound AZD0328 that also targets alpha7-nAChR. However, they also observed worsening when administering both high as well as ultra-low-doses [264].

Serotonergic neurons are distributed across the brain with a high density in the PFC [265] and hippocampus [266-268]. Serotonin has also been implicated in the pathophysiology of cognitive impairments - such as attention, working memory and learning in schizophrenia [268-270]. This assumption is based on observations presented by Cano-Colino et al. who studied the impact of 5HT on spatial working memory and delineated compromised functioning at both very high and very low concentrations [271]. Tryptophan - the precursor amino acid of 5HT - also shows an inverted U-shape relationship to cognition [272].

These findings highlight the complex neurobiological mechanisms governing monoaminergic modulation of cortical circuits and cognition, which represent a major challenge for pharmacological research. This might also explain why so far, strategies 
focusing on direct receptor modulation have not yielded any consistent positive results. In fact, a recent meta-analysis on pharmacological cognitive enhancers in schizophrenia did not detect any discernable benefit for any type of medication over placebo [273].

\section{Allosteric modulators}

As a result of the negative findings in these trials, indirect approaches, (specifically, allosteric modulators) have recently been gaining increasing attention (Table 1). Traditionally, most drugs act as a direct ligand when coupling to receptors, thus either inhibiting or activating the receptor. However, specificity is compromised as most receptors have a variety of subtypes characterized by different functions. Therefore, a direct ligand tends to be less selective and more likely to cause side effects. 
Table 1: Pharmacological approaches.Pharmacological treatments of cognitive impairment associated with schizophrenia using an allosteric modulator, neuroplastic or anti-inflammatory approach.

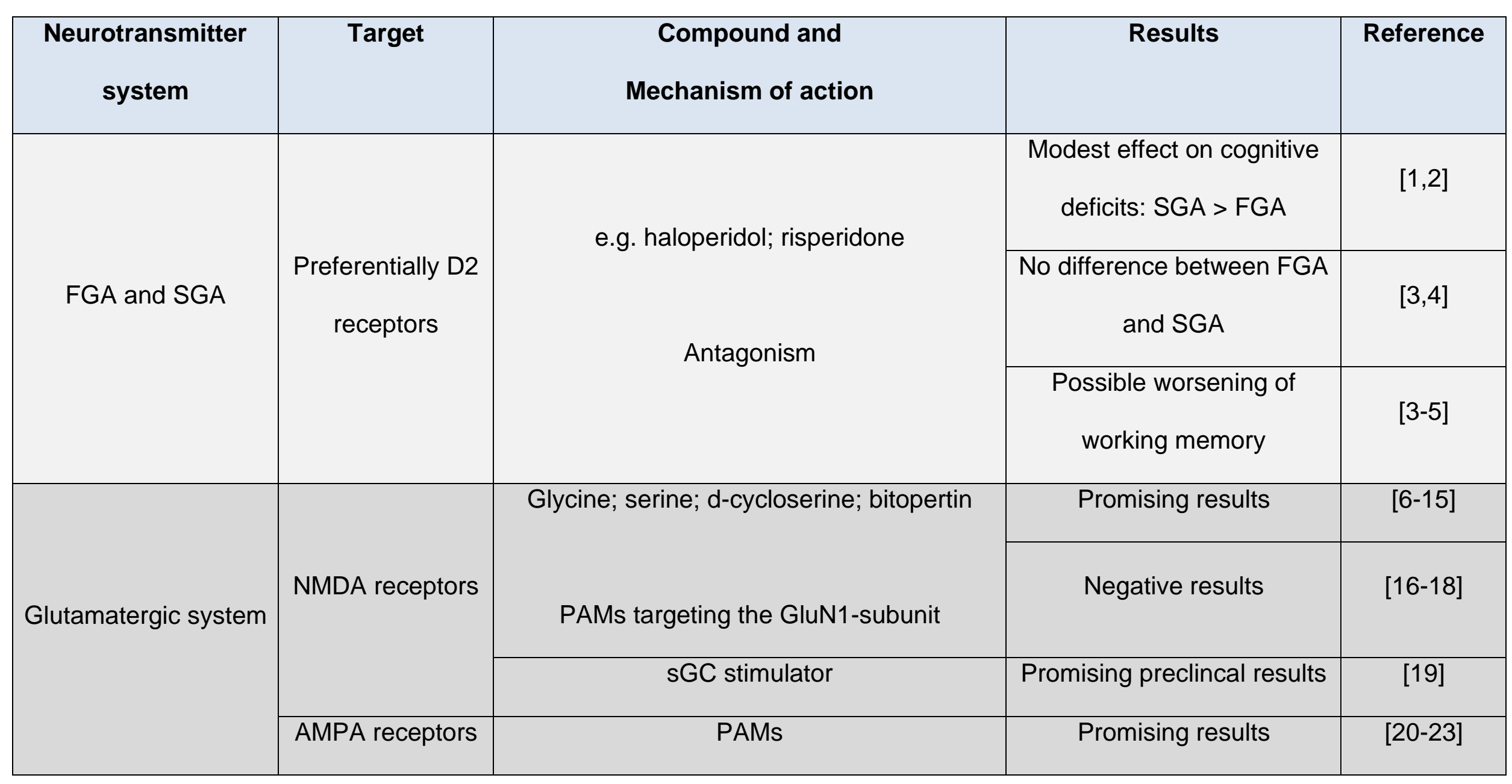

(2)




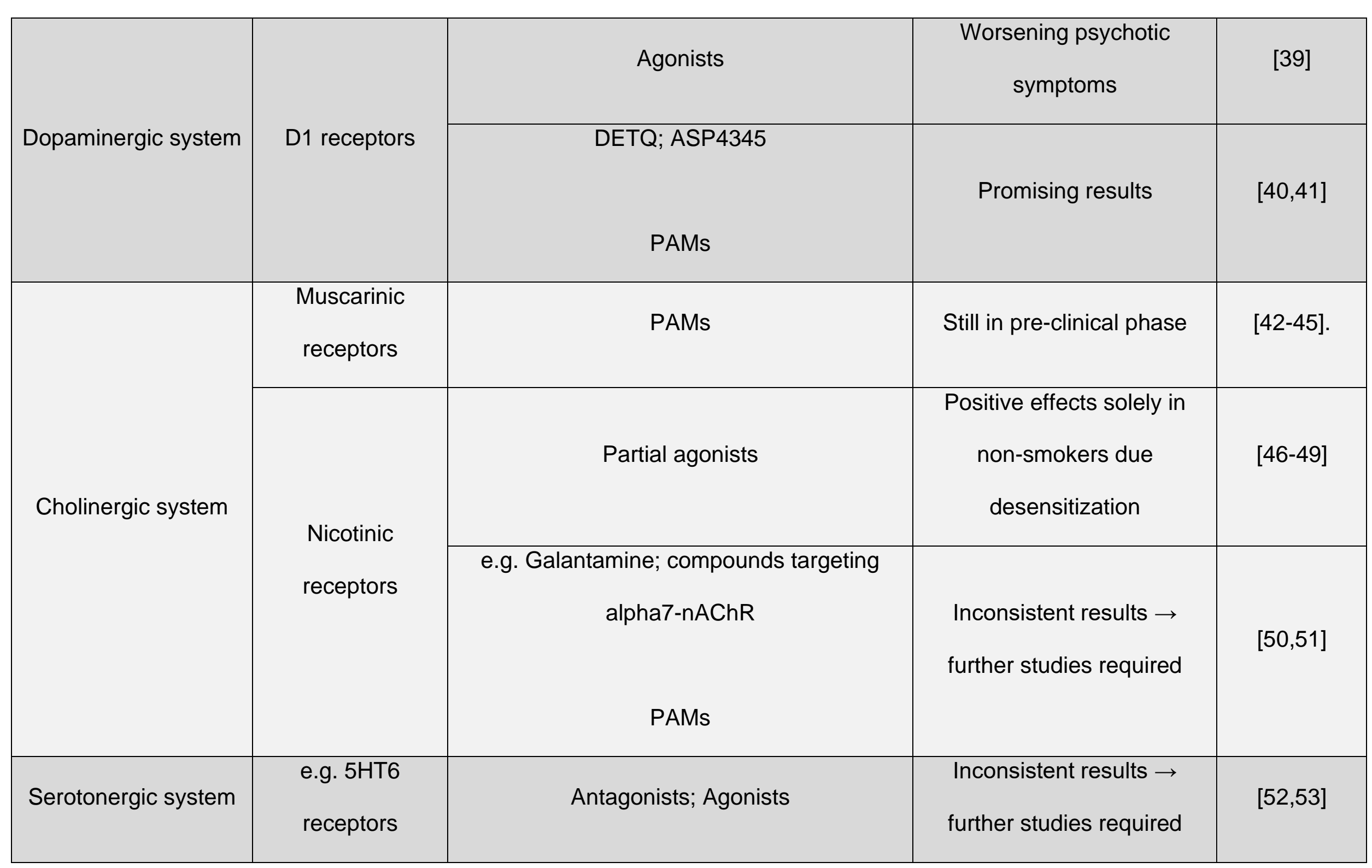




\begin{tabular}{|c|c|c|c|c|}
\hline & & PAMs; NAMs & Further studies required & [54] \\
\hline \multirow{2}{*}{ EPO } & \multirow{2}{*}{ EPO receptors } & \multirow{2}{*}{ Pleiotropic effects } & $\begin{array}{l}\text { Promising transdiagnostic } \\
\text { results }\end{array}$ & $\begin{array}{c}{[55-64,65} \\
, 66,67]\end{array}$ \\
\hline & & & $\begin{array}{c}\text { Specific monitoring } \\
\text { advisable }\end{array}$ & [68-75] \\
\hline \multirow{2}{*}{$\begin{array}{c}\text { Anti-inflammatory } \\
\text { approaches }\end{array}$} & & \multirow{2}{*}{$\begin{array}{l}\text { e.g. minocycline; simvastatin; omega-3- } \\
\text { unsaturated fatty acids; N-acetylcystein; } \\
\text { COX-2-inhibitor }\end{array}$} & Promising results & {$[76-86]$} \\
\hline & & & $\begin{array}{l}\text { Inconsistent result } \rightarrow \\
\text { further studies required }\end{array}$ & [87-93] \\
\hline
\end{tabular} \\ doi:10.20944/preprints202105.0257.v1}

\section{Preprints (uruw.preprints.org) | NOT PEER-REVIEWED | Posted: 12 May 2021}

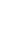

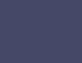

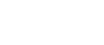

(5897

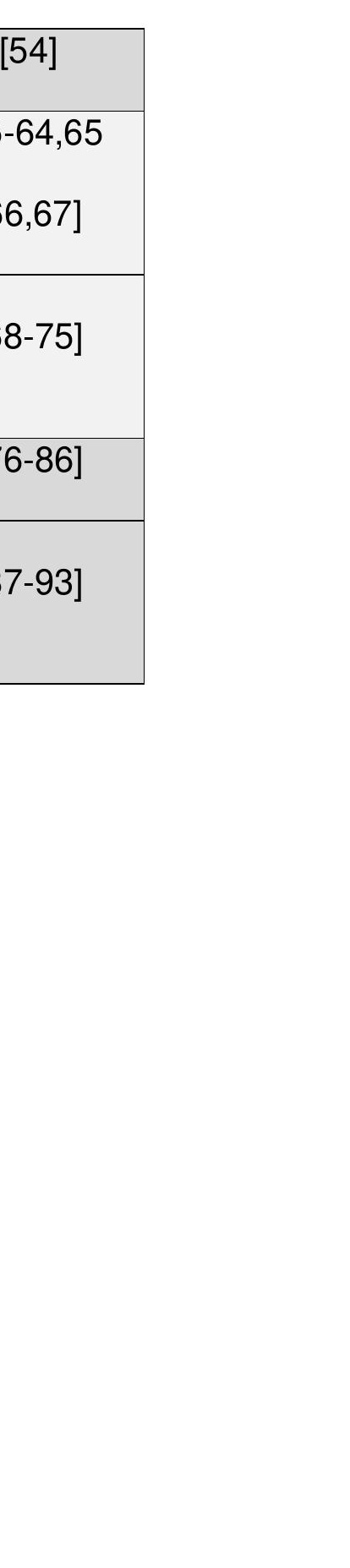

(20)


Furthermore, pharmacological compounds which directly block or stimulate certain receptor types have one crucial disadvantage. They follow a "homeostasis" approach by imposing fixed, inflexible values on synaptic parameters. However, this likely impedes the brain's ability to quickly adapt its synapses and neural circuits in respond to cognitive demands using its stored knowledge to predict appropriate values [274]. This predictive regulation strategy is known as "allostasis". In contrast to homeostatic regulation of synaptic function, which can achieve stability only after an abnormal parameter was detected, allostatic regulation utilizes parameter alteration to maintain stability $[275,276]$.

Antipsychotic drugs, accordingly, follow a "homeostasis" strategy by blocking dopamine receptors, and target not only D2- but also D3- and D4-receptors implicated in a variety of functions including cognitive processes [277]. Hence, antagonizing D2like receptors using antipsychotics counteracts positive symptoms but can also induce deterioration of cognition in a dose-dependent manner [242,244,278-283].

In contrast to such direct receptor agonists or antagonists, allosteric modulators bind to remote parts of the receptor's active site and require the endogenous ligand to improve receptor function, thus preserving the brain's inherent ability for allostatic regulation to a much greater degree. Therefore, positive allosteric modulators (PAM) might be particularly useful for ameliorating network dysfunctions underlying a particular cognitive impairment. Additionally, they might be advantageous when aiming to obviate receptor-desensitization and -downregulation [284]. For example, smoking leads to desensitization of nicotinic acetylcholine receptors due to chronic nicotine exposure, thus impeding the use of nicotinic agonist to improve working memory and attention disturbances in patients who smoke $[285,286]$. Another potentially useful feature of allosteric modulators is the so-called ceiling effect. This is characterized by 
a plateau regarding a drug's neurobiological effect leading to a wider therapeutic margin [287] and, consequently, better safety profile.

One generally distinguishes between allosteric modulators amplifying (positive allosteric modulators, PAM) and allosteric modulators suppressing receptor activity [287-289]. A third group is termed as "silent allosteric modulators" (SAM) [290]. These modulators are also called neutral allosteric ligands since they do not possess any impact on the receptor's activity. Instead, they compete with and potentially antagonize negative allosteric modulators (NAM) and PAMs. However, SAMs currently do not play any role treatment approaches [291]. Rather, they can help elucidate the receptor binding profile of NAMs and PAMs.

Allosteric modulators can also possess intrinsic activity at higher doses [292294]. Naturally, this principle can be extended to other important targets such as metabotropic glutamate (mGluR), nicotinic, muscarinic as well as dopaminergic receptors [295-299].

\section{Glutamatergic system}

Interestingly, the mechanism of allosteric modulation is extensively exploited in the brain, underscoring its potential. This is especially true for the glutamatergic system. Importantly, there is converging evidence for a role of disturbances in glutamatergic neurotransmission - especially NMDA receptor hypofunction - for both the clinical and cognitive symptoms of schizophrenia [300-303]. NMDA receptor hypofunction in particular has been implicated as a cause for $E / /$ imbalance abnormal gamma oscillations in schizophrenia [304].

Overall, glutamatergic abnormalities involve both mGluR and ionotropic glutamate receptors [299,305,306]. While the mGluR-family is characterized by its 
modulatory function, the ionotropic glutamate receptor exhibits fast excitatory properties [306]. Ionotropic glutamate receptors comprise three groups, namely NMDA- [307], AMPA- [308] and kainate receptors [309]. While NMDA receptors remain the primary focus of the glutamatergic hypotheses of schizophrenia, more recently AMPA- and to a lesser extent also kainate receptors have also been studied [309,310]. There is converging evidence from studies with the ketamine and phencyclidine, which target the NMDA receptor, in both humans and animal models that a disruption of NMDA receptors leads to wide ranging cognitive deficits $[300,303]$. These include impairments in perception [119], cognitive flexibility [311], attention [312], working memory [313] and learning [314].

NMDA receptors always contain two GluN1-subunits binding glycine that are then combined with either two GluN2-subunits or one GluN2-subunit and a GluN3subunit[307]. Since direct NMDA receptor agonism can induce excitotoxicity due to glutamatergic overload [305], researchers recently focused on alternative mechanisms. The search for novel PAMs binding to NMDA receptors focuses on GluN1- and GluN2-subtypes, as these are the most prevalent ones [299,315]. Findings from NAMs (traxoprodil and BMT-108908) targeting GluR2B support the effects of glutamatergic PAMs binding to this receptor subtype and its involvement in cognitive processes such as recognition memory and learning as shown in non-human primates [316]. Nevertheless, research regarding novel allosteric modulators targeting the NMDA receptor is still in its early phase $[315,317,318]$. Glycine, which is crucial for NMDA receptor mediated glutamatergic neurotransmission, is a prominent example for an endogenous allosteric modulator [319]. The activation of NMDA receptors not only requires Glu binding to the GluN2-subunit, but also glycine binding to the GluN1subunit [320,321]. In contrast to the GluN1-subtype, the GluN2-subunit is 
characterized by 4 isoforms with differing distribution in the CNS [322]. Due to evidence for alterations in glycine-mediated processes in neuropsychiatric disorders, namely schizophrenia and ASD, glycine has been implicated for therapeutic approaches targeting cognitive dysfunction [323,324].

D-Serine, another endogenous co-agonist is as potent as glycine, and binds to the glycine site of the NMDA receptor as well. In addition, glycine modulates $d$-serine metabolism by inhibiting serine racemase [325]. Several studies using $d$-serine, $d$ cycloserine and glycine examined effects of these substrate on cognitive impairments in patients, but with overall negative results [326]. Administration of d-cycloserine might lead to amelioration of cognitive deficits when co-administered with antipsychotics other than clozapine [327-329]. However, it appears to be associated with an inverted U-shape response curve and its positive effects could not be maintained during longterm treatment $[330,331]$.

Re-uptake inhibition of glycine is another potentially relevant mechanism, exemplified by sarcosine and bitopertin. Yet, a recent meta-analysis failed to show consistent pro-cognitive benefits for both compounds [332,333]. Inhibiting DAAO, the enzyme catabolizing [334,335] glycine, might also improve cognitive functioning [336338]. Sodium benzoate is a DAAO-inhibitor that showed promising initial results in treating cognitive impairments in patients with schizophrenia when used as an add-on therapy [334,335], yet data await further replication. Recently, a double-blind, randomized, placebo-controlled phase 2 trial with BI425809 as a glycine transporter-1 inhibitor reported first encouraging findings in patients with schizophrenia [339]. Targeting mechanisms downstream of the NMDA receptor might also be a promising avenue. Glutamate binding to NMDA leads to calcium influx that in turn activates nitric oxide synthase to produce NO, which in turn stimulates soluble guanylyl cyclase (sGC) 
to form cyclic GMP [340]. Accordingly, evaluation of an sGC stimulator as a potential treatment for cognitive impairment in schizophrenia is underway.

One important goal of NMDA receptor modulation is to promote long-term potentiation (LTP) and memory performance [341], and to increase the release of neurotrophic factors $[341,342]$. To this end, AMPA receptors are another promising target for allosteric modulation strategies [310,343,344]. AMPA receptors modulate NMDA-R-activity and show altered density in patients with schizophrenia - in particular, increased density in the PFC and diminished density in the hippocampus. Pro-cognitive effects were indeed observed in preclinical and small-scale clinical studies [345,346]. Overstimulation however leads to detrimental effects, namely seizures and apoptosis [347-349].

Kainate receptors have less frequently been the focus of research compared to NMDA and AMPA receptors [310]. However, to our knowledge studies regarding allosteric modulation of kainate receptors are still scarce [350]. In sum, the procognitive effects of PAMs targeting ionotropic glutamatergic receptors are at best inconsistent, as shown by a recent meta-analysis [351].

Regarding metabotropic glutamate receptors, one distinguishes eight subtypes. These are classified into three broad groups with differential involvement in cognitive processes [352], making them promising targets [353]. Group I receptors mGluR1 and mGluR5 are involved in LTP and long-term depression (LTD), mechanisms crucial for neural plasticity [354,355], while group II receptors mGluR2 and mGluR3 show neuroprotective effects - in particular protection against NDMA-mediated excitotoxicity [356]. Group III receptors include mGluR4, mGluR5, mGluR6, and mGluR8 [297]. Recent observations in patients with schizophrenia treated with pomaglumetad, a highly selective mGluR2 and mGluR3 agonist, indicated that only specific patient 
groups might benefit from treatment with mGluR-2-PAMs, as only patients in the early phase of the disorder showed improvements in global psychopathology [357]. However, the effects of pomaglumetad on cognitive deficits remains to be investigated. An mGluR5-PAM might facilitate the improvement of cognitive deficits due to its interaction with NMDA-R [358]. However, this approach appears to be associated with considerable side effects in the form of seizures, particularly in mGluR5-PAMs with intrinsic activity. It has therefore been suggested that beneficial modulation of LTP and LTD would have to rely on mGluR5-PAMs without intrinsic activity [359].

Preclinical reports for positive allosteric mGluR3 modulators indicate potential neuroprotective properties [360,361]. Studies using NAMs offer indirect support for a benefit of mGluR5 PAMs. For instance, the NAM MPEP intensified cognitive impairments in rats previously treated with phencyclidine [362].

\section{$\underline{\text { GABAergic system }}$}

GABAergic neurons play a crucial role in the disruption of neural circuits in bipolar disorder and schizophrenia [53,363,364]. Furthermore, they are closely involved in schizophrenia-associated cognitive deficits [365,366]. A recent study observed decreased GABA-levels in patients with first-episode psychosis, which was correlated with illness severity and deficits in visual learning, working memory, attention, speed of processing and reasoning [367]. As outlined above, this is primarily attributable to reduced inhibition of excitatory pyramidal cells by PV neurons contributes, which results in widespread E/l imbalance in cortical microcircuits [52].

For GABA-A receptors, the subunits alpha-2, -3 and -5 are of particular relevance for cognitive processes. While benzodiazepines are PAMs binding to GABAA receptors, they lack subunit selectivity [368] and appear to further impair cognitive 
function $[369,370]$ underscoring the need for highly selective allosteric modulators. Importantly, depending on the specific subunit, pro-cognitive effects might be attained either by a PAM $[371,372]$ or NAM $[371,373]$. However, clinical trials with patients with schizophrenia receiving the PAM TPA023, targeting the alpha-2 and -3-subunit, revealed inconsistent results regarding amelioration of cognitive dysfunction [372,374]. NAMs of the alpha-5-subunit are still evaluated in pre-clinical studies with respect to the improvement of working memory, but appear to have side effects such as seizures, anxiety or even a worsening of psychotic symptoms [375]. Quercetin - a NAM targeting GABA-A receptors - reduces MK801-induced locomotor hyperactivity in vivo by disinhibiting glutamatergic transmission elicited by GABAergic hyperactivity in the PFC. Locomotor hyperactivity in rodents model positive symptoms. Notwithstanding aiming to treat psychosis, this compound corroborates the potential benefits of allosteric modulators binding to GABA-A receptors [376,377]. Other selective compounds did not prove to be successful due to side effects [368].

GABA-B receptors are metabotropic receptors that are particularly relevant for neurodevelopment by promoting neurotrophic processes [378] and neural plasticity [379] especially LTP [380]. Notably, they have also been implicated in cognitive dysfunction in schizophrenia $[381,382]$ including working memory $[383,384]$. However, data about allosteric modulators targeting GABA-B receptors scarce and remain limited to animal models [375,385-387].

\section{Dopaminergic system}

Since antipsychotics can partly worsen cognitive function by inhibiting DA receptors in ventral striatal and cortical areas, it is of particular importance to develop 
alternative approaches [388,389]. Dopamine D1-like receptors, comprising D1 and D5receptors, have been suggested as targets to ameliorate cognitive deficits in patients with schizophrenia $[390,391]$. Attempts to target D1-like receptors by agonists, DA transporter inhibition, or MAO- and COMT inhibition were however not successful due to worsening of psychotic symptoms [295]. So far, most studies with dopaminergic PAMs are in-vitro studies. For instance, in transgenic mice over-expressing D1 receptors, the D1-receptor PAM DETQ led to improved performance in an object recognition task and in cortical $\mathrm{ACH}$ release [392]. A phase 1 clinical trial with the D1receptor PAM ASP4345 showed improvements in psychomotor function, visual attention and corresponding improvements in neurophysiological markers [393]. However, studies in humans are still lacking.

\section{$\underline{\text { Cholinergic system }}$}

As mentioned before, both nicotinic as well as muscarinic-(M)-cholinergic receptors play an important role in the pathophysiology of cognitive deficits in schizophrenia. Associations between muscarinic receptors and cognition are supported by studies using xanomeline, a M1/M4 receptor orthosteric agonist that led to cognitive improvements in patients with schizophrenia [394]. Both the M1 and M4 receptors are of particular relevance [395]. Here, M1 receptors are involved in memory and attention processes and the M4 receptors appear to be crucial for anti-psychotic treatment. Unfortunately, the development of muscarinic agonists initially failed due peripheral - especially gastrointestinal - side effects. However, combining xanomeline with trospium (which blocks peripheral acetylcholine receptors) showed significant improvement of schizophrenia symptoms measured with the "Positive and Negative Syndrome Scale" (PANSS) but a much better safety profile [396]. Unfortunately, 
cognitive measures were not reported. Attempts to selectively target the muscarinic receptor subtypes are complicated by the considerable similarities of each subtype. Therefore, PAMs which promote the affinity of $\mathrm{ACH}$ to the muscarinic receptor's orthosteric binding site have increasingly been investigated [397-399]. However, these compounds are still in the pre-clinical phase [395,400-402].

Additionally, the nicotinic system has been a major focus. An estimated $70 \%$ of patients consume nicotine, and a self-medication strategy for the cognitive and clinical symptoms of the disorder is generally assumed to be the cause $[403,404]$. Specifically, an association between the nicotinic system through altered alpha7-nAChR with cognitive impairment is supported by genetic studies [405]. So far, a number of compounds selectively targeting alpha7-nAChR have been developed, which either did not improve or even worsened working memory and other cognitive processes in patients with schizophrenia that were smokers. Positive effects were observed solely in non-smokers. Suboptimal results using partial agonists have been primarily attributed to a desensitization of nAChR in smokers [286,406-408].

Some scientists tried to discover PAMs targeting nicotinic receptors - especially since PAMs do not tend to lead to desensitization. Galantamine is a well-known PAM that is used in Alzheimer's disease - however without significant results. A pilot study investigating the effects of galantamine and nicotine in healthy populations [409] indicated that positive allosteric modulation in $\mathrm{nAChR}$ is feasible, but that further research is required to establish an optimal dosing range. Unfortunately, phase 3 trials evaluating the effects of compound binding alpha7-nAChR failed to show a beneficial effect on cognition [298]. With respect to galantamine, results were not statistically significant regarding the primary outcomes on negative symptoms measured with the PANSS and cognitive symptoms measured with the MCCB. Yet, global function and 
verbal recall improved significantly in patients with schizophrenia after they received galantamine in combination with citicoline. Citicoline was administered to counteract a possible desensitization of the nAChR [410].

\section{$\underline{\text { Serotonergic system }}$}

Involvement of the $5 \mathrm{HT}$ system in cognitive dysfunction, in particular in the perturbation of short- and long-term memory as well as learning $[411,412]$ has been observed in schizophrenia [413]. Several trials with 5HT6-antagonists have been conducted. These comprised animal studies as well as clinical trials with patients with Alzheimer's disease and schizophrenia targeting long-term memory with some initially promising results [414]. However, direct early studies with serotonergic agonists and antagonists failed to improve cognitive impairments, most likely due to a lack of subtype specificity [415]. Despite the potential of allosteric serotonergic modulators, so far there is still a relatively limited number of pre-clinical studies examining PAMs and NAMs in the context of cognitive impairments [416].

Overall, the development of allosteric modulators that target the major neurotransmitter systems appears to be a promising approach. However, presently more studies in healthy subjects and patients with schizophrenia are urgently needed to corroborate preclinical findings. While research efforts related to less prominent neurotransmitter systems beyond the scope of this review are also ongoing, so far these have similarly yielded no clinically relevant positive findings.

\section{Erythropoietin}


Another line of research has focused on the study of neuroprotective compounds, especially erythropoietin (EPO). EPO is a glycoprotein and growth-factor synthesized in and secreted especially by the fetal liver and adult kidney. Moreover, approximately $15-20 \%$ is synthesized and secreted in other parts of the body including cerebral endothelial cells, astrocytes, hippocampus and the cerebral cortex [417-419].

EPO does not only regulate erythropoiesis but is also characterized by pleiotropic effects in the CNS mediated by a brain specific EPO receptor [419]. These comprise the reduction of glutamate-based neurotoxicity [420], enhancement of dopamine- and acetylcholine-release, the reduction of apoptosis as well as the inhibition of microglial function and pro-inflammatory cytokines such as IL6 and TNF$\alpha 1[421,422]$.

In addition to further positive effects on the integrity of the blood-brain barrier (BBB) and on oxidative stress, EPO also shows modulatory effects on neurogenesis by promoting neuronal proliferation and differentiation $[423,424]$. This is particularly relevant as cognitive impairment in schizophrenia has also been linked to disturbed adult neurogenesis [425]. EPO synthesis and secretion are induced by hypoxia and ischemia [426]. The binding of EPO to its specific homodimerized receptor causes a downstream cascade activating further transcription factors, kinases, and also increases calcium. The mechanisms appear to facilitate cell differentiation and neural plasticity $[423,427,428]$.

EPO is most commonly used to treat anemia in patients suffering from chronic kidney failure. However, over the past decades several studies have demonstrated positive effects in the brain. These include the reduction of BBB leakage $[429,430]$, inflammation [431,432] and the amelioration of cognitive deficits in neuropsychiatric disorders [424,433-437]. 
Most importantly, consistent pro-cognitive effects were reported for schizophrenia $[424,434]$. These effects were accompanied by a reduced decline of gray matter volume in a network of brain regions closely involved in attention and memory processes [438]. Interestingly, improvements of cognitive deficits were also observed in bipolar disorder [437], chronic-progressive multiple sclerosis [433] and Parkinson's disease [439] clearly indicating EPO's transdiagnostic relevance.

In contrast to previous assumptions, current evidence strongly supports a direct effect of EPO on brain function and thus on cognition by enhancing neurotrophic and neuroprotective processes [434,435]. For instance, EPO appears to induce the production of brain-derived neurotrophic factor (BDNF) in the hippocampal tissue. In addition, in patients with schizophrenia, a decrease of $\mathrm{S100}$ protein - a marker for glial damage - predicted a better clinical outcome after one month of treatment $[434,438,440,441]$. Studies with mice receiving EPO showed an increase of LTP in the hippocampus. Additionally, antidepressant effects in treatment resistant patients with major depression have been reported $[437,442]$. A longitudinal fMRI study reported an increase of hippocampal activation in healthy subjects seven days after infusion of EPO with corresponding improvements in verbal fluency and working memory. These effects were evident without any obvious hematopoietic effects [435] (Figure 3).

Several aspects of the effects of EPO remain to be elucidated. This includes the optimal duration of EPO treatment and the durability of its pro-cognitive effects. Importantly, EPO might promote the progression of some forms of tumors expressing EPO receptors as a result of its anti-apoptotic effects and its impact on angiogenesis $[443,444]$. This appears to apply to some forms of breast cancer $[445,446]$ as well as head and neck cancer [447]. Sufficient pretreatment screening is therefore crucial. Regular safety monitoring is also required to manage the potential risk for thrombosis 
[448] and hypertension [449]. The likelihood of the former can already be mitigated by reducing iron intake, considerably limiting the hematopoietic side effects of EPO [450]. Furthermore, these might also be surmountable by a modification at the molecular level - i.e. carbamylation of EPO [451,452]. This strategy takes advantage of differences between the brain-specific and hematopoietic EPO receptors [452-454].

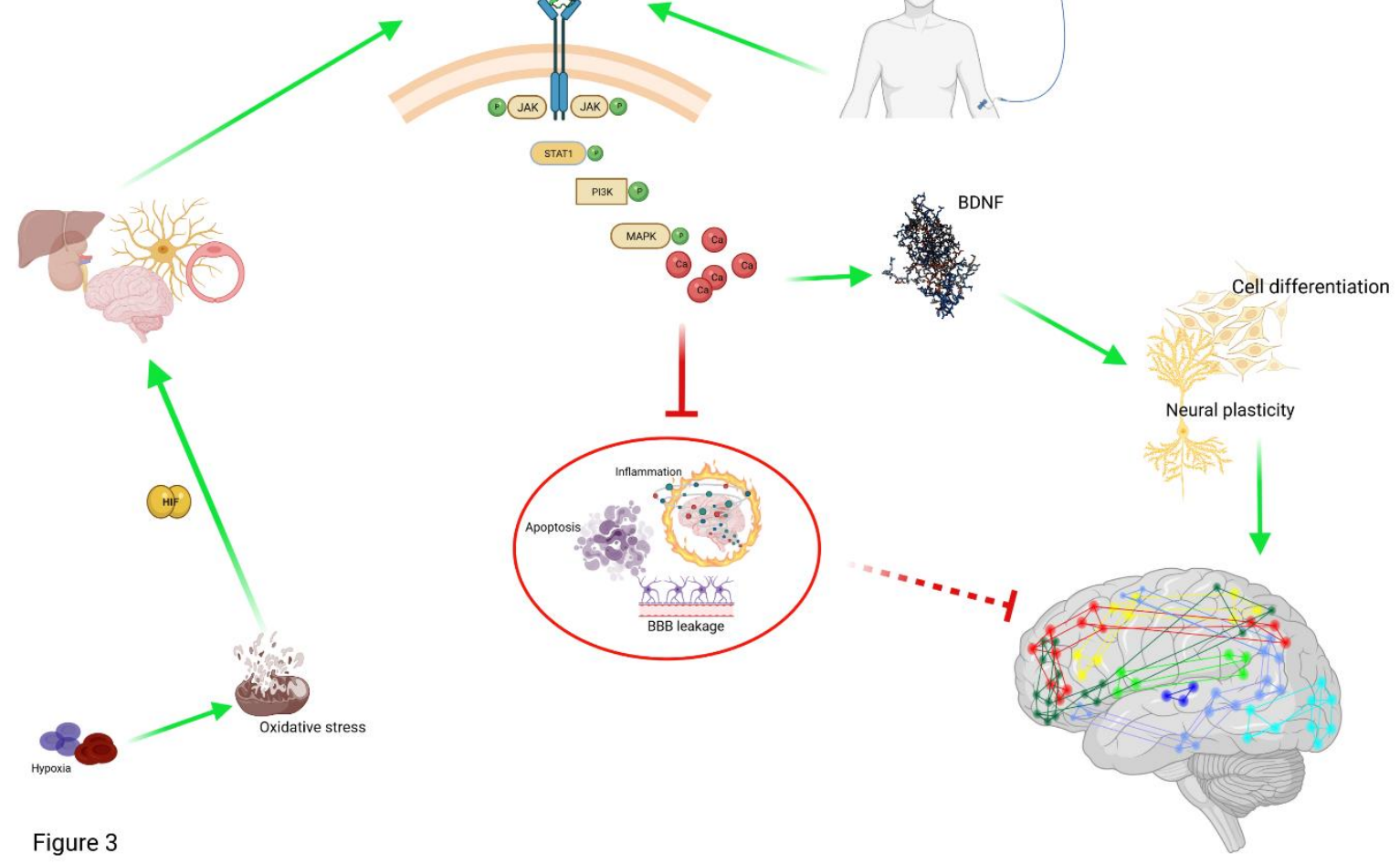

Figure 3: Pro-cognitive effects of erythropoietin

Synthesis of erythropoietin (EPO) is induced by hypoxia and shows pleiotropic effects that go far beyond its hematopoietic effects. In the brain, EPO shows anti-inflammatory and anti-apoptic effects and reduces BBB leakage. Beyond these neuroprotective effects, EPO also induces differentiation neural progenitor cells, increases dendritic spine density. Together these effects are the basis for the pro-cognitive properties of EPO. 
Interestingly, the beneficial effects of EPO on cognition might also extend to cognitive deficits induced by electroconvulsive therapy (ECT). Furthermore, evidence from animal studies suggests that ECT might also act partly through the intracerebral induction of EPO [455]. ECT is an effective treatment for patients with schizophrenia with an insufficient response to clozapine [456]. Cognitive side effects following ECT are transient and appear to be less common in patients with schizophrenia than in patients with major depressive disorder (MDD) $[457,458]$. Yet, they can still be a limiting factor due to an increased likelihood of patients refusing to continue treatment. Several studies indicate an improvement in some cognitive domains over time after receiving ECT [456], which would be compatible with the purported influence of ECT on intracerebral EPO. Based on recent findings in animal studies, it has even been suggested [459] that EPO and ECT should be combined to counteract these transient cognitive deficits. Efforts to examine the effects of such a combination in patients with uni- or bipolar depression are currently underway [460], which could pave the way for similar studies in patients with schizophrenia.

\section{Anti-inflammatory approaches}

There is increasing evidence that a chronic low level inflammatory syndrome might contribute to the pathophysiology of schizophrenia [461-464]. A variety of peripheral pro-inflammatory markers have been shown to be increased in subgroups of patients with schizophrenia $[465,466]$. Moreover, meta-analytic evidence indicate a correlation between inflammation and cognitive dysfunction in patients with schizophrenia [467]. It has been hypothesized that chronic inflammation might lead to 
a disruption of the BBB in these patients, which could facilitate intracerebral inflammatory processes [468-471]

Minocycline is a second-generation tetracycline which also inhibits microglial function and appears to ameliorate cognitive and negative symptoms in patients with schizophrenia when co-administered in early phases of the disorder [472]. Several studies indicate an interaction between minocycline and microglia [473], proinflammatory cytokines [474] and free radicals [475,476]. As a result minocycline has been associated with both anti-inflammatory and anti-apoptotic properties [477].

Simvastatin is used to treat hyperlipidemia and has additionally demonstrated pleiotropic effects including the decrease of pro-inflammatory cytokines and the amelioration of both cognitive and positive symptoms in patients with schizophrenia [478-481]. Celecoxib, a cyclo-oxygenase-2-(COX-2)-inhibitor has also been shown to improve cognition in patients with schizophrenia [482].

Furthermore, omega-3-unsaturated fatty acids, which are regarded as antioxidants have been evaluated. When combined with ascorbic acid and a-tocopherol they appear to improve global psychopathology [483], but overall results have been mixed [484-487]. The number of studies examining the impact of unsaturated fatty acids on schizophrenia-associated cognitive impairment is limited and equally inconsistent $[485,488-490]$ with some indication for a positive effect on semantic memory and language [491].

$\mathrm{N}$-acetylcystein reduces redox dysregulation and oxidative stress through its effects on glutathione activity and improves mitochondrial integrity $[492,493]$. As a result, it has anti-inflammatory properties and appears to normalize glutamatergic and GABAergic neurotransmission to some degree $[487,493]$. So far, studies have reported improvements in negative symptoms [494,495] and working memory [496]. Overall, 
while the exact pathophysiological mechanisms underlying the link between inflammation and cognitive impairments in schizophrenia remain to be elucidated, these findings highlight the potential therapeutic relevance of anti-inflammatory approaches, particularly in the early stages of the disorder $[472,497]$. Yet, current evidence regarding the utility of the aforementioned anti-inflammatory and neurotrophic agents for improving cognitive dysfunction is still regarded as inconclusive, emphasizing the need for larger, well-controlled studies [498]. 


\section{Section III: Non-pharmacological strategies}

Cognitive remediation therapy

For several decades, cognitive remediation therapy (CRT) has been utilized to improve cognitive performance and ultimately daily functioning in schizophrenia. CRT exploits the inherent neuroplastic properties of neural circuits, which are essential for their development, refinement and reorganization, in response to the targeted training of cognitive processes [499]. Originally, CRT programs for schizophrenia were closely modeled after the neuropsychological concepts used for patients with traumatic brain injury [500] but have evolved considerably based on more current concepts of the specific underpinnings of cognitive dysfunction in schizophrenia [501-503]. Overall, the benefits of cognitive remediation include moderate improvements of cognitive performance across all relevant domains and more importantly psychosocial functioning, but also a reduction of clinical symptoms [107,504]. The concurrent improvement in daily functioning after cognitive remediation has been repeatedly confirmed in meta-analyses [504,505]. The integration of cognitive remediation with psychiatric rehabilitation programs is associated with particularly beneficial outcomes because it closely links the acquisition of cognitive skills to real-life situations [506,507]. Thus, its potential proximity to real world situations is on one of the inherent advantages of cognitive remediation. This also limits the usefulness of predominantly computer-based programs, which might negate this advantage. In this context, one central principle involves intensive support from a therapist to modify behavioral strategies in order to improve cognition and tie that to everyday behavioral exercises [508].

A complementary approach involves the development of compensatory strategies in order to modify the interaction of patients' cognitive strengths and 
weaknesses with the environment [500]. Cognitive remediation affects all relevant cognitive domains and appears to facilitate brain reorganization on both the micro- and macro-circuit level [509]. However, our current understanding of the neurophysiological consequences of cognitive remediation remains limited due to the considerable heterogeneity of available neuroimaging studies.

Several meta-analyses have tried to identify predictors factors for a positive response to CRT, but with relatively inconsistent results. One recent study reported a positive association of premorbid IQ, baseline cognition and training task progress, i.e. improvement on CRT tasks [510]. Interestingly, there is conflicting evidence regarding the differential utility of cognitive remediation in early versus chronic schizophrenia. In a recent meta-analysis, effect sizes for global cognitive improvement were somewhat larger for chronic schizophrenia compared to early schizophrenia [511]. Conversely, other studies have reported that younger, less chronic patients receiving lower doses of antipsychotic medication respond best to these types of intervention [512,513]. Overall, current evidence points to a moderate effectiveness of cognitive remediation across illness stages, making it the most established and most universally recommended approach among pro-cognitive interventions for schizophrenia $[514,515]$.

\section{Virtual reality}

The use of virtual reality - interactive immersive computer environments - is an exciting new way to investigate a number of aspects of schizophrenia. This includes the assessment and treatment of cognitive impairments [516]. To a certain degree, virtual reality combines the power and flexibility of computer-based cognitive remediation techniques with the proximity to real-life situations of interactive group 
settings. Virtual reality has indeed been used in rehabilitation programs [517]. Patients can practice cognitive tasks and refine compensatory mechanisms in simulated reallife situations. VR-based therapy is well accepted by patients with schizophrenia [518]. Social cognition has been an important focus of virtual reality studies in schizophrenia [519-522], particularly the evaluation and interpretation of social cues from others. Several studies have demonstrated improvements of social cognition in patients after VR-based trainings $[521,523,524]$. Due to its potential, future studies should expand the use of VR-based cognitive remediation to other domains.

As neural plasticity is use-dependent, it may be a promising strategy to couple pharmacological intervention with CRT/VR-CRT. While questions such as optimal sequence and timing remain to be clarified, such combination may even be required to unleash the full potential of pharmacological approaches. However, we are not aware of any respective study.

\section{Aerobic physical exercise}

There is growing interest in exercise interventions, especially aerobic training, as an add-on treatment for patients with schizophrenia. In addition to positive effects of exercise on positive and negative symptom severity, need of care, social and global functioning, and quality of life [525-530] aerobic physical exercise appears to confer a number of neurocognitive benefits. Meta-analytic evidence indicates a general performance increase in a pooled assessment of cognitive functions following exercise interventions [531]. However, effects on individual MATRICS domains [532] are rather heterogeneous. Physical exercise appears to be particularly beneficial for working memory, attention/vigilance and social cognition, with effect sizes comparable to cognitive remediation therapy $[531,533]$. Conversely, there is no consistent evidence 
for effects on processing speed, verbal and visual learning and memory, and reasoning and problem solving [531]. Longitudinal studies indicate that exercise-induced improvements may not be sustainable to the same degree across cognitive domains [528,534]. It must be noted, however that existing studies show a large degree of heterogeneity with respect to sample sizes and implemented interventions, differing in duration, intensity, type of exercise and combinations with other interventions [527,535]. The strongest impact on cognition is likely induced by aerobic training and by interventions that are supervised by professional physical activity instructors [531]. The intensity, length, frequency and fidelity required for exercise-based interventions to improve cognition is still unclear. Yet, both exercise dose and the length of interventions have been positively linked to greater cognitive improvements $[536,537]$. At least 90 min per week of moderate-to-vigorous exercise with blood lactate concentrations of approx. $2.0 \mathrm{mmol} / \mathrm{l}$ and intensity levels between $10-13$ on the Borgscale of perceived exertion [538] have been proposed to be required to induce changes in physical fitness, neurocognition and functional outcome $[527,535]$. This is especially relevant considering that patients' adherence to (group) exercise interventions may be limited by factors such as somatic comorbidities, social anxiety, and sedative effects of antipsychotic medication [526,539]. On the neurobiological level, multiple lines of evidence indicate a central role of exercise-induced multi-level neuroplasticity, which directly counteract some of the pathophysiological processes implicated in schizophrenia [540].

Potential levels of actions include increased gray matter volume [541], white matter integrity [542,543], improved angio- and [544,545] neurogenesis [545-547], epigenetic adaptations [548,549], increased levels of a number of neurotrophic factors [550-552], enhanced dopaminergic, cholinergic and norepinephrinergic 
neurotransmission [553-556], normalization of the hypothalamus-pituitary-axis [557] and an improved antioxidant defense [540,558]. Importantly, these proposed mechanisms are predominantly based on animal studies and observations in healthy individuals [540]. In schizophrenia, neuroplastic responses to exercise appear to be attenuated [559] and are further affected by individual risk factors such as polygenic risk [560]. Increased hippocampal volume and concurrent enhancements of verbal short-term memory following three months of endurance training in patients with schizophrenia have been reported [561]. However, this could not be replicated consistently in subsequent studies [542,562,563] and meta-analyses [564]. Nevertheless, other forms of exercise-induced structural and functional neuroplasticity $[234,542,543,563,565,566]$ and increased serum levels of BDNF [550-552] have been reported.

Therefore, irrespective of the remaining uncertainties regarding its exact neurobiological mechanisms, physical exercise remains one of the most promising approaches for the non-pharmacological treatment of cognitive deficits and their psychosocial sequelae in schizophrenia.

\section{Brain stimulation}

Non-invasive brain-stimulation (NIBS) techniques in the form of repetitive transcranial magnetic stimulation (rTMS) and transcranial direct current stimulation (tDCS) constitute an elegant approach for the modulation of neural activity and neuronal plasticity $[40,567-571]$. Their effects on psychopathology in patients with schizophrenia have been studied extensively. Positive effects on medication-resistant auditory hallucinations have been the most consistent finding $[572,573]$. However, there is increasing evidence for their efficacy in treating cognitive symptoms in 
psychiatric disorders. Improvements in working memory and long-term memory following high-frequency stimulation with rTMS [574,575] have been demonstrated consistently in schizophrenia.

For tDCS, so far positive effects on working memory, attention and social cognition have been reported [574,576]. Interestingly, tDCS applied during the performance of a working memory task lead to greater cognitive improvements than tDCS applied during rest in healthy subjects [577] suggesting a potential benefit for the concurrent use of brain stimulation and cognitive remediation techniques. This observation also implies that tDCS might enhance neural plasticity.

Overall, both NIBS-methods show considerable potential for treating cognitive impairments, but this line of research still appears to be in its early stages and the neurophysiological underpinnings and the rationale for specific stimulation protocols need to be established much more clearly.

\section{Section IV: Outlook}

The need for a personalized approach

As reviewed, currently available cognitive enhancement interventions show at best a moderate effect size. On the one hand, this can be attributed to the lack of knowledge about more effective pro-cognitive mechanisms. On the other hand, another important aspect is the great variability of response to pro-cognitive interventions.

Several important factors underlying this phenomenon have been proposed, particularly genetics [578] and patients' baseline level of cognitive functioning. Individuals with low cognitive performance typically respond more strongly to cognitive enhancement interventions. Furthermore, genotypes influencing specific 
neurotransmitter or signaling pathways targeted by a compound might have a pronounced effect on the degree of cognitive enhancement [578]. Additionally, the complex neurobiological and neurophysiological mechanisms giving rise to cognitive functions and their disturbance make it highly unlikely that a single approach will be successful for a substantial number of patients. Thus, although large-scale randomized controlled trials offer protection from false positive findings, they also have the potential to disregard the crucial fact that only specific subgroups might benefit from a particular intervention. These issues underscore the need for a personalized medicine approach $[113,579,580]$ and the development of suitable biomarkers based primarily on genetic, neurophysiological and cognitive data.

In general terms, biomarkers are defined as biological parameters of "defined characteristic", which are utilized as reliable indicators for physiological and pathological processes and for monitoring the "response to an exposure and intervention" [581]. Thus, biomarkers can be used to estimate illness risk and prognosis, to study pharmacodynamics, to evaluate treatment responses, and to predict the effect of a therapeutic intervention [582-584].

\section{Cognitive imaging biomarkers}

Functional neuroimaging methods including EEG [585,586], MEG [585] or fMRI have been essential for increasing our understanding of the neurophysiological basis of cognitive impairment in schizophrenia $[587,588]$. While a more detailed review of these findings is beyond the scope of this article, it is clear going forward that their relevance for this purpose will only continue to increase, not least due to technological advances. 
Beyond its traditional role, functional neuroimaging will also be essential for biomarker research [589]. Here, an increasing number of promising biomarker candidates for illness-risk and response to antipsychotic treatment have been reported in recent years [590-593]. Yet, the development of biomarkers suitable for the treatment of impaired cognition is still in its early stages. Ideally, they should closely reflect the targeted neural system [113] pointing to cognitive imaging biomarkers as the most promising candidates $[113,578]$. Recent studies reporting markers of brain oscillations related to perceptual training underscore the potential of this approach $[594,595]$. Functional connectomics approaches $[596,597]$ appear to be particularly well suited due to their close links to the dysconnection syndrome $[598,599]$ and the genetic architecture of schizophrenia [600]. The high-dimensional nature of functional neuroimaging data and the imperative to include genetic data of even greater dimensionality strongly argues for the use of machine-learning techniques [590]. In schizophrenia research, functional connectomics have been applied predominantly to resting state data [601], but a cognitive imaging biomarker would have to be based on a cognitive paradigm with sufficient construct validity and sensitivity.

These prerequisites make cognitive imaging biomarkers one of the most challenging classes of biomarkers along with the fact that they require further extensive optimization and validation of cognitive, physiological and technical parameters for multi-site administration. This includes the standardization of task and stimulus parameters, calibration against floor and ceiling effects, the assessment of effect sizes for patient control differences, the assessment of internal and test-retest reliability and the establishment of the relationship between both performance and neural activity measures and clinical and functional measures [113,590]. 
While cognitive imaging biomarker can be regarded as the gold standard for cognitive enhancement intervention studies, they should be complemented by other biomarker modalities to gain additional mechanistic insights regarding the investigated pro-cognitive interventions. For instance, structural imaging markers including DTI might be used to reveal neuroprotective and neuroplastic effects [40,602-604]. Advances in the imaging of activated microglia using PET $[605,606]$ should allow to monitor the effects of anti-inflammatory treatments in specific brain systems. Bloodbased biomarkers and neurotrophic markers such as BDNF $[441,607,608]$ as well as pro- and anti-inflammatory markers [607] have also been evaluated.

\section{Neuroplasticity: a final common pathway}

Many of the therapeutic approaches covered in this review converge mechanistically on the level of neural plasticity. This might not be particularly surprising, given that neural plasticity is crucial for improving cognitive abilities in healthy individuals throughout adult life [609]. On the other hand, the dysconnection syndrome is closely related to fundamental disturbances of neural plasticity and enhancing neural plasticity. Therefore, directly augmenting this essential mechanism for the reorganization of neural circuits and thus reducing the widespread impact of the dysconnection syndrome might currently come closest to a pathophysiology-based treatment of cognitive impairment in schizophrenia is thus probably the most promising therapeutic approach at this moment.

Despite the clear involvement of all the reviewed neurotransmitter systems in neural plasticity and in the etiology of cognitive dysfunction, their pharmacological modulation has so far been less successful than approaches which target neural plasticity more directly and broadly. This is compatible with the notion that abnormal 
neural plasticity in schizophrenia is a final common pathway for cognitive dysfunction, also integrating disturbances in individual neurotransmitter systems with inflammatory processes.

Such an interpretation would further imply that intervening at this point of pathophysiological convergence, i.e. at the level of neural plasticity, is practically essential for any successful pro-cognitive intervention. In this context, the mechanistic convergence of widely different treatment options such as cognitive remediation, aerobic exercise, NIBS and EPO highlights the potential for therapeutic synergy $[610,611]$. This synergy might be further increased by the modulation of neurotransmitter systems with the explicit aim to enhance neural plasticity [612]. Notably, this would also include attempts to restore E/I imbalance in schizophrenia with the goal to normalize attenuated gamma oscillations given increasing evidence for their role in shaping cortical plasticity [613].

In the light of the current state of the field, a development strategy for pharmacological compounds with the aim to synergistically enhance neural plasticity appears to be the most promising. However, one has to acknowledge the enormous challenges associated with such a strategy in terms of study design, required sample sizes and attractiveness for the pharmaceutical industry.

Conversely, for current clinical practice, exploiting existing potentials for therapeutic synergy in treating cognitive dysfunction should already be regarded as essential, but may face its own set of obstacles.

\section{Early intervention strategies}

Identifying individuals at heightened risk for psychosis serves as the foundation for intervention studies aimed at avoiding, ameliorating, or delaying progression to 
psychosis [614]. This has prompted a surge of research into the prodromal phase of schizophrenia - also termed the "ultra-high-risk state for psychosis" (UHR). Initiating appropriate treatment as early as possible has the potential of improving both the clinical and functional outcome of UHR individuals [615]. Notably, cognitive decline during the prodromal phase is an important predictor not only of functional decline but also of transition to psychosis [616,617]. This emphasizes the specific relevance of improving cognitive dysfunction in UHR individuals. Compared to full-blown schizophrenia, studies of pro-cognitive interventions remain relatively scarce. However, meta-analytical evidence indicates that CRT is effective in UHR individuals [618]. Due to the possibility of preventing further cognitive decline during its early stages, the prodromal phase might constitute a critical period for cognitive enhancement strategies and should be a major focus of research. Yet, the UHR state also warrants particularly great caution when weighing the possible benefits and side effects of treatments, which currently favors non-pharmacological interventions.

\section{Transdiagnostic approaches}

A large body of behavioral evidence indicates that cognitive impairments are clearly present across diagnostic categories, albeit to different degrees [578]. For instance, most transdiagnostic studies observed a gradient of cognitive impairment with patients with schizophrenia generally more affected than patients with bipolar disorder [619-625]. In light of these findings and in line with the neurodevelopmental gradient hypothesis, cognitive dysfunction can therefore be regarded as a fundamental feature of neurodevelopmental psychiatric disorders in general $[60,626]$.

Likewise, there is increasing evidence for the existence of distinct biotypes at the systems level across diagnostic boundaries which are characterized by shared 
neurobiological features which might not be present in the majority of patients within a diagnostic category [627]. This would imply that studying the relationship between clearly defined transdiagnostic biotypes and cognitive deficits might be a more successful way to develop effective pro-cognitive treatments. In line with the RDoC concept, it might thus be more effective to target the most relevant neural circuitry than to target a specific diagnostic category. This also might substantially increase the potential number of patients, which might benefit from a particular form of therapy. CRT, which in modified form is also effective for patients with MDD, bipolar disorder, ADHD, substance use disorder, ASD, anorexia nervosa, and obsessive-compulsive disorder $[628,629]$ is a primary example of such an approach. However, it should be possible to extend this strategy to other pharmacological and non-pharmacological techniques to enhance neural plasticity as demonstrated the transdiagnostic efficacy of EPO $[424,437,438]$.

\section{Conclusion}

The findings and concepts reviewed in this paper clearly implicate the enhancement of neural plasticity as the most promising currently established pathway for improving cognitive deficits in schizophrenia. Furthermore, the recent developments in the field of cognitive dysfunction exemplify the ongoing paradigm shift toward a general conceptualization of many forms of mental illness as information processing disorders with gradual rather than categorical differences in cognitive profiles. Accordingly, ameliorating cognitive dysfunction continues to emerge as an essential goal for psychiatry in general. Addressing the urgent demand for progress in this field depends critically on substantially advancing our knowledge of the neurophysiological and neurobiological basis of intact cognition. Successfully 
translating such findings into better pro-cognitive treatments requires an intensified exchange between basic, cognitive and clinical neuroscience on all levels. This should prove to be mutually beneficial as the study of neuropsychiatric disorders itself has increased our understanding of brain function to a considerable degree. Most importantly, these efforts should help to substantially improve patients' long-term outcomes and reduce the considerable burden of schizophrenia. 


\section{ABBREVIATIONS}

5HT serotonin

$\mathrm{ACH} \quad$ acetylcholine

ADHD attention deficit hyperactivity disorder

alpha-7- alpha-7-nicotinic-acetylcholine-receptor

nAChR

AMPA a-amino-3-hydroxy-5-methyl-4-isoxazolepropionic acid

ASD autism spectrum disorder

BBB blood-brain barrier

BDNF brain derived neurotrophic factor

BMT- $\quad$ NAM selective for the NR2B NMDA ubtype

108908

BZD benzodiazepines

Ca calcium

CATIE Clinical Antipsychotic Trials of Intervention Effectiveness

CIAS cognitive impairment associated with schizophrenia

CNS central nervous system

CNTRACS Cognitive Neuroscience Test Reliability and Clinical applications for Schizophrenia

CNTRICS Cognitive Neuroscience Treatment Research to Improve Cognition in Schizophrenia

COMT catechol-o-methyltransferase

cOX-2 cyclo-oxygenase-2

CRT cognitive remediation therapy 
DA dopamine

DAAO d-amino acid oxidase

DETQ 2-(2,6-dichlorophenyl)-1-((1S,3R)-3-(hydroxymethyl)-5-(2-

hydroxypropan-2-yl)-1-methyl-3,4-dihydroisoquinolin-2(1H)-yl)ethan-1-

one

DLPFC dorso-lateral prefrontal cortex

ECT electroconvulsive therapy

EEG electroencephalography

E/I excitatory / inhibitory

EPO erythropoietin

FGA first-generation antipsychotic

fMRI functional magnetic resonance imaging

GABA gamma-Aminobutyric acid

GAD67 Glutamate decarboxylase 67

Glu glutamate

HIF hypoxia inducible factor

ICD-11 International Classification of Diseases $11^{\text {th }}$ Revision

IL6 interleukin 6

IQ intelligence quotient

JAK Janus kinase

LC locus coeruleus

LTD long-term depression

LTP long-term potentiation

MAPK Mitogen-activated protein kinase 
MATRICS Measurement and Treatment Research to Improve Cognition in Schizophrenia

MCCB MATRICS cognitive consensus battery

MDD major depressive disorder

MEG magnetoencephalography

mGluR metabotropic glutamate receptor

MPEP 2-methyl-6-(phenylethynyl)-pyridine

nAChR nicotinic acetylcholine-receptor

NAM negative allosteric modulators

NE norepinephrine

NIBS Non-invasive brain-stimulation

NIMH National Institute of Mental Health

NMDA N-methyl-D-aspartate receptor

NO nictric oxide

OCD obsessive-compulsive disorder

PAM positive allosteric modulator

PET positron emission tomography

PFC prefrontal cortex

PI3K phosphoinositide 3-kinase

PV parvalbumin

RNA nibonucleic acid

RDoC research domain criteria

rhEPO recombinant erythropoietin

rTMS repetitive transcranial magnetic stimulation 


$\begin{array}{ll}\text { SAD } & \text { seasonal affective disorder } \\ \text { SAM } & \text { silent allosteric modulator } \\ \text { SGA } & \text { second-generation antipsychotic } \\ \text { SGC } & \text { soluble guanylyl cyclase } \\ \text { STAT } & \text { signal transducers and activators of transcription } \\ \text { SUD } & \text { substance use disorders } \\ \text { tDCS } & \text { transcranial direct current stimulation } \\ \text { TNF- } \alpha 1 & \text { tumor necrosis factor } \alpha 1 \\ \text { VR } & \text { virtual reality }\end{array}$

\section{FUNDING}

Catherine V. Barnes-Scheufler was supported by a "main doctus" scholarship from The Polytechnic Foundation of Frankfurt am Main. Meike D. Hettwer was funded by the Max Planck Society.

\section{ACKNOWLEDGEMENTS}

We thank one of our patients for providing a detailed description of his subjective experience regarding the impact of cognitive dysfunction on his daily life.

\section{AUTHOR CONTRIBUTIONS}

R.A.B., C.V.B.-S., M.D.H., A.R. and M.Q. individually contributed to manuscript writing, manuscript check and preparation of its final version. All authors have read and agreed to the published version of the manuscript 


\section{INSTITUTIONAL REVIEW BOARD STATEMENT}

Not applicable

\section{INFORMED CONSENT STATEMENT}

Not applicable

\section{DATA AVAILABILITY STATEMENT}

Not applicable

\section{CONFLICTS OF INTEREST}

The authors have declared that there are no conflicts of interest in relation to the subject of this review. 


\section{REFERENCES}

1. Aquila, R. and L. Citrome, Cognitive impairment in schizophrenia: the great unmet need. CNS Spectrums, 2015. 20(S1): p. 32-40.

2. Green, M.F., R.S. Kern, and R.K. Heaton, Longitudinal studies of cognition and functional outcome in schizophrenia: implications for MATRICS. Schizophr Res, 2004. 72(1): p. 41-51.

3. Green, M.F., W.P. Horan, and J. Lee, Nonsocial and social cognition in schizophrenia: current evidence and future directions. World Psychiatry, 2019. 18(2): p. 146-161.

4. Mohamed, S., et al., Generalized cognitive deficits in schizophrenia: a study of first-episode patients. Arch Gen Psychiatry, 1999. 56(8): p. 749-54.

5. Gruzelier, J., et al., Impairments on neuropsychologic tests of temporohippocampal and frontohippocampal functions and word fluency in remitting schizophrenia and affective disorders. Arch Gen Psychiatry, 1988. 45(7): p. 623-9.

6. Bilder, R.M., et al., Neuropsychology of first-episode schizophrenia: initial characterization and clinical correlates. Am J Psychiatry, 2000. 157(4): p. 549-59.

7. Gold, S., et al., Longitudinal study of cognitive function in first-episode and recent-onset schizophrenia. Am J Psychiatry, 1999. 156(9): p. 1342-8.

8. Braff, D.L., et al., The generalized pattern of neuropsychological deficits in outpatients with chronic schizophrenia with heterogeneous Wisconsin Card Sorting Test results. Arch Gen Psychiatry, 1991. 48(10): p. 891-8.

9. Kuperberg, G. and S. Heckers, Schizophrenia and cognitive function. Curr Opin Neurobiol, 2000. 10(2): p. 205-10.

10. Fioravanti, M., V. Bianchi, and M.E. Cinti, Cognitive deficits in schizophrenia: an updated metanalysis of the scientific evidence. BMC Psychiatry, 2012. 12(1): p. 64.

11. Marder, S.R. and W. Fenton, Measurement and Treatment Research to Improve Cognition in Schizophrenia: NIMH MATRICS initiative to support the development of agents for improving cognition in schizophrenia. Schizophrenia Research, 2004. 72(1): p. 5-9.

12. Schaefer, J., et al., The global cognitive impairment in schizophrenia: consistent over decades and around the world. Schizophr Res, 2013. 150(1): p. 42-50.

13. Braff, D.L., Information processing and attention dysfunctions in schizophrenia. Schizophr Bull, 1993. 19(2): p. 233-59.

14. Carr, V. and J. Wale, Schizophrenia: An Information Processing Model. Australian and New Zealand Journal of Psychiatry, 1986. 20: p. 136-155.

15. Giersch, A., et al., Disruption of information processing in schizophrenia: The time perspective. Schizophrenia research. Cognition, 2015. 2(2): p. 78-83.

16. Kahn, R.S. and R.S. Keefe, Schizophrenia is a cognitive illness: time for a change in focus. JAMA Psychiatry, 2013. 70(10): p. 1107-12.

17. Rossler, W., et al., Size of burden of schizophrenia and psychotic disorders. Eur Neuropsychopharmacol, 2005. 15(4): p. 399-409.

18. American Psychiatric Association, D.-. Diagnostic and statistical manual of mental disorders: $D S M-5^{T M}$, 5th ed. Diagnostic and statistical manual of mental disorders: DSM- $5^{\mathrm{TM}}, 5$ th ed. 2013, Arlington, VA, US: American Psychiatric Publishing, Inc. xliv, 947-xliv, 947.

19. Khoury, B., C. Kogan, and S. Daouk, International Classification of Diseases 11th Edition (ICD11). 2017. p. 1-6.

20. Green, M.F. and P.D. Harvey, Cognition in schizophrenia: Past, present, and future. Schizophrenia research. Cognition, 2014. 1(1): p. e1-e9.

21. Gaebel, W., Status of psychotic disorders in ICD-11. Schizophrenia bulletin, 2012. 38(5): p. 895-898.

22. Chapman, L.J. and J.P. Chapman, Problems in the measurement of cognitive deficit. Psychol Bull, 1973. 79(6): p. 380-5. 
23. Knight, R.A. and S.M. Silverstein, A process-oriented approach for averting confounds resulting from general performance deficiencies in schizophrenia. J Abnorm Psychol, 2001. 110(1): p. 15-30.

24. Gold, J.M., et al., Turning it upside down: areas of preserved cognitive function in schizophrenia. Neuropsychol Rev, 2009. 19(3): p. 294-311.

25. Weickert, T.W., et al., Cognitive impairments in patients with schizophrenia displaying preserved and compromised intellect. Arch Gen Psychiatry, 2000. 57(9): p. 907-13.

26. Marenco, S. and D.R. Weinberger, The neurodevelopmental hypothesis of schizophrenia: following a trail of evidence from cradle to grave. Dev Psychopathol, 2000. 12(3): p. 501-27.

27. Tamminga, C.A. and H.H. Holcomb, Phenotype of schizophrenia: a review and formulation. Molecular Psychiatry, 2005. 10(1): p. 27-39.

28. Davis, J., et al., A review of vulnerability and risks for schizophrenia: Beyond the two hit hypothesis. Neuroscience \& Biobehavioral Reviews, 2016. 65: p. 185-194.

29. Friston, K., et al., The dysconnection hypothesis (2016). Schizophrenia research, 2016. 176(23): p. 83-94.

30. Friston, K.J., The disconnection hypothesis. Schizophr Res, 1998. 30(2): p. 115-25.

31. Friston, K., et al., The dysconnection hypothesis (2016). Schizophrenia Research, 2016. 176: p. 83-94.

32. Stephan, K.E., K.J. Friston, and C.D. Frith, Dysconnection in schizophrenia: from abnormal synaptic plasticity to failures of self-monitoring. Schizophr Bull, 2009. 35(3): p. 509-27.

33. Föcking, M., et al., Proteomic and genomic evidence implicates the postsynaptic density in schizophrenia. Molecular Psychiatry, 2015. 20(4): p. 424-432.

34. Forsyth, J.K., et al., Synaptic and Gene Regulatory Mechanisms in Schizophrenia, Autism, and 22q11.2 Copy Number Variant-Mediated Risk for Neuropsychiatric Disorders. Biological Psychiatry, 2020. 87(2): p. 150-163.

35. Fromer, M., et al., De novo mutations in schizophrenia implicate synaptic networks. Nature, 2014. 506(7487): p. 179-184.

36. Hall, J., et al., Genetic Risk for Schizophrenia: Convergence on Synaptic Pathways Involved in Plasticity. Biological Psychiatry, 2015. 77(1): p. 52-58.

37. Schrode, N., et al., Synergistic effects of common schizophrenia risk variants. Nature genetics, 2019. 51(10): p. 1475-1485.

38. Forsyth, J.K. and D.A. Lewis, Mapping the Consequences of Impaired Synaptic Plasticity in Schizophrenia through Development: An Integrative Model for Diverse Clinical Features. Trends in Cognitive Sciences, 2017. 21(10): p. 760-778.

39. Daskalakis, Z.J., et al., Dysfunctional neural plasticity in patients with schizophrenia. Arch Gen Psychiatry, 2008. 65(4): p. 378-85.

40. Balu, D.T. and J.T. Coyle, Neuroplasticity signaling pathways linked to the pathophysiology of schizophrenia. Neuroscience and biobehavioral reviews, 2011. 35(3): p. 848-870.

41. Frost, D.O., et al., Neuroplasticity and schizophrenia. Biological Psychiatry, 2004. 56(8): p. 540-543.

42. Keshavan, M.S., et al., Dysplasticity, metaplasticity, and schizophrenia: Implications for risk, illness, and novel interventions. Development and psychopathology, 2015. 27(2): p. 615-635.

43. Buzsáki, G. and X.J. Wang, Mechanisms of gamma oscillations. Annu Rev Neurosci, 2012. 35 : p. 203-25.

44. Fries, P., Neuronal Gamma-Band Synchronization as a Fundamental Process in Cortical Computation. Annual Review of Neuroscience, 2009. 32(1): p. 209-224.

45. Giraud, A.-L. and D. Poeppel, Cortical oscillations and speech processing: emerging computational principles and operations. Nature neuroscience, 2012. 15(4): p. 511-517.

46. Singer, W., Neuronal synchrony: a versatile code for the definition of relations? Neuron, 1999. 24(1): p. 49-65, 111-25.

47. Singer, W., Cortical dynamics revisited. Trends Cogn Sci, 2013. 17(12): p. 616-26. 
48. Uhlhaas, P.J. and W. Singer, Abnormal neural oscillations and synchrony in schizophrenia. Nat Rev Neurosci, 2010. 11(2): p. 100-13.

49. Haenschel, C., et al., Cortical Oscillatory Activity Is Critical for Working Memory as Revealed by Deficits in Early-Onset Schizophrenia. The Journal of Neuroscience, 2009. 29(30): p. 9481.

50. Reilly, T.J., et al., Gamma band oscillations in the early phase of psychosis: A systematic review. Neuroscience \& Biobehavioral Reviews, 2018. 90: p. 381-399.

51. Anticevic, A. and J. Lisman, How Can Global Alteration of Excitation/Inhibition Balance Lead to the Local Dysfunctions That Underlie Schizophrenia? Biological Psychiatry, 2017. 81(10): p. 818-820.

52. Gonzalez-Burgos, G., R.Y. Cho, and D.A. Lewis, Alterations in Cortical Network Oscillations and Parvalbumin Neurons in Schizophrenia. Biological Psychiatry, 2015. 77(12): p. 1031-1040.

53. Lewis, D.A., et al., Cortical parvalbumin interneurons and cognitive dysfunction in schizophrenia. Trends Neurosci, 2012. 35(1): p. 57-67.

54. Lewis, D.A., T. Hashimoto, and D.W. Volk, Cortical inhibitory neurons and schizophrenia. Nat Rev Neurosci, 2005. 6(4): p. 312-24.

55. Hajos, N. and O. Paulsen, Network mechanisms of gamma oscillations in the CA3 region of the hippocampus. Neural Netw, 2009. 22(8): p. 1113-9.

56. Packer, A.M. and R. Yuste, Dense, unspecific connectivity of neocortical parvalbumin-positive interneurons: a canonical microcircuit for inhibition? J Neurosci, 2011. 31(37): p. 13260-71.

57. Cardin, J.A., et al., Driving fast-spiking cells induces gamma rhythm and controls sensory responses. Nature, 2009. 459(7247): p. 663-7.

58. Sohal, V.S., et al., Parvalbumin neurons and gamma rhythms enhance cortical circuit performance. Nature, 2009. 459(7247): p. 698-702.

59. Senkowski, D. and J. Gallinat, Dysfunctional Prefrontal Gamma-Band Oscillations Reflect Working Memory and Other Cognitive Deficits in Schizophrenia. Biological Psychiatry, 2015. 77(12): p. 1010-1019.

60. Pearlson, G.D., Etiologic, Phenomenologic, and Endophenotypic Overlap of Schizophrenia and Bipolar Disorder. Annual Review of Clinical Psychology, 2015. 11(1): p. 251-281.

61. Valli, I., C. Fabbri, and A.H. Young, Uncovering neurodevelopmental features in bipolar affective disorder. The British Journal of Psychiatry, 2019. 215(1): p. 383-385.

62. Bora, E. and C. Pantelis, Meta-analysis of cognitive impairment in first-episode bipolar disorder: comparison with first-episode schizophrenia and healthy controls. Schizophrenia bulletin, 2015. 41(5): p. 1095-1104.

63. Owen, M.J. and M.C. O'Donovan, Schizophrenia and the neurodevelopmental continuum: evidence from genomics. World Psychiatry, 2017. 16(3): p. 227-235.

64. Pearlson, G.D., Etiologic, phenomenologic, and endophenotypic overlap of schizophrenia and bipolar disorder. Annu Rev Clin Psychol, 2015. 11: p. 251-81.

65. Cornblatt, B., et al., Cognitive and behavioral precursors of schizophrenia. Development and Psychopathology, 1999. 11(3): p. 487-508.

66. Keefe, R.S., et al., A longitudinal study of neurocognitive function in individuals at-risk for psychosis. Schizophr Res, 2006. 88(1-3): p. 26-35.

67. Lencz, T., et al., Generalized and specific neurocognitive deficits in prodromal schizophrenia. Biol Psychiatry, 2006. 59(9): p. 863-71.

68. Hambrecht, M., et al., Subjective and objective neuropsychological abnormalities in a psychosis prodrome clinic. Br J Psychiatry Suppl, 2002. 43: p. s30-7.

69. Hawkins, K.A., et al., Neuropsychological status of subjects at high risk for a first episode of psychosis. Schizophr Res, 2004. 67(2-3): p. 115-22.

70. Osler, M., D.A. Lawlor, and M. Nordentoft, Cognitive function in childhood and early adulthood and hospital admission for schizophrenia and bipolar disorders in Danish men born in 1953. Schizophr Res, 2007. 92(1-3): p. 132-41. 
71. Reichenberg, A., et al., Elaboration on premorbid intellectual performance in schizophrenia: premorbid intellectual decline and risk for schizophrenia. Arch Gen Psychiatry, 2005. 62(12): p. 1297-304.

72. Reichenberg, A., et al., A population-based cohort study of premorbid intellectual, language, and behavioral functioning in patients with schizophrenia, schizoaffective disorder, and nonpsychotic bipolar disorder. Am J Psychiatry, 2002. 159(12): p. 2027-35.

73. Millan, M.J., et al., Altering the course of schizophrenia: progress and perspectives. Nat Rev Drug Discov, 2016. 15(7): p. 485-515.

74. Fusar-Poli, P., et al., Predicting Psychosis: Meta-analysis of Transition Outcomes in Individuals at High Clinical Risk. Archives of General Psychiatry, 2012. 69(3): p. 220-229.

75. Heaton, R.K., et al., Stability and course of neuropsychological deficits in schizophrenia. Arch Gen Psychiatry, 2001. 58(1): p. 24-32.

76. Zanelli, J., et al., Cognitive Change in Schizophrenia and Other Psychoses in the Decade Following the First Episode. American Journal of Psychiatry, 2019. 176(10): p. 811-819.

77. Farmer, C.M., et al., Visual perception and working memory in schizotypal personality disorder. Am J Psychiatry, 2000. 157(5): p. 781-8.

78. VogImaier, M.M., et al., Verbal and nonverbal neuropsychological test performance in subjects with schizotypal personality disorder. Am J Psychiatry, 2000. 157(5): p. 787-93.

79. Cannon, T.D., et al., Neuropsychological functioning in siblings discordant for schizophrenia and healthy volunteers. Arch Gen Psychiatry, 1994. 51(8): p. 651-61.

80. Hans, S.L., et al., Neurobehavioral deficits at adolescence in children at risk for schizophrenia: The Jerusalem Infant Development Study. Arch Gen Psychiatry, 1999. 56(8): p. 741-8.

81. Egan, M.F., et al., Relative risk for cognitive impairments in siblings of patients with schizophrenia. Biol Psychiatry, 2001. 50(2): p. 98-107.

82. Schubert, E.W. and T.F. McNeil, Neuropsychological impairment and its neurological correlates in adult offspring with heightened risk for schizophrenia and affective psychosis. Am J Psychiatry, 2005. 162(4): p. 758-66.

83. Bilder, R.M., et al., The genetics of cognitive impairment in schizophrenia: a phenomic perspective. Trends Cogn Sci, 2011. 15(9): p. 428-35.

84. Smeland, O.B., et al., Identification of Genetic Loci Jointly Influencing Schizophrenia Risk and the Cognitive Traits of Verbal-Numerical Reasoning, Reaction Time, and General Cognitive Function. JAMA Psychiatry, 2017. 74(10): p. 1065-1075.

85. Thygesen, J.H., et al., Genetic copy number variants, cognition and psychosis: a meta-analysis and a family study. Molecular Psychiatry, 2020.

86. Toulopoulou, T., et al., Polygenic risk score increases schizophrenia liability through cognitionrelevant pathways. Brain, 2019. 142(2): p. 471-485.

87. Zai, G., et al., A review of molecular genetic studies of neurocognitive deficits in schizophrenia. Neuroscience \& Biobehavioral Reviews, 2017. 72: p. 50-67.

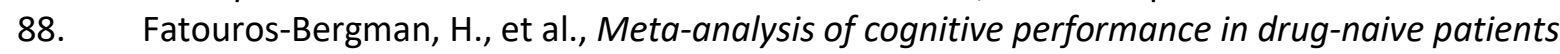
with schizophrenia. Schizophr Res, 2014. 158(1-3): p. 156-62.

89. Andreasen, N.C., A unitary model of schizophrenia: Bleuler's "fragmented phrene" as schizencephaly. Arch Gen Psychiatry, 1999. 56(9): p. 781-7.

90. Millan, M.J., et al., Cognitive dysfunction in psychiatric disorders: characteristics, causes and the quest for improved therapy. Nat Rev Drug Discov, 2012. 11(2): p. 141-68.

91. Insel, T., et al., Research domain criteria (RDoC): toward a new classification framework for research on mental disorders. 2010, Am Psychiatric Assoc.

92. Cuthbert, B.N. and T.R. Insel, Toward the future of psychiatric diagnosis: the seven pillars of RDoC. BMC medicine, 2013. 11(1): p. 126.

93. Cuthbert, B.N., The RDoC framework: facilitating transition from ICD/DSM to dimensional approaches that integrate neuroscience and psychopathology. World Psychiatry, 2014. 13(1): p. 28-35. 
94. Green, M.F., What are the functional consequences of neurocognitive deficits in schizophrenia? The American journal of psychiatry, 1996.

95. Tandon, R., H.A. Nasrallah, and M.S. Keshavan, Schizophrenia, "Just the Facts" 5. Treatment and prevention Past, present, and future. Schizophrenia research, 2010. 122(1-3): p. 1-23.

96. Harvey, P.D. and M. Strassnig, Predicting the severity of everyday functional disability in people with schizophrenia: cognitive deficits, functional capacity, symptoms, and health status. World Psychiatry, 2012. 11(2): p. 73-9.

97. McGurk, S.R., et al., Cognitive and symptom predictors of work outcomes for clients with schizophrenia in supported employment. Psychiatric services, 2003. 54(8): p. 1129-1135.

98. Green, M.F., W.P. Horan, and J. Lee, Nonsocial and social cognition in schizophrenia: current evidence and future directions. World psychiatry : official journal of the World Psychiatric Association (WPA), 2019. 18(2): p. 146-161.

99. Wu, E.Q., et al., The economic burden of schizophrenia in the United States in 2002. Journal of Clinical Psychiatry, 2005. 66(9): p. 1122-1129.

100. Foster, A., J. Gable, and J. Buckley, Homelessness in schizophrenia. Psychiatric Clinics, 2012. 35(3): p. 717-734.

101. Fasseeh, A., et al., A systematic review of the indirect costs of schizophrenia in Europe. European Journal of Public Health, 2018. 28(6): p. 1043-1049.

102. Jin, H. and I. Mosweu, The societal cost of schizophrenia: a systematic review. Pharmacoeconomics, 2017. 35(1): p. 25-42.

103. Nanko, S. and J. Moridaira, Reproductive rates in schizophrenic outpatients. Acta Psychiatrica Scandinavica, 1993. 87(6): p. 400-404.

104. Hofer, A., et al., Patient outcomes in schizophrenia Il: the impact of cognition. European Psychiatry, 2005. 20(5-6): p. 395-402.

105. Hansson, L., et al., Living situation, subjective quality of life and social network among individuals with schizophrenia living in community settings. Acta Psychiatrica Scandinavica, 2002. 106(5): p. 343-350.

106. Twamley, E.W., et al., Supported employment for middle-aged and older people with schizophrenia. American journal of psychiatric rehabilitation, 2008. 11(1): p. 76-89.

107. McGurk, S.R. and K.T. Mueser, Cognitive functioning, symptoms, and work in supported employment: a review and heuristic model. Schizophrenia research, 2004. 70(2-3): p. 147173.

108. Prouteau, A., et al., Cognitive predictors of psychosocial functioning outcome in schizophrenia: A follow-up study of subjects participating in a rehabilitation program. Schizophrenia Research, 2005. 77(2): p. 343-353.

109. Watzke, S., et al., A Longitudinal Study of Learning Potential and Rehabilitation Outcome in Schizophrenia. Psychiatric Services, 2008. 59(3): p. 248-255.

110. Nuechterlein, K.H., et al., The MATRICS Consensus Cognitive Battery, part 1: test selection, reliability, and validity. Am J Psychiatry, 2008. 165(2): p. 203-13.

111. Carter, C.S., et al., Cognitive Neuroscience Treatment Research to Improve Cognition in Schizophrenia II: Developing Imaging Biomarkers to Enhance Treatment Development for Schizophrenia and Related Disorders. Biological Psychiatry, 2011. 70(1): p. 7-12.

112. Carter, C.S., et al., CNTRICS final task selection: social cognitive and affective neurosciencebased measures. Schizophrenia bulletin, 2009. 35(1): p. 153-162.

113. Carter, C.S., D.M. Barch, and C.E.C. the, Imaging Biomarkers for Treatment Development for Impaired Cognition: Report of the Sixth CNTRICS Meeting: Biomarkers Recommended for Further Development. Schizophrenia Bulletin, 2012. 38(1): p. 26-33.

114. Carter, C.S. and D.M. Barch, Cognitive neuroscience-based approaches to measuring and improving treatment effects on cognition in schizophrenia: the CNTRICS initiative. Schizophr Bull, 2007. 33(5): p. 1131-7. 
115. Barch, D.M., et al., Selecting paradigms from cognitive neuroscience for translation into use in clinical trials: proceedings of the third CNTRICS meeting. Schizophr Bull, 2009. 35(1): p. 10914.

116. Moore, $\mathrm{H}$. , et al., Harnessing cognitive neuroscience to develop new treatments for improving cognition in schizophrenia: CNTRICS selected cognitive paradigms for animal models. Neuroscience \& Biobehavioral Reviews, 2013. 37(9, Part B): p. 2087-2091.

117. Gold, J., Cognitive neuroscience test reliability and clinical applications for schizophrenia. Schizophr Bull, 2012. 38(1): p. 103.

118. Gold, J.M., et al., Clinical, functional, and intertask correlations of measures developed by the Cognitive Neuroscience Test Reliability and Clinical Applications for Schizophrenia Consortium. Schizophr Bull, 2012. 38(1): p. 144-52.

119. Javitt, D.C., When doors of perception close: Bottom-up models of disrupted cognition in schizophrenia. Annual Review of Clinical Psychology, 2009. 5: p. 249-275.

120. Kiss, I., et al., When doors of perception open: Visual contrast sensitivity in never-medicated, first-episode schizophrenia. Journal of Abnormal Psychology, 2010. 119: p. 586-593.

121. Butler, P.D., S.M. Silverstein, and S.C. Dakin, Visual Perception and Its Impairment in Schizophrenia. Biological Psychiatry, 2008. 64: p. 40-47.

122. Deng, Y., et al., Ventral and dorsal visual pathways exhibit abnormalities of static and dynamic connectivities, respectively, in patients with schizophrenia. Schizophrenia Research, 2019. 206: p. 103-110.

123. Plomp, G., et al., Electrophysiological Evidence for Ventral Stream Deficits in Schizophrenia Patients. Schizophrenia Bulletin, 2013. 39: p. 547-554.

124. Sehatpour, P., et al., Impaired Visual Object Processing Across an Occipital-FrontalHippocampal Brain Network in Schizophrenia. Archives of General Psychiatry, 2010. 67: p. 772.

125. Tek, C., et al., Visual Perceptual and Working Memory Impairments in Schizophrenia. Archives of General Psychiatry, 2002. 59(2): p. 146.

126. Butler, P.D., et al., Sensory contributions to impaired emotion processing in schizophrenia. Schizophrenia bulletin, 2009. 35: p. 1095-107.

127. Kim, D.-W., et al., Early visual processing deficits in patients with schizophrenia during spatial frequency-dependent facial affect processing. Schizophrenia Research, 2015. 161: p. 314-321.

128. Bittner, R.A., et al., The When and Where of Working Memory Dysfunction in Early-Onset Schizophrenia-A Functional Magnetic Resonance Imaging Study. Cereb Cortex, 2015. 25(9): p. 2494-506.

129. Haenschel, C., et al., Contribution of impaired early-stage visual processing to working memory dysfunction in adolescents with schizophrenia: a study with event-related potentials and functional magnetic resonance imaging. Arch Gen Psychiatry, 2007. 64(11): p. 1229-40.

130. Kelemen, O., et al., Perceptual and cognitive effects of antipsychotics in first-episode schizophrenia: The potential impact of GABA concentration in the visual cortex. Progress in Neuro-Psychopharmacology and Biological Psychiatry, 2013. 47: p. 13-19.

131. Turetsky, B.I., et al., Facial emotion recognition in schizophrenia: When and why does it go awry? Schizophrenia Research, 2007. 94: p. 253-263.

132. Uhlhaas, P.J. and A.L. Mishara, Perceptual Anomalies in Schizophrenia: Integrating Phenomenology and Cognitive Neuroscience. Schizophrenia Bulletin, 2006. 33: p. 142-156.

133. Javitt, D.C. and R.A. Sweet, Auditory dysfunction in schizophrenia: Integrating clinical and basic features. Nature Reviews Neuroscience, 2015. 16: p. 535-550.

134. Javitt, D.C., et al., Impaired precision, but normal retention, of auditory sensory ("echoic") memory information in schizophrenia. Journal of Abnormal Psychology, 1997. 106: p. 315324. 
135. Li, C.S.R., et al., Altered performance of schizophrenia patients in an auditory detection and discrimination task: Exploring the 'self-monitoring' model of hallucination. Schizophrenia Research, 2002. 55: p. 115-128.

136. Rabinowicz, E.F., et al., Auditory Sensory Dysfunction in Schizophrenia. Archives of General Psychiatry, 2000. 57: p. 1149.

137. Javitt, D.C. and R. Freedman, Sensory processing dysfunction in the personal experience and neuronal machinery of schizophrenia. American Journal of Psychiatry, 2015. 172: p. 17-31.

138. Ford, J.M., et al., Tuning in to the Voices: A Multisite fMRI Study of Auditory Hallucinations. Schizophrenia Bulletin, 2009. 35: p. 58-66.

139. Gaser, C., et al., Neuroanatomy of "hearing voices": a frontotemporal brain structural abnormality associated with auditory hallucinations in schizophrenia. Cerebral cortex (New York, N.Y. : 1991), 2004. 14: p. 91-6.

140. Johns, L.C., et al., Verbal self-monitoring and auditory verbal hallucinations in patients with schizophrenia. Psychological Medicine, 2001. 31: p. 705-715.

141. Kompus, K., R. Westerhausen, and K. Hugdahl, The "paradoxical" engagement of the primary auditory cortex in patients with auditory verbal hallucinations: A meta-analysis of functional neuroimaging studies. Neuropsychologia, 2011. 49: p. 3361-3369.

142. Molendijk, M.L., et al., Neuropsychiatric Genetics A Systematic Review and Meta-Analysis on the Association Between BDNF val 66 met and Hippocampal Volume - A Genuine Effect or a Winners Curse ? american journal of medical genetics, 2012. 169B: p. 731-740.

143. Silverstein, S.M., Y. Wang, and B.P. Keane, Cognitive and Neuroplasticity Mechanisms by Which Congenital or Early Blindness May Confer a Protective Effect Against Schizophrenia. Frontiers in Psychology, 2013. 3: p. 1327-1328.

144. Desimone, R. and J. Duncan, Neural mechanisms of selective visual attention. Annu Rev Neurosci, 1995. 18: p. 193-222.

145. Vossel, S., et al., Cholinergic stimulation enhances Bayesian belief updating in the deployment of spatial attention. Journal of Neuroscience, 2014. 34(47): p. 15735-15742.

146. Nuechterlein, K.H., et al., CNTRICS final task selection: control of attention. Schizophr Bull, 2009. 35(1): p. 182-96.

147. Gold, J.M., et al., Impaired top-down control of visual search in schizophrenia. Schizophr Res, 2007. 94(1-3): p. 148-55.

148. Hahn, B., et al., Failure of schizophrenia patients to overcome salient distractors during working memory encoding. Biol Psychiatry, 2010. 68(7): p. 603-9.

149. Luck, S.J. and J.M. Gold, The construct of attention in schizophrenia. Biol Psychiatry, 2008. 64(1): p. 34-9.

150. Hemsley, D.R., Schizophrenia: A cognitive model and its implications for psychological intervention. Behavior Modification, 1996. 20(2): p. 139-169.

151. Kapur, S., Psychosis as a state of aberrant salience: a framework linking biology, phenomenology, and pharmacology in schizophrenia. Am J Psychiatry, 2003. 160(1): p. 13-23.

152. Howes, O.D. and S. Kapur, The dopamine hypothesis of schizophrenia: version III--the final common pathway. Schizophr Bull, 2009. 35(3): p. 549-62.

153. Erickson, M., et al., Enhanced vulnerability to distraction does not account for working memory capacity reduction in people with schizophrenia. Schizophr Res Cogn, 2014. 1(3): p. 149-154.

154. Luck, S.J., et al., The speed of visual attention in schizophrenia: electrophysiological and behavioral evidence. Schizophr Res, 2006. 85(1-3): p. 174-95.

155. Gold, J.M., et al., Intact attentional control of working memory encoding in schizophrenia. J Abnorm Psychol, 2006. 115(4): p. 658-73.

156. Baddeley, A., Working memory. Science, 1992. 255(5044): p. 556-559.

157. Cowan, N., Working memory underpins cognitive development, learning, and education. Educational psychology review, 2014. 26(2): p. 197-223. 
158. Baddeley, A.D. and G. Hitch, Working memory, in Psychology of learning and motivation. 1974, Elsevier. p. 47-89.

159. Lee, J. and S. Park, Working memory impairments in schizophrenia: a meta-analysis. J Abnorm Psychol, 2005. 114(4): p. 599.

160. Barch, D.M. and E. Smith, The cognitive neuroscience of working memory: relevance to CNTRICS and schizophrenia. Biol Psychiatry, 2008. 64(1): p. 11-7.

161. Anticevic, A., et al., Negative and nonemotional interference with visual working memory in schizophrenia. Biol Psychiatry, 2011. 70(12): p. 1159-1168.

162. Leonard, C.J., et al., Altered spatial profile of distraction in people with schizophrenia. J Abnorm Psychol, 2017. 126(8): p. 1077-1086.

163. Mayer, J.S., et al., Functional Dissociation of Confident and Not-Confident Errors in the Spatial Delayed Response Task Demonstrates Impairments in Working Memory Encoding and Maintenance in Schizophrenia. Frontiers in psychiatry, 2018. 9: p. 202.

164. Fuller, R.L., et al., Impaired visual working memory consolidation in schizophrenia. Neuropsychology, 2009. 23: p. 71-80.

165. Lencz, T., et al., Generalized and specific neurocognitive deficits in prodromal schizophrenia. Biological psychiatry, 2006. 59(9): p. 863-871.

166. Wood, S.J., et al., Spatial working memory ability is a marker of risk-for-psychosis. Psychological medicine, 2003. 33(7): p. 1239-1247.

167. Dias, E.C., et al., Early Sensory Contributions to Contextual Encoding Deficits in Schizophrenia. Archives of General Psychiatry, 2011. 68(7): p. 654-664.

168. Durstewitz, D. and J.K. Seamans, The dual-state theory of prefrontal cortex dopamine function with relevance to catechol-o-methyltransferase genotypes and schizophrenia. Biol Psychiatry, 2008. 64(9): p. 739-49.

169. Rolls, E.T., et al., Computational models of schizophrenia and dopamine modulation in the prefrontal cortex. Nat Rev Neurosci, 2008. 9(9): p. 696-709.

170. Hahn, B., et al., Control of working memory content in schizophrenia. Schizophr Res, 2012. 134(1): p. 70-5.

171. Gold, J.M., et al., Intact attentional control of working memory encoding in schizophrenia. Journal of abnormal psychology, 2006. 115(4): p. 658.

172. Johnson, M.K., et al., The relationship between working memory capacity and broad measures of cognitive ability in healthy adults and people with schizophrenia. Neuropsychology, 2013. 27(2): p. 220-9.

173. Gold, J.M., et al., Refining the empirical constraints on computational models of spatial working memory in schizophrenia. Biological Psychiatry: Cognitive Neuroscience and Neuroimaging, 2020. 5(9): p. 913-922.

174. Gold, J.M., et al., Working Memory Impairment Across Psychotic disorders. Schizophrenia bulletin, 2019. 45(4): p. 804-812.

175. Ranganath, C., M.J. Minzenberg, and J.D. Ragland, The cognitive neuroscience of memory function and dysfunction in schizophrenia. Biological psychiatry, 2008. 64(1): p. 18-25.

176. Ragland, J.D., et al., Prefrontal activation deficits during episodic memory in schizophrenia. American Journal of Psychiatry, 2009. 166(8): p. 863-874.

177. Bonner-Jackson, A., et al., The influence of encoding strategy on episodic memory and cortical activity in schizophrenia. Biological psychiatry, 2005. 58(1): p. 47-55.

178. Guo, J.Y., J.D. Ragland, and C.S. Carter, Memory and cognition in schizophrenia. Mol Psychiatry, 2019. 24(5): p. 633-642.

179. Brebion, G., et al., Mechanisms underlying memory impairment in schizophrenia. Psychological medicine, 1997. 27(2): p. 383-393.

180. Holthausen, E.A., et al., Long-term memory deficits in schizophrenia: primary or secondary dysfunction? Neuropsychology, 2003. 17(4): p. 539. 
181. Danion, J.-M., et al., Functional mechanisms of episodic memory impairment in schizophrenia. The Canadian Journal of Psychiatry, 2007. 52(11): p. 693-701.

182. Tan, E.J., et al., Semantic Memory Impairment Across the Schizophrenia Continuum: A MetaAnalysis of Category Fluency Performance. Schizophrenia Bulletin Open, 2020. 1(1).

183. Ranganath, C., Binding Items and Contexts: The Cognitive Neuroscience of Episodic Memory. Current Directions in Psychological Science, 2010. 19(3): p. 131-137.

184. Ragland, J.D., et al., Neural correlates of relational and item-specific encoding during working and long-term memory in schizophrenia. Neurolmage, 2012. 59(2): p. 1719-1726.

185. Etkin, A., A. Gyurak, and R. O'Hara, A neurobiological approach to the cognitive deficits of psychiatric disorders. Dialogues in clinical neuroscience, 2013. 15(4): p. 419.

186. Orellana, G. and A. Slachevsky, Executive functioning in schizophrenia. Frontiers in psychiatry, 2013. 4: p. 35.

187. Eisenberg, D.P. and K.F. Berman, Executive function, neural circuitry, and genetic mechanisms in schizophrenia. Neuropsychopharmacology, 2010. 35(1): p. 258-277.

188. Miyake, A., et al., The unity and diversity of executive functions and their contributions to complex "frontal lobe" tasks: A latent variable analysis. Cognitive psychology, 2000. 41(1): p. 49-100.

189. Raffard, S. and S. Bayard, Understanding the executive functioning heterogeneity in schizophrenia. Brain and Cognition, 2012. 79(1): p. 60-69.

190. Barch, D.M., et al., CNTRICS final task selection: executive control. Schizophrenia bulletin, 2009. 35(1): p. 115-135.

191. Kerns, J.G., et al., Executive Functioning Component Mechanisms and Schizophrenia. Biological Psychiatry, 2008. 64(1): p. 26-33.

192. Martinez-Aran, A., et al., Executive function in patients with remitted bipolar disorder and schizophrenia and its relationship with functional outcome. Psychotherapy and psychosomatics, 2002. 71(1): p. 39-46.

193. Sharma, T. and L. Antonova, Cognitive function in schizophrenia. Deficits, functional consequences, and future treatment. Psychiatric Clinics of North America, 2003.

194. Johnson-Selfridge, M. and C. Zalewski, Moderator variables of executive functioning in schizophrenia: meta-analytic findings. Schizophrenia bulletin, 2001. 27(2): p. 305-316.

195. Green, M.F., K. Llerena, and R.S. Kern, The "Right Stuff" Revisited: What Have We Learned About the Determinants of Daily Functioning in Schizophrenia? Schizophrenia bulletin, 2015. 41: p. 781-5.

196. Savla, G.N., et al., Deficits in Domains of Social Cognition in Schizophrenia: A Meta-Analysis of the Empirical Evidence. Schizophrenia Bulletin, 2013. 39: p. 979-992.

197. Edwards, J., H.J. Jackson, and P.E. Pattison, Emotion recognition via facial expression and affective prosody in schizophrenia. Clinical Psychology Review, 2002. 22: p. 789-832.

198. Murphy, D. and J. Cutting, Prosodic comprehension and expression in schizophrenia. Journal of Neurology, Neurosurgery \& Psychiatry, 1990. 53: p. 727-730.

199. Turner, J.L.B., Schizophrenics as judges of vocal expressions ofemotional meaning, in The communication of emotional meaning, J.R. Davis, Editor. 1964, McGraw-Hill: New York. p. 129-142.

200. Carter, C.S., et al., CNTRICS final task selection: social cognitive and affective neurosciencebased measures. Schizophrenia bulletin, 2009. 35: p. 153-62.

201. Chen, Y., L.C. Bidwell, and D. Norton, Trait vs. State Markers for Schizophrenia: Identification and Characterization through Visual Processes. Current psychiatry reviews, 2006. 2: p. 431438.

202. Green, M.F., et al., Perception measurement in clinical trials of schizophrenia: promising paradigms from CNTRICS. Schizophrenia bulletin, 2009. 35: p. 163-81.

203. Haxby, Hoffman, and Gobbini, The distributed human neural system for face perception. Trends in cognitive sciences, 2000. 4: p. 223-233. 
204. Johnston, P.J., et al., Functional MRI of facial emotion recognition deficits in schizophrenia and their electrophysiological correlates. European Journal of Neuroscience, 2005. 22: p. 1221-1232.

205. Phillips, W.A. and S.M. Silverstein, Convergence of biological and psychological perspectives on cognitive coordination in schizophrenia. Behavioral and Brain Sciences, 2003. 26: p. 65-82.

206. Schneider, F., et al., Impairment in the Specificity of Emotion Processing in Schizophrenia. American Journal of Psychiatry, 2006. 163: p. 442-447.

207. Sergi, M.J. and M.F. Green, Social perception and early visual processing in schizophrenia. Schizophrenia Research, 2003. 59: p. 233-241.

208. Cook, J., G. Barbalat, and S.-J. Blakemore, Top-down modulation of the perception of other people in schizophrenia and autism. Frontiers in Human Neuroscience, 2012. 6: p. 175.

209. Ciaramidaro, A., et al., Schizophrenia and Autism as Contrasting Minds: Neural Evidence for the Hypo-Hyper-Intentionality Hypothesis. Schizophrenia Bulletin, 2015. 41: p. 171-179.

210. Frith, C.D., Schizophrenia and theory of mind. Psychological Medicine, 2004. 34: p. 385-389.

211. Green, M.F., W.P. Horan, and J. Lee, Social cognition in schizophrenia. Nature Reviews Neuroscience, 2015. 16(10): p. 620-631.

212. Brekke, J., et al., Biosocial pathways to functional outcome in schizophrenia. Schizophrenia Research, 2005. 80: p. 213-225.

213. Couture, S.M., The Functional Significance of Social Cognition in Schizophrenia: A Review. Schizophrenia Bulletin, 2006. 32: p. S44-S63.

214. Fett, A.-K.J., et al., The relationship between neurocognition and social cognition with functional outcomes in schizophrenia: A meta-analysis. Neuroscience \& Biobehavioral Reviews, 2011. 35: p. 573-588.

215. Schmidt, S.J., D.R. Mueller, and V. Roder, Social cognition as a mediator variable between neurocognition and functional outcome in schizophrenia: Empirical review and new results by structural equation modeling. Schizophrenia Bulletin, 2011. 37.

216. Sergi, M.J., et al., Social perception as a mediator of the influence of early visual processing on functional status in schizophrenia. American Journal of Psychiatry, 2006. 163: p. 448-454.

217. Green, M.F., W.P. Horan, and J. Lee, Social cognition in schizophrenia. Nature Reviews Neuroscience, 2015. 16: p. 620-631.

218. Cohen, A.S. and K.S. Minor, Emotional Experience in Patients With Schizophrenia Revisited: Meta-analysis of Laboratory Studies. Schizophrenia Bulletin, 2010. 36: p. 143-150.

219. Kring, A.M. and E.K. Moran, Emotional Response Deficits in Schizophrenia: Insights From Affective Science. Schizophrenia Bulletin, 2008. 34: p. 819-834.

220. Andreasen, N.C. and s.b. Bleulerian. Thought, Language, and Communication Disorders I. Clinical Assessment, Definition of Terms, and Evaluation of Their Reliability The concept of thought disorder was given preeminence in Bleuler's conceptualization of schizophrenia, and prior to the recent neo-Kraepelinian revival, Bleuler's influence. in Arch Gen Psychiatry. 1979.

221. Chaika, E., Understanding psychotic speech: Beyond Freud and Chomsky. 1990.

222. Andreasen, N.C. and W.M. Grove, Thought, Language, and Communication in Schizophrenia: Diagnosis and Prognosis. Schizophrenia Bulletin, 1986. 12(3): p. 348-359.

223. Covington, M.A., et al., Schizophrenia and the structure of language: The linguist's view. Schizophrenia Research, 2005. 77: p. 85-98.

224. Kuperberg, G.R., Language in schizophrenia part 1: an introduction. Language and linguistics compass, 2010. 4(8): p. 576-589.

225. Ditman, T. and G.R. Kuperberg, Building coherence: $A$ framework for exploring the breakdown of links across clause boundaries in schizophrenia. Journal of neurolinguistics, 2010. 23(3): p. 254-269.

226. DeLisi, L.E., Speech disorder in schizophrenia: review of the literature and exploration of its relation to the uniquely human capacity for language. Schizophrenia bulletin, 2001. 27(3): p. 481-496. 
227. Fraser, W.I., et al., The diagnosis of schizophrenia by language analysis. The British Journal of Psychiatry, 1986. 148(3): p. 275-278.

228. Morice, R. and D. McNicol, Language changes in schizophrenia: a limited replication. Schizophrenia Bulletin, 1986. 12(2): p. 239-251.

229. Alpert, M., et al., Vocal acoustic correlates of flat affect in schizophrenia. Similarity to Parkinson's disease and right hemisphere disease and contrast with depression. The British journal of psychiatry. Supplement, 1989: p. 51-6.

230. Rieber, R.W. and H. Vetter, The problem of language and thought in schizophrenia: A review, in Journal of Psycholinguistic Research. 1994, Kluwer Academic Publishers-Plenum Publishers. p. 149-195.

231. Stein, J., Vocal alterations in schizophrenic speech. Journal of Nervous and Mental Disease, 1993. 181: p. 59-62.

232. Rochester, S., Crazy talk: A study of the discourse of schizophrenic speakers. 2013.

233. Sanders, G.S., S.M. Platek, and G.G. Gallup, No blind schizophrenics: Are NMDA-receptor dynamics involved? Behavioral and Brain Sciences, 2003. 26: p. 103-104.

234. Malchow, B., et al., Effects of Three Months of Aerobic Endurance Training on Motor Cortical Excitability in Schizophrenia Patients and Healthy Subjects. Neuropsychobiology, 2020. 79: p. 100-107.

235. Désaméricq, G., et al., Long-term neurocognitive effects of antipsychotics in schizophrenia: a network meta-analysis. Eur J Clin Pharmacol, 2014. 70(2): p. 127-34.

236. Nielsen, R.E., et al., Second-generation antipsychotic effect on cognition in patients with schizophrenia--a meta-analysis of randomized clinical trials. Acta Psychiatr Scand, 2015. 131(3): p. 185-96.

237. Keefe, R.S., et al., Neurocognitive effects of antipsychotic medications in patients with chronic schizophrenia in the CATIE Trial. Arch Gen Psychiatry, 2007. 64(6): p. 633-47.

238. Goldberg, T.E., et al., Cognitive improvement after treatment with second-generation antipsychotic medications in first-episode schizophrenia: is it a practice effect? Arch Gen Psychiatry, 2007. 64(10): p. 1115-22.

239. Heinrichs, R.W., Cognitive improvement in response to antipsychotic drugs: neurocognitive effects of antipsychotic medications in patients with chronic schizophrenia in the CATIE Trial. Arch Gen Psychiatry, 2007. 64(6): p. 631-2.

240. Robbins, T.W., Pharmacological treatment of cognitive deficits in nondementing mental health disorders. Dialogues in clinical neuroscience, 2019. 21(3): p. 301.

241. Keefe, R.S., The longitudinal course of cognitive impairment in schizophrenia: an examination of data from premorbid through posttreatment phases of illness. J Clin Psychiatry, 2014. 75 Suppl 2: p. 8-13.

242. Reilly, J.L., et al., Adverse effects of risperidone on spatial working memory in first-episode schizophrenia. Arch Gen Psychiatry, 2006. 63(11): p. 1189-97.

243. Eum, S., et al., Cognitive burden of anticholinergic medications in psychotic disorders. Schizophr Res, 2017. 190: p. 129-135.

244. MacKenzie, N.E., et al., Antipsychotics, Metabolic Adverse Effects, and Cognitive Function in Schizophrenia. Frontiers in Psychiatry, 2018. 9(622).

245. Helfer, B., et al., Efficacy and Safety of Antidepressants Added to Antipsychotics for Schizophrenia: A Systematic Review and Meta-Analysis. American Journal of Psychiatry, 2016. 173(9): p. 876-886.

246. Vernon, J.A., et al., Antidepressants for cognitive impairment in schizophrenia--a systematic review and meta-analysis. Schizophrenia research, 2014. 159(2-3): p. 385-394.

247. Abi-Dargham, A., et al., Prefrontal dopamine D1 receptors and working memory in schizophrenia. J Neurosci, 2002. 22(9): p. 3708-19.

248. Ibrahim, H.M. and C.A. Tamminga, Schizophrenia: treatment targets beyond monoamine systems. Annu Rev Pharmacol Toxicol, 2011. 51: p. 189-209. 
249. Mäki-Marttunen, V., O.A. Andreassen, and T. Espeseth, The role of norepinephrine in the pathophysiology of schizophrenia. Neuroscience \& Biobehavioral Reviews, 2020. 118: p. 298314.

250. Arnsten, A.F., M. Wang, and C.D. Paspalas, Dopamine's Actions in Primate Prefrontal Cortex: Challenges for Treating Cognitive Disorders. Pharmacol Rev, 2015. 67(3): p. 681-96.

251. Cools, R. and M. D'Esposito, Inverted-U-shaped dopamine actions on human working memory and cognitive control. Biological psychiatry, 2011. 69(12): p. e113-e125.

252. Robbins, T.W. and A.F. Arnsten, The neuropsychopharmacology of fronto-executive function: monoaminergic modulation. Annu Rev Neurosci, 2009. 32: p. 267-87.

253. Tunbridge, E.M., et al., Catechol-o-methyltransferase inhibition improves set-shifting performance and elevates stimulated dopamine release in the rat prefrontal cortex. J Neurosci, 2004. 24(23): p. 5331-5.

254. Mattay, V.S., et al., Catechol O-methyltransferase val158-met genotype and individual variation in the brain response to amphetamine. Proc Natl Acad Sci U S A, 2003. 100(10): p. 6186-91.

255. Meyer-Lindenberg, A., et al., Midbrain dopamine and prefrontal function in humans: interaction and modulation by COMT genotype. Nat Neurosci, 2005. 8(5): p. 594-6.

256. Meyer-Lindenberg, A., et al., Impact of complex genetic variation in COMT on human brain function. Mol Psychiatry, 2006. 11(9): p. 867-77, 797.

257. Samuels, E.R. and E. Szabadi, Functional neuroanatomy of the noradrenergic locus coeruleus: its roles in the regulation of arousal and autonomic function part I: principles of functional organisation. Current neuropharmacology, 2008. 6(3): p. 235-253.

258. Aston-Jones, G. and J.D. Cohen, AN INTEGRATIVE THEORY OF LOCUS COERULEUSNOREPINEPHRINE FUNCTION: Adaptive Gain and Optimal Performance. Annual Review of Neuroscience, 2005. 28(1): p. 403-450.

259. Aston-Jones, G., J. Rajkowski, and J. Cohen, Role of locus coeruleus in attention and behavioral flexibility. Biol Psychiatry, 1999. 46(9): p. 1309-20.

260. Arnsten, A.F., Through the looking glass: differential noradenergic modulation of prefrontal cortical function. Neural Plast, 2000. 7(1-2): p. 133-46.

261. Arnsten, A.F., J.C. Steere, and R.D. Hunt, The contribution of alpha 2-noradrenergic mechanisms of prefrontal cortical cognitive function. Potential significance for attentiondeficit hyperactivity disorder. Arch Gen Psychiatry, 1996. 53(5): p. 448-55.

262. Robbins, T.W. and A.F.T. Arnsten, The neuropsychopharmacology of fronto-executive function: monoaminergic modulation. Annual review of neuroscience, 2009. 32: p. 267-287.

263. Yang, Y., et al., Nicotinic $\alpha 7$ receptors enhance NMDA cognitive circuits in dorsolateral prefrontal cortex. Proceedings of the National Academy of Sciences of the United States of America, 2013. 110(29): p. 12078-12083.

264. Castner, S.A., et al., Immediate and Sustained Improvements in Working Memory After Selective Stimulation of $\alpha 7$ Nicotinic Acetylcholine Receptors. Biological Psychiatry, 2011. 69(1): p. 12-18.

265. Dean, B., A predicted cortical serotonergic/cholinergic/GABAergic interface as a site of pathology in schizophrenia. Clin Exp Pharmacol Physiol, 2001. 28(1-2): p. 74-8.

266. Charnay, Y. and L. Léger, Brain serotonergic circuitries. Dialogues in clinical neuroscience, 2010. 12(4): p. 471-487.

267. Boyer, P., et al., Hippocampal abnormalities and memory deficits: new evidence of a strong pathophysiological link in schizophrenia. Brain Res Rev, 2007. 54(1): p. 92-112.

268. Bacqué-Cazenave, J., et al., Serotonin in Animal Cognition and Behavior. International journal of molecular sciences, 2020. 21(5): p. 1649.

269. Kapur, S. and G. Remington, Serotonin-dopamine interaction and its relevance to schizophrenia. Am J Psychiatry, 1996. 153(4): p. 466-76. 
270. Harvey, J.A., Role of the serotonin 5-HT(2A) receptor in learning. Learning \& memory (Cold Spring Harbor, N.Y.), 2003. 10(5): p. 355-362.

271. Cano-Colino, M., et al., Serotonin Regulates Performance Nonmonotonically in a Spatial Working Memory Network. Cerebral Cortex, 2014. 24(9): p. 2449-2463.

272. Hulsken, S., et al., Food-derived serotonergic modulators: effects on mood and cognition. Nutrition Research Reviews, 2013. 26(2): p. 223-234.

273. Sinkeviciute, I., et al., Efficacy of different types of cognitive enhancers for patients with schizophrenia: a meta-analysis. NPJ schizophrenia, 2018. 4(1): p. 1-14.

274. Sterling, P., Homeostasis vs allostasis: implications for brain function and mental disorders. JAMA Psychiatry, 2014. 71(10): p. 1192-3.

275. Sterling, P., Principles of Allostasis: Optimal Design, Predictive Regulation, Pathophysiology, and Rational Therapeutics, in Allostasis, Homeostasis, and the Costs of Physiological Adaptation, J. Schulkin, Editor. 2004, Cambridge University Press: Cambridge. p. 17-64.

276. Sterling, P., Allostasis: a model of predictive regulation. Physiol Behav, 2012. 106(1): p. 5-15.

277. Luedtke, R.R., et al., Bitropic D3 Dopamine Receptor Selective Compounds as Potential Antipsychotics. Curr Pharm Des, 2015. 21(26): p. 3700-24.

278. Carpenter, W.T., Jr., D.W. Heinrichs, and L.D. Alphs, Treatment of negative symptoms. Schizophr Bull, 1985. 11(3): p. 440-52.

279. Kirkpatrick, B., Developing concepts in negative symptoms: primary vs secondary and apathy vs expression. J Clin Psychiatry, 2014. 75 Suppl 1: p. 3-7.

280. Kirschner, M., A. Aleman, and S. Kaiser, Secondary negative symptoms - A review of mechanisms, assessment and treatment. Schizophrenia Research, 2017. 186: p. 29-38.

281. Keedy, S.K., et al., Impact of antipsychotic treatment on attention and motor learning systems in first-episode schizophrenia. Schizophrenia bulletin, 2015. 41(2): p. 355-365.

282. Ramaekers, J.G., et al., Psychomotor, Cognitive, extrapyramidal, and affective functions of healthy volunteers during treatment with an atypical (amisulpride) and a classic (haloperidol) antipsychotic. J Clin Psychopharmacol, 1999. 19(3): p. 209-21.

283. Reilly, J.L., et al., Antipsychotic drugs exacerbate impairment on a working memory task in first-episode schizophrenia. Biol Psychiatry, 2007. 62(7): p. 818-21.

284. Gao, Z.-G. and K.A. Jacobson, Allosteric modulation and functional selectivity of $G$ proteincoupled receptors. Drug discovery today. Technologies, 2013. 10(2): p. e237-e243.

285. Harris, J.G., et al., Effects of Nicotine on Cognitive Deficits in Schizophrenia. Neuropsychopharmacology, 2004. 29(7): p. 1378-1385.

286. Quick, M.W. and R.A.J. Lester, Desensitization of neuronal nicotinic receptors. Journal of Neurobiology, 2002. 53(4): p. 457-478.

287. Kenakin, T. and L.J. Miller, Seven transmembrane receptors as shapeshifting proteins: the impact of allosteric modulation and functional selectivity on new drug discovery. Pharmacological reviews, 2010. 62(2): p. 265-304.

288. Conn, P.J., A. Christopoulos, and C.W. Lindsley, Allosteric modulators of GPCRs: a novel approach for the treatment of CNS disorders. Nature reviews. Drug discovery, 2009. 8(1): p. 41-54.

289. Nussinov, R. and C.J. Tsai, The different ways through which specificity works in orthosteric and allosteric drugs. Curr Pharm Des, 2012. 18(9): p. 1311-6.

290. Lu, S., S. Li, and J. Zhang, Harnessing allostery: a novel approach to drug discovery. Med Res Rev, 2014. 34(6): p. 1242-85.

291. Burford, N.T., et al., Strategies for the identification of allosteric modulators of G-proteincoupled receptors. Biochemical Pharmacology, 2011. 81(6): p. 691-702.

292. Noetzel, M.J., et al., Functional impact of allosteric agonist activity of selective positive allosteric modulators of metabotropic glutamate receptor subtype 5 in regulating central nervous system function. Mol Pharmacol, 2012. 81(2): p. 120-33. 
293. Roche, D., D. Gil, and J. Giraldo, Mechanistic analysis of the function of agonists and allosteric modulators: reconciling two-state and operational models. British journal of pharmacology, 2013. 169(6): p. 1189-1202.

294. Schwartz, T.W. and B. Holst, Ago-allosteric modulation and other types of allostery in dimeric 7TM receptors. J Recept Signal Transduct Res, 2006. 26(1-2): p. 107-28.

295. Arnsten, A.F., et al., Novel Dopamine Therapeutics for Cognitive Deficits in Schizophrenia. Biol Psychiatry, 2017. 81(1): p. 67-77.

296. Perez, D.M., $\alpha(1)$-Adrenergic Receptors in Neurotransmission, Synaptic Plasticity, and Cognition. Frontiers in pharmacology, 2020. 11: p. 581098-581098.

297. Sheffler, D.J., et al., Allosteric modulation of metabotropic glutamate receptors. Adv Pharmacol, 2011. 62: p. 37-77.

298. Tregellas, J.R. and K.P. Wylie, Alpha7 Nicotinic Receptors as Therapeutic Targets in Schizophrenia. Nicotine Tob Res, 2019. 21(3): p. 349-356.

299. Menniti, F.S., et al., Allosteric modulators for the treatment of schizophrenia: targeting glutamatergic networks. Current topics in medicinal chemistry, 2013. 13(1): p. 26-54.

300. Javitt, D.C., Glutamate and schizophrenia: phencyclidine, N-methyl-D-aspartate receptors, and dopamine-glutamate interactions. Int Rev Neurobiol, 2007. 78: p. 69-108.

301. Javitt, D.C., Glutamatergic theories of schizophrenia. Isr J Psychiatry Relat Sci, 2010. 47(1): p. 4-16.

302. Krystal, J.H., et al., NMDA receptor antagonist effects, cortical glutamatergic function, and schizophrenia: toward a paradigm shift in medication development. Psychopharmacology (Berl), 2003. 169(3-4): p. 215-33.

303. Moghaddam, B., et al., Activation of glutamatergic neurotransmission by ketamine: a novel step in the pathway from NMDA receptor blockade to dopaminergic and cognitive disruptions associated with the prefrontal cortex. J Neurosci, 1997. 17(8): p. 2921-7.

304. Murray, J.D., et al., Linking Microcircuit Dysfunction to Cognitive Impairment: Effects of Disinhibition Associated with Schizophrenia in a Cortical Working Memory Model. Cerebral Cortex, 2014. 24(4): p. 859-872.

305. Dauvermann, M.R., G. Lee, and N. Dawson, Glutamatergic regulation of cognition and functional brain connectivity: insights from pharmacological, genetic and translational schizophrenia research. British journal of pharmacology, 2017. 174(19): p. 3136-3160.

306. Lee, G. and Y. Zhou, NMDAR Hypofunction Animal Models of Schizophrenia. Frontiers in Molecular Neuroscience, 2019. 12(185).

307. Adell, A., Brain NMDA Receptors in Schizophrenia and Depression. Biomolecules, 2020. 10: p. 947.

308. Harms, M.P., et al., Structural abnormalities in gyri of the prefrontal cortex in individuals with schizophrenia and their unaffected siblings. British Journal of Psychiatry, 2010. 196: p. 150157.

309. McCullumsmith, R.E., et al., Recent advances in targeting the ionotropic glutamate receptors in treating schizophrenia. Curr Pharm Biotechnol, 2012. 13(8): p. 1535-42.

310. Meador-Woodruff, J.H. and D.J. Healy, Glutamate receptor expression in schizophrenic brain. Brain Res Brain Res Rev, 2000. 31(2-3): p. 288-94.

311. Dawson, N., B.J. Morris, and J.A. Pratt, Subanaesthetic ketamine treatment alters prefrontal cortex connectivity with thalamus and ascending subcortical systems. Schizophrenia bulletin, 2013. 39(2): p. 366-377.

312. Barnes, S.A., et al., Dopamine D1 receptor activation improves PCP-induced performance disruption in the 5C-CPT by reducing inappropriate responding. Behav Brain Res, 2016. 300: $p$. 45-55.

313. Seillier, A. and A. Giuffrida, Evaluation of NMDA receptor models of schizophrenia: divergences in the behavioral effects of sub-chronic PCP and MK-801. Behav Brain Res, 2009. 204(2): p. 410-5. 
314. Didriksen, M., T. Skarsfeldt, and J. Arnt, Reversal of PCP-induced learning and memory deficits in the Morris' water maze by sertindole and other antipsychotics. Psychopharmacology (Berl), 2007. 193(2): p. 225-33.

315. Zhu, S. and P. Paoletti, Allosteric modulators of NMDA receptors: multiple sites and mechanisms. Current Opinion in Pharmacology, 2015. 20: p. 14-23.

316. Weed, M.R., et al., Negative Allosteric Modulators Selective for The NR2B Subtype of The NMDA Receptor Impair Cognition in Multiple Domains. Neuropsychopharmacology, 2016. 41(2): p. 568-77.

317. Kondej, M., P. Stępnicki, and A.A. Kaczor, Multi-Target Approach for Drug Discovery against Schizophrenia. International journal of molecular sciences, 2018. 19(10): p. 3105.

318. Yao, L. and Q. Zhou, Enhancing NMDA Receptor Function: Recent Progress on Allosteric Modulators. Neural Plasticity, 2017. 2017: p. 2875904.

319. Traynelis, S.F., et al., Glutamate receptor ion channels: structure, regulation, and function. Pharmacological reviews, 2010. 62(3): p. 405-496.

320. Hirai, H., et al., The glycine binding site of the N-methyl-D-aspartate receptor subunit NR1: identification of novel determinants of co-agonist potentiation in the extracellular M3-M4 loop region. Proceedings of the National Academy of Sciences of the United States of America, 1996. 93(12): p. 6031-6036.

321. Kleckner, N.W. and R. Dingledine, Requirement for glycine in activation of NMDA-receptors expressed in Xenopus oocytes. Science, 1988. 241(4867): p. 835.

322. Laube, B., J. Kuhse, and H. Betz, Evidence for a tetrameric structure of recombinant NMDA receptors. J Neurosci, 1998. 18(8): p. 2954-61.

323. Coyle, J.T. and G. Tsai, The NMDA receptor glycine modulatory site: a therapeutic target for improving cognition and reducing negative symptoms in schizophrenia. Psychopharmacology (Berl), 2004. 174(1): p. 32-8.

324. Ghanizadeh, A., Targeting of glycine site on NMDA receptor as a possible new strategy for autism treatment. Neurochem Res, 2011. 36(5): p. 922-3.

325. Neame, S., et al., The NMDA receptor activation by \& It;span class=\&quot;sc\&quot;\&gt; \& It;/span\&gt;-serine and glycine is controlled by an astrocytic Phgdh-dependent serine shuttle. Proceedings of the National Academy of Sciences, 2019. 116(41): p. 20736.

326. Balu, D.T. and J.T. Coyle, The NMDA receptor 'glycine modulatory site' in schizophrenia: Dserine, glycine, and beyond. Curr Opin Pharmacol, 2015. 20: p. 109-15.

327. Javitt, D.C., Is the glycine site half saturated or half unsaturated? Effects of glutamatergic drugs in schizophrenia patients. Curr Opin Psychiatry, 2006. 19(2): p. 151-7.

328. Yang, C.R. and K.A. Svensson, Allosteric modulation of NMDA receptor via elevation of brain glycine and D-serine: the therapeutic potentials for schizophrenia. Pharmacol Ther, 2008. 120(3): p. 317-32.

329. Tsai, G.E. and P.Y. Lin, Strategies to enhance N-methyl-D-aspartate receptor-mediated neurotransmission in schizophrenia, a critical review and meta-analysis. Curr Pharm Des, 2010. 16(5): p. 522-37.

330. Goff, D.C., et al., Dose-finding trial of D-cycloserine added to neuroleptics for negative symptoms in schizophrenia. Am J Psychiatry, 1995. 152(8): p. 1213-5.

331. Quartermain, D., et al., Acute but not chronic activation of the NMDA-coupled glycine receptor with D-cycloserine facilitates learning and retention. Eur J Pharmacol, 1994. 257(12): p. 7-12.

332. Chang, C.H., et al., Efficacy and cognitive effect of sarcosine ( $N$-methylglycine) in patients with schizophrenia: A systematic review and meta-analysis of double-blind randomised controlled trials. J Psychopharmacol, 2020. 34(5): p. 495-505.

333. Kantrowitz, J.T., et al., Neurophysiological Effects of Bitopertin in Schizophrenia. J Clin Psychopharmacol, 2017. 37(4): p. 447-451. 
334. Lane, H.-Y., et al., Add-on Treatment of Benzoate for Schizophrenia: A Randomized, Doubleblind, Placebo-Controlled Trial of d-Amino Acid Oxidase Inhibitor. JAMA Psychiatry, 2013. 70(12): p. 1267-1275.

335. Lin, C.-H., et al., Sodium Benzoate, a D-Amino Acid Oxidase Inhibitor, Added to Clozapine for the Treatment of Schizophrenia: A Randomized, Double-Blind, Placebo-Controlled Trial. Biological Psychiatry, 2018. 84(6): p. 422-432.

336. Kozak, R., et al., Reduction of brain kynurenic acid improves cognitive function. J Neurosci, 2014. 34(32): p. 10592-602.

337. Szalárdy, L., et al., Manipulating Kynurenic Acid Levels in the Brain - On the Edge Between Neuroprotection and Cognitive Dysfunction. Current topics in medicinal chemistry, 2012. 12.

338. Muneer, A., Kynurenine Pathway of Tryptophan Metabolism in Neuropsychiatric Disorders: Pathophysiologic and Therapeutic Considerations. Clin Psychopharmacol Neurosci, 2020. 18(4): p. 507-526.

339. Fleischhacker, W.W., et al., Efficacy and safety of the novel glycine transporter inhibitor $B I$ 425809 once daily in patients with schizophrenia: a double-blind, randomised, placebocontrolled phase 2 study. Lancet Psychiatry, 2021. 8(3): p. 191-201.

340. Susana S. Correia, R.R.I., Peter Germano, Kim Tang, Sylvie G. Bernier, Chad D. Schwartzkopf, Jenny Tobin, Thomas W. Lee, Guang Liu, Sarah Jacobson, Andrew Carvalho, Glen R. Rennie, Joon Jung, Paul A. Renhowe, Elisabeth Lonie, Christopher J. Winrow, John R. Hadcock, Juli E. Jones and Mark G. Curri, The CNS-penetrant soluble guanylate cyclase stimulator CY6463 reveals its potential as a therapy in neurodegenerative diseases. Frontiers in Pharmacology, 2021.

341. Marenco, S. and D.R. Weinberger, Therapeutic potential of positive AMPA receptor modulators in the treatment of neuropsychiatric disorders. CNS Drugs, 2006. 20(3): p. 173-85.

342. Egan, M.F., et al., The BDNF val66met polymorphism affects activity-dependent secretion of BDNF and human memory and hippocampal function. Cell, 2003. 112(2): p. 257-69.

343. Lynch, G., Memory enhancement: the search for mechanism-based drugs. Nat Neurosci, 2002. 5 Suppl: p. 1035-8.

344. Staubli, U., G. Rogers, and G. Lynch, Facilitation of glutamate receptors enhances memory. Proceedings of the National Academy of Sciences of the United States of America, 1994. 91(2): p. 777-781.

345. Goff, D.C., et al., A placebo-controlled pilot study of the ampakine CX516 added to clozapine in schizophrenia. J Clin Psychopharmacol, 2001. 21(5): p. 484-7.

346. Marenco, S., et al., Preliminary experience with an ampakine (CX516) as a single agent for the treatment of schizophrenia: a case series. Schizophr Res, 2002. 57(2-3): p. 221-6.

347. Garthwaite, G. and J. Garthwaite, Mechanisms of AMPA Neurotoxicity in Rat Brain Slices. Eur J Neurosci, 1991. 3(8): p. 729-736.

348. Shaffer, C.L., et al., Positive allosteric modulation of AMPA receptors from efficacy to toxicity: the interspecies exposure-response continuum of the novel potentiator PF-4778574. J Pharmacol Exp Ther, 2013. 347(1): p. 212-24.

349. Yamada, K.A., Modulating Excitatory Synaptic Neurotransmission: Potential Treatment for Neurological Disease? Neurobiology of Disease, 1998. 5(2): p. 67-80.

350. Larsen, A.P., et al., Identification and Structure-Function Study of Positive Allosteric Modulators of Kainate Receptors. Molecular Pharmacology, 2017. 91(6): p. 576.

351. Iwata, Y., et al., Effects of glutamate positive modulators on cognitive deficits in schizophrenia: a systematic review and meta-analysis of double-blind randomized controlled trials. Molecular Psychiatry, 2015. 20(10): p. 1151-1160.

352. Ferraguti, F., et al., Metabotropic glutamate receptor 8-expressing nerve terminals target subsets of GABAergic neurons in the hippocampus. J Neurosci, 2005. 25(45): p. 10520-36.

353. Foster, D.J. and P.J. Conn, Allosteric Modulation of GPCRs: New Insights and Potential Utility for Treatment of Schizophrenia and Other CNS Disorders. Neuron, 2017. 94(3): p. 431-446. 
354. Anwyl, R., Metabotropic glutamate receptors: electrophysiological properties and role in plasticity. Brain Res Brain Res Rev, 1999. 29(1): p. 83-120.

355. Bellone, C., C. Lüscher, and M. Mameli, Mechanisms of synaptic depression triggered by metabotropic glutamate receptors. Cell Mol Life Sci, 2008. 65(18): p. 2913-23.

356. Corti, C., et al., The Use of Knock-Out Mice Unravels Distinct Roles for mGlu2 and mGlu3 Metabotropic Glutamate Receptors in Mechanisms of Neurodegeneration/Neuroprotection. The Journal of Neuroscience, 2007. 27(31): p. 8297-8308.

357. Kinon, B.J., et al., Exploratory analysis for a targeted patient population responsive to the metabotropic glutamate 2/3 receptor agonist pomaglumetad methionil in schizophrenia. Biol Psychiatry, 2015. 78(11): p. 754-62.

358. Mannaioni, G., et al., Metabotropic glutamate receptors 1 and 5 differentially regulate CA1 pyramidal cell function. J Neurosci, 2001. 21(16): p. 5925-34.

359. Rook, J.M., et al., Unique signaling profiles of positive allosteric modulators of metabotropic glutamate receptor subtype 5 determine differences in in vivo activity. Biol Psychiatry, 2013. 73(6): p. 501-9.

360. Bruno, V., et al., Neuroprotection by glial metabotropic glutamate receptors is mediated by transforming growth factor-beta. J Neurosci, 1998. 18(23): p. 9594-600.

361. Woltering, T., et al., Chem Inform Abstract: Synthesis and Characterization of 1,3-Dihydrobenzo[b][1,4]diazepin-2-one Derivatives. Part 4. In vivo Active Potent and Selective Noncompetitive Metabotropic Glutamate Receptor 2/3 Antagonists. Bioorganic \& medicinal chemistry letters, 2010. 20: p. 6969-74.

362. Campbell, U.C., et al., The mGluR5 antagonist 2-methyl-6-(phenylethynyl)-pyridine (MPEP) potentiates PCP-induced cognitive deficits in rats. Psychopharmacology (Berl), 2004. 175(3): p. 310-8.

363. Benes, F.M. and S. Berretta, GABAergic Interneurons: Implications for Understanding Schizophrenia and Bipolar Disorder. Neuropsychopharmacology, 2001. 25(1): p. 1-27.

364. Tang, X., R. Jaenisch, and M. Sur, The role of GABAergic signalling in neurodevelopmental disorders. Nature Reviews Neuroscience, 2021. 22(5): p. 290-307.

365. Kann, O., I.E. Papageorgiou, and A. Draguhn, Highly energized inhibitory interneurons are a central element for information processing in cortical networks. J Cereb Blood Flow Metab, 2014. 34(8): p. 1270-82.

366. Uhlhaas, P.J., High-frequency oscillations in schizophrenia. Clin EEG Neurosci, 2011. 42(2): p. 77-82.

367. Orhan, F., et al., CSF GABA is reduced in first-episode psychosis and associates to symptom severity. Molecular Psychiatry, 2018. 23(5): p. 1244-1250.

368. Rudolph, U. and F. Knoflach, Beyond classical benzodiazepines: novel therapeutic potential of GABAA receptor subtypes. Nature reviews. Drug discovery, 2011. 10(9): p. 685-697.

369. Arolfo, M.P. and J.D. Brioni, Diazepam impairs place learning in the Morris water maze. Behav Neural Biol, 1991. 55(1): p. 131-6.

370. Buffett-Jerrott, S.E. and S.H. Stewart, Cognitive and sedative effects of benzodiazepine use. Curr Pharm Des, 2002. 8(1): p. 45-58.

371. Serrats, J., M.O. Cunningham, and C.H. Davies, GABAB receptor modulation-to $B$ or not to be $B$ a pro-cognitive medicine? Current Opinion in Pharmacology, 2017. 35: p. 125-132.

372. Buchanan, R.W., et al., A randomized clinical trial of $M K-0777$ for the treatment of cognitive impairments in people with schizophrenia. Biol Psychiatry, 2011. 69(5): p. 442-9.

373. Knust, H., et al., The discovery and unique pharmacological profile of RO4938581 and RO4882224 as potent and selective GABAA alpha5 inverse agonists for the treatment of cognitive dysfunction. Bioorg Med Chem Lett, 2009. 19(20): p. 5940-4.

374. Lewis, D.A., et al., Subunit-selective modulation of GABA type A receptor neurotransmission and cognition in schizophrenia. Am J Psychiatry, 2008. 165(12): p. 1585-93. 
375. Xu, M.-Y. and A.H.C. Wong, GABAergic inhibitory neurons as therapeutic targets for cognitive impairment in schizophrenia. Acta pharmacologica Sinica, 2018. 39(5): p. 733-753.

376. Fan, H.R., et al., Quercetin Reduces Cortical GABAergic Transmission and Alleviates MK-801Induced Hyperactivity. EBioMedicine, 2018. 34: p. 201-213.

377. Page, C.E. and L. Coutellier, Reducing inhibition: A promising new strategy for the treatment of schizophrenia. EBioMedicine, 2018. 35: p. 25-26.

378. Gaiarsa, J.L. and C. Porcher, Emerging neurotrophic role of GABAB receptors in neuronal circuit development. Front Cell Neurosci, 2013. 7: p. 206.

379. Lei, S. and C.J. McBain, GABA B receptor modulation of excitatory and inhibitory synaptic transmission onto rat CA3 hippocampal interneurons. The Journal of physiology, 2003. 546(Pt 2): p. 439-453.

380. Olpe, H.-R., et al., The actions of orally active GABAB receptor antagonists on GABAergic transmission in vivo and in vitro. European Journal of Pharmacology, 1993. 233(2): p. 179186.

381. Kantrowitz, J., L. Citrome, and D. Javitt, $G A B A(B)$ receptors, schizophrenia and sleep dysfunction: a review of the relationship and its potential clinical and therapeutic implications. CNS drugs, 2009. 23(8): p. 681-691.

382. Wang, Y., et al., GABAB receptor-dependent modulation of network activity in the rat prefrontal cortex in vitro. Eur J Neurosci, 2010. 31(9): p. 1582-94.

383. Bañuelos, C., et al., Prefrontal Cortical GABAergic Dysfunction Contributes to Age-Related Working Memory Impairment. The Journal of Neuroscience, 2014. 34(10): p. 3457.

384. Erickson, E.J., K.D. Watts, and M.B. Parent, Septal co-infusions of glucose with a GABAB agonist impair memory. Neurobiology of Learning and Memory, 2006. 85(1): p. 66-70.

385. Chen, L.-H., et al., Discovery of a Negative Allosteric Modulator of GABAB Receptors. ACS medicinal chemistry letters, 2014. 5(7): p. 742-747.

386. Pin, J.-P. and L. Prézeau, Allosteric modulators of $G A B A(B)$ receptors: mechanism of action and therapeutic perspective. Current neuropharmacology, 2007. 5(3): p. 195-201.

387. Sun, B., et al., A negative allosteric modulator modulates $G A B A B$-receptor signalling through GB2 subunits. Biochem J, 2016. 473(6): p. 779-87.

388. Fouriezos, G., P. Hansson, and R.A. Wise, Neuroleptic-induced attenuation of brain stimulation reward in rats. J Comp Physiol Psychol, 1978. 92(4): p. 661-71.

389. Howes, O.D., et al., The Role of Genes, Stress, and Dopamine in the Development of Schizophrenia. Biol Psychiatry, 2017. 81(1): p. 9-20.

390. Castner, S.A. and P.S. Goldman-Rakic, Enhancement of Working Memory in Aged Monkeys by a Sensitizing Regimen of Dopamine D\&/t;sub\&gt;1\&/t;/sub\&gt; Receptor Stimulation. The Journal of Neuroscience, 2004. 24(6): p. 1446.

391. Sibley, D.R. and F.J. Monsma, Molecular biology of dopamine receptors. Trends in Pharmacological Sciences, 1992. 13: p. 61-69.

392. Svensson, K.A., J. Hao, and R.F. Bruns, Chapter Nine - Positive allosteric modulators of the dopamine D1 receptor: A new mechanism for the treatment of neuropsychiatric disorders, in Advances in Pharmacology, J.M. Witkin, Editor. 2019, Academic Press. p. 273-305.

393. Desai, A., et al., Phase 1 randomized study on the safety, tolerability, and pharmacodynamic cognitive and electrophysiological effects of a dopamine $D 1$ receptor positive allosteric modulator in patients with schizophrenia. Neuropsychopharmacology, 2020.

394. Shekhar, A., et al., Selective muscarinic receptor agonist xanomeline as a novel treatment approach for schizophrenia. Am J Psychiatry, 2008. 165(8): p. 1033-9.

395. Yohn, S. and P. Conn, Positive allosteric modulation of M 1 and M 4 muscarinic receptors as potential therapeutic treatments for schizophrenia. Neuropharmacology, 2017. 136.

396. Brannan, S.K., et al., Muscarinic Cholinergic Receptor Agonist and Peripheral Antagonist for Schizophrenia. N Engl J Med, 2021. 384(8): p. 717-726. 
397. Conn, P.J., C.K. Jones, and C.W. Lindsley, Subtype-selective allosteric modulators of muscarinic receptors for the treatment of CNS disorders. Trends Pharmacol Sci, 2009. 30(3): p. 148-55.

398. Melancon, B.J., et al., Allosteric modulation of seven transmembrane spanning receptors: theory, practice, and opportunities for central nervous system drug discovery. J Med Chem, 2012. 55(4): p. 1445-64.

399. Nickols, H.H. and P.J. Conn, Development of allosteric modulators of GPCRs for treatment of CNS disorders. Neurobiol Dis, 2014. 61: p. 55-71.

400. Marino, M.J., et al., Activation of the genetically defined $m 1$ muscarinic receptor potentiates $N$-methyl-D-aspartate (NMDA) receptor currents in hippocampal pyramidal cells. Proceedings of the National Academy of Sciences of the United States of America, 1998. 95(19): p. 1146511470.

401. Bymaster, F.P., et al., Unexpected antipsychotic-like activity with the muscarinic receptor ligand (5R,6R)6-(3-propylthio-1,2,5-thiadiazol-4-yl)-1-azabicyclo[3.2.1]octane. Eur J Pharmacol, 1998. 356(2-3): p. 109-19.

402. Carruthers, S.P., C.T. Gurvich, and S.L. Rossell, The muscarinic system, cognition and schizophrenia. Neurosci Biobehav Rev, 2015. 55: p. 393-402.

403. Kalman, D., S.B. Morissette, and T.P. George, Co-morbidity of smoking in patients with psychiatric and substance use disorders. The American journal on addictions, 2005. 14(2): p. 106-123.

404. Kumari, V. and P. Postma, Nicotine use in schizophrenia: the self medication hypotheses. Neurosci Biobehav Rev, 2005. 29(6): p. 1021-34.

405. Stefansson, H., et al., Large recurrent microdeletions associated with schizophrenia. Nature, 2008. 455(7210): p. 232-236.

406. Hauser, T.A., et al., TC-5619: an alpha7 neuronal nicotinic receptor-selective agonist that demonstrates efficacy in animal models of the positive and negative symptoms and cognitive dysfunction of schizophrenia. Biochem Pharmacol, 2009. 78(7): p. 803-12.

407. Lieberman, J.A., et al., A randomized exploratory trial of an $\alpha-7$ nicotinic receptor agonist (TC5619) for cognitive enhancement in schizophrenia. Neuropsychopharmacology, 2013. 38(6): p. 968-75.

408. Walling, D., et al., Phase 2 Trial of an Alpha-7 Nicotinic Receptor Agonist (TC-5619) in Negative and Cognitive Symptoms of Schizophrenia. Schizophr Bull, 2016. 42(2): p. 335-43.

409. Hahn, B., et al., Evidence for positive allosteric modulation of cognitive-enhancing effects of nicotine in healthy human subjects. Psychopharmacology, 2020. 237(1): p. 219-230.

410. Deutsch, S.I., et al., Targeting alpha-7 nicotinic neurotransmission in schizophrenia: a novel agonist strategy. Schizophrenia research, 2013. 148(1-3): p. 138-144.

411. Altman, H.J. and H.J. Normile, Different temporal effects of serotonergic antagonists on passive avoidance retention. Pharmacol Biochem Behav, 1987. 28(3): p. 353-9.

412. Buhot, M.-C., S. Martin, and L. Segu, Role of serotonin in memory impairment. Annals of Medicine, 2000. 32(3): p. 210-221.

413. Meneses, A., 5-HT systems: emergent targets for memory formation and memory alterations. Rev Neurosci, 2013. 24(6): p. 629-64.

414. Upton, N., et al., 5-HT6 receptor antagonists as novel cognitive enhancing agents for Alzheimer's disease. Neurotherapeutics, 2008. 5(3): p. 458-69.

415. Terry, A.V., J.J. Buccafusco, and C. Wilson, Cognitive dysfunction in neuropsychiatric disorders: Selected serotonin receptor subtypes as therapeutic targets. Behavioural Brain Research, 2008. 195(1): p. 30-38.

416. Fasciani, I., et al., Allosteric Modulators of G Protein-Coupled Dopamine and Serotonin Receptors: A New Class of Atypical Antipsychotics. Pharmaceuticals (Basel, Switzerland), 2020. 13(11): p. 388. 
417. Erslev, A.J., In vitro production of erythropoietin by kidneys perfused with a serum-free solution. Blood, 1974. 44(1): p. 77-85.

418. Ponce, L.L., et al., Erythropoietin neuroprotection with traumatic brain injury. Pathophysiology : the official journal of the International Society for Pathophysiology, 2013. 20(1): p. 31-38.

419. Tan, C.C., et al., Feedback modulation of renal and hepatic erythropoietin mRNA in response to graded anemia and hypoxia. Am J Physiol, 1992. 263(3 Pt 2): p. F474-81.

420. Kawakami, M., et al., Erythropoietin receptor-mediated inhibition of exocytotic glutamate release confers neuroprotection during chemical ischemia. J Biol Chem, 2001. 276(42): p. 39469-75.

421. Koshimura, K., et al., Effects of Erythropoietin on Neuronal Activity. Journal of Neurochemistry, 1999. 72(6): p. 2565-2572.

422. Maiese, K., F. Li, and Z.Z. Chong, Erythropoietin in the brain: can the promise to protect be fulfilled? Trends Pharmacol Sci, 2004. 25(11): p. 577-83.

423. Brines, M. and A. Cerami, Emerging biological roles for erythropoietin in the nervous system. Nat Rev Neurosci, 2005. 6(6): p. 484-94.

424. Ehrenreich, H., et al., Erythropoietin: a candidate compound for neuroprotection in schizophrenia. Mol Psychiatry, 2004. 9(1): p. 42-54.

425. Reif, A., et al., Neurogenesis and schizophrenia: dividing neurons in a divided mind? Eur Arch Psychiatry Clin Neurosci, 2007. 257(5): p. 290-9.

426. Schiffman, J., et al., Minor physical anomalies and schizophrenia spectrum disorders: a prospective investigation. Am J Psychiatry, 2002. 159(2): p. 238-43.

427. Lacombe, C. and P. Mayeux, The molecular biology of erythropoietin. Nephrol Dial Transplant, 1999. 14 Suppl 2: p. 22-8.

428. Witthuhn, B.A., et al., JAK2 associates with the erythropoietin receptor and is tyrosine phosphorylated and activated following stimulation with erythropoietin. Cell, 1993. 74(2): p. 227-236.

429. Li, W., et al., Beneficial effect of erythropoietin on experimental allergic encephalomyelitis. Ann Neurol, 2004. 56(6): p. 767-77.

430. Martínez-Estrada, O.M., et al., Erythropoietin protects the in vitro blood-brain barrier against VEGF-induced permeability. Eur J Neurosci, 2003. 18(9): p. 2538-44.

431. Agnello, D., et al., Erythropoietin exerts an anti-inflammatory effect on the CNS in a model of experimental autoimmune encephalomyelitis. Brain Res, 2002. 952(1): p. 128-34.

432. Villa, P., et al., Erythropoietin selectively attenuates cytokine production and inflammation in cerebral ischemia by targeting neuronal apoptosis. J Exp Med, 2003. 198(6): p. 971-5.

433. Ehrenreich, H., et al., Exploring recombinant human erythropoietin in chronic progressive multiple sclerosis. Brain, 2007. 130(Pt 10): p. 2577-88.

434. Ehrenreich, H., et al., Improvement of cognitive functions in chronic schizophrenic patients by recombinant human erythropoietin. Mol Psychiatry, 2007. 12(2): p. 206-20.

435. Miskowiak, K., et al., Differential effects of erythropoietin on neural and cognitive measures of executive function 3 and 7 days post-administration. Exp Brain Res, 2008. 184(3): p. 31321.

436. Miskowiak, K., U. O'Sullivan, and C.J. Harmer, Erythropoietin enhances hippocampal response during memory retrieval in humans. J Neurosci, 2007. 27(11): p. 2788-92.

437. Miskowiak, K.W., et al., Recombinant human erythropoietin to target cognitive dysfunction in bipolar disorder: a double-blind, randomized, placebo-controlled phase 2 trial. J Clin Psychiatry, 2014. 75(12): p. 1347-55.

438. Wüstenberg, T., et al., Recombinant human erythropoietin delays loss of gray matter in chronic schizophrenia. Mol Psychiatry, 2011. 16(1): p. 26-36, 1.

439. Pedroso, I., et al., Protective Activity of Erythropoyetine in the Cognition of Patients with Parkinson's Disease. Behavioral sciences (Basel, Switzerland), 2018. 8(5): p. 51-51. 
440. Li, X.B., et al., Erythropoietin for Cognitive Deficits Associated with Schizophrenia, Bipolar Disorder, and Major Depression: A Systematic Review. Pharmacopsychiatry, 2018. 51(3): p. 100-104.

441. Viviani, B., et al., Erythropoietin protects primary hippocampal neurons increasing the expression of brain-derived neurotrophic factor. J Neurochem, 2005. 93(2): p. 412-21.

442. Adamcio, B., et al., Erythropoietin enhances hippocampal long-term potentiation and memory. 2008. 6.

443. Pajonk, F., et al., The erythropoietin-receptor pathway modulates survival of cancer cells. Oncogene, 2004. 23(55): p. 8987-8991.

444. Debeljak, N., P. Solár, and A.J. Sytkowski, Erythropoietin and cancer: the unintended consequences of anemia correction. Frontiers in immunology, 2014. 5: p. 563-563.

445. Leyland-Jones, B., Breast cancer trial with erythropoietin terminated unexpectedly. The Lancet Oncology, 2003. 4(8): p. 459-460.

446. Leyland-Jones, B., et al., Maintaining normal hemoglobin levels with epoetin alfa in mainly nonanemic patients with metastatic breast cancer receiving first-line chemotherapy: a survival study. J Clin Oncol, 2005. 23(25): p. 5960-72.

447. Henke, M., et al., Erythropoietin to treat head and neck cancer patients with anaemia undergoing radiotherapy: randomised, double-blind, placebo-controlled trial. Lancet, 2003. 362(9392): p. 1255-60.

448. Stohlawetz, P.J., et al., Effects of erythropoietin on platelet reactivity and thrombopoiesis in humans. Blood, 2000. 95(9): p. 2983-2989.

449. Agarwal, R., Mechanisms and mediators of hypertension induced by erythropoietin and related molecules. Nephrol Dial Transplant, 2018. 33(10): p. 1690-1698.

450. Ehrenreich, H., et al., Exploring recombinant human erythropoietin in chronic progressive multiple sclerosis. Brain, 2007. 130(10): p. 2577-2588.

451. Ding, J., et al., Carbamylated erythropoietin ameliorates hypoxia-induced cognitive and behavioral defects with the generation of choline acetyltransferase-positive neurons. Journal of Neuroscience Research, 2013. 91(1): p. 73-82.

452. Leist, M., et al., Derivatives of erythropoietin that are tissue protective but not erythropoietic. Science, 2004. 305(5681): p. 239-42.

453. Masuda, S., et al., Functional erythropoietin receptor of the cells with neural characteristics. Comparison with receptor properties of erythroid cells. Journal of Biological Chemistry, 1993. 268(15): p. 11208-11216.

454. Kellner, C.H., D.A. Adams, and A. Benferhat, Further improving the cognitive effect profile of electroconvulsive therapy (ECT): The case for studying carbamylated erythropoietin. Medical Hypotheses, 2015. 84(3): p. 258-261.

455. Girgenti, M.J., et al., Erythropoietin induction by electroconvulsive seizure, gene regulation, and antidepressant-like behavioral effects. Biol Psychiatry, 2009. 66(3): p. 267-74.

456. Ali, S.A., et al., Electroconvulsive Therapy and Schizophrenia: A Systematic Review. Complex Psychiatry, 2019. 5(2): p. 75-83.

457. Kaster, T.S., Z.J. Daskalakis, and D.M. Blumberger, Clinical Effectiveness and Cognitive Impact of Electroconvulsive Therapy for Schizophrenia: A Large Retrospective Study. J Clin Psychiatry, 2017. 78(4): p. e383-e389.

458. Danenberg, R., et al., A Pilot Study of Cognitive Impairment in Longstanding Electroconvulsive Therapy-treated Schizophrenia Patients Versus Controls. The Journal of ECT, 2021. 37(1).

459. Kjær, K., et al., The effect of erythropoietin on electroconvulsive stimulation induced cognitive impairment in rats. Behav Brain Res, 2020. 382: p. 112484.

460. Schmidt, L.S., et al., Erythropoietin as an add-on treatment for cognitive side effects of electroconvulsive therapy: a study protocol for a randomized controlled trial. Trials, 2018. 19(1): p. 234. 
461. Potvin, S., et al., Inflammatory cytokine alterations in schizophrenia: a systematic quantitative review. Biol Psychiatry, 2008. 63(8): p. 801-8.

462. Korschenhausen, D.A., et al., Fibrin degradation products in post mortem brain tissue of schizophrenics: a possible marker for underlying inflammatory processes. Schizophr Res, 1996. 19(2-3): p. 103-9.

463. Muller, N. and M.J. Schwarz, A psychoneuroimmunological perspective to Emil Kraepelins dichotomy: schizophrenia and major depression as inflammatory CNS disorders. Eur Arch Psychiatry Clin Neurosci, 2008. 258 Suppl 2: p. 97-106.

464. Müller, N., et al., The role of inflammation in schizophrenia. Frontiers in neuroscience, 2015. 9: p. 372-372.

465. Fillman, S.G., et al., Elevated peripheral cytokines characterize a subgroup of people with schizophrenia displaying poor verbal fluency and reduced Broca's area volume. Mol Psychiatry, 2016. 21(8): p. 1090-8.

466. Yenari, M.A., et al., Microglia potentiate damage to blood-brain barrier constituents: improvement by minocycline in vivo and in vitro. Stroke, 2006. 37(4): p. 1087-93.

467. Bora, E., Peripheral inflammatory and neurotrophic biomarkers of cognitive impairment in schizophrenia: A meta-analysis. Psychological medicine, 2019. 49(12): p. 1971-1979.

468. Greene, C., N. Hanley, and M. Campbell, Blood-brain barrier associated tight junction disruption is a hallmark feature of major psychiatric disorders. Translational Psychiatry, 2020. 10(1): p. 373.

469. Greene, C., et al., Dose-dependent expression of claudin-5 is a modifying factor in schizophrenia. Molecular Psychiatry, 2018. 23(11): p. 2156-2166.

470. Kealy, J., C. Greene, and M. Campbell, Blood-brain barrier regulation in psychiatric disorders. Neuroscience Letters, 2020. 726: p. 133664.

471. Wong, A.D., et al., The blood-brain barrier: an engineering perspective. Frontiers in neuroengineering, 2013. 6: p. 7-7.

472. Levkovitz, Y., et al., A double-blind, randomized study of minocycline for the treatment of negative and cognitive symptoms in early-phase schizophrenia. J Clin Psychiatry, 2010. 71(2): p. 138-49.

473. Monji, A., et al., Neuroinflammation in schizophrenia especially focused on the role of microglia. Progress in Neuro-Psychopharmacology and Biological Psychiatry, 2013. 42: p. 115-121.

474. Monji, A., T. Kato, and S. Kanba, Cytokines and schizophrenia: Microglia hypothesis of schizophrenia. Psychiatry Clin Neurosci, 2009. 63(3): p. 257-65.

475. Miyaoka, T., Minocycline for Schizophrenia: A critical review. Open Journal of Psychiatry, 2012. 02: p. 399-406.

476. Amin, A.R., et al., A novel mechanism of action of tetracyclines: effects on nitric oxide synthases. Proc Natl Acad Sci U S A, 1996. 93(24): p. 14014-9.

477. Zhang, L. and J. Zhao, Profile of minocycline and its potential in the treatment of schizophrenia. Neuropsychiatric disease and treatment, 2014. 10: p. 1103-1111.

478. Rosendo, A.B., et al., Lipid and C-Reactive Protein Levels, Cardiovascular Disease Risk Factors and Simvastatin Treatment in Brazilian Individuals. Inflammation, 2010. 33(4): p. 244-250.

479. Vevera, J., et al., The effect of prolonged simvastatin application on serotonin uptake, membrane microviscosity and behavioral changes in the animal model. Physiol Behav, 2016. 158: p. 112-20.

480. Wang, Q., et al., High doses of simvastatin upregulate dopamine D1 and D2 receptor expression in the rat prefrontal cortex: possible involvement of endothelial nitric oxide synthase. Br J Pharmacol, 2005. 144(7): p. 933-9.

481. Wang, Q., et al., Chronic treatment with simvastatin upregulates muscarinic M1/4 receptor binding in the rat brain. Neuroscience, 2008. 154(3): p. 1100-6. 
482. Müller, N., et al., Clinical effects of COX-2 inhibitors on cognition in schizophrenia. European Archives of Psychiatry and Clinical Neuroscience, 2005. 255(2): p. 149-151.

483. Arvindakshan, M., et al., Supplementation with a combination of $\omega-3$ fatty acids and antioxidants (vitamins $E$ and $C$ ) improves the outcome of schizophrenia. Schizophrenia Research, 2003. 62(3): p. 195-204.

484. Fusar-Poli, P. and G. Berger, Eicosapentaenoic acid interventions in schizophrenia: metaanalysis of randomized, placebo-controlled studies. J Clin Psychopharmacol, 2012. 32(2): p. 179-85.

485. Knöchel, C., et al., Omega 3 Fatty Acids: Novel Neurotherapeutic Targets for Cognitive Dysfunction in Mood Disorders and Schizophrenia? Current neuropharmacology, 2015. 13(5): p. 663-680.

486. Bozzatello, P., et al., Supplementation with Omega-3 Fatty Acids in Psychiatric Disorders: A Review of Literature Data. Journal of clinical medicine, 2016. 5(8): p. 67.

487. Sommer, I.E., et al., Efficacy of Anti-inflammatory Agents to Improve Symptoms in Patients With Schizophrenia: An Update. Schizophrenia Bulletin, 2013. 40(1): p. 181-191.

488. Satogami, K., et al., Omega-3 fatty acids related to cognitive impairment in patients with schizophrenia. Schizophrenia research. Cognition, 2017. 9: p. 8-12.

489. Bozzatello, P., et al., Effects of Omega 3 Fatty Acids on Main Dimensions of Psychopathology. International journal of molecular sciences, 2020. 21(17): p. 6042.

490. Hsu, M.-C., Y.-S. Huang, and W.-C. Ouyang, Beneficial effects of omega-3 fatty acid supplementation in schizophrenia: possible mechanisms. Lipids in Health and Disease, 2020. 19(1): p. 159.

491. Condray, R., et al., Semantic memory in schizophrenia: Association with cell membrane essential fatty acids. Schizophrenia Research, 2008. 106(1): p. 13-28.

492. Do, K.Q., et al., Redox dysregulation, neurodevelopment, and schizophrenia. Current Opinion in Neurobiology, 2009. 19(2): p. 220-230.

493. Yao, J.K. and M.S. Keshavan, Antioxidants, redox signaling, and pathophysiology in schizophrenia: an integrative view. Antioxidants \& redox signaling, 2011. 15(7): p. 2011-2035.

494. Berk, M., et al., N-acetyl cysteine as a glutathione precursor for schizophrenia--a doubleblind, randomized, placebo-controlled trial. Biol Psychiatry, 2008. 64(5): p. 361-8.

495. Yolland, C.O.B., et al., Improvement of cognitive function in schizophrenia with $\mathrm{N}$ acetylcysteine: A theoretical review. Nutritional Neuroscience, 2020. 23(2): p. 139-148.

496. Rapado-Castro, M., et al., Cognitive effects of adjunctive $\mathrm{N}$-acetyl cysteine in psychosis. Psychological Medicine, 2017. 47(5): p. 866-876.

497. Müller, N. and M.J. Schwarz, Immune System and Schizophrenia. Curr Immunol Rev, 2010. 6(3): p. 213-220.

498. Çakici, N., et al., An update on the efficacy of anti-inflammatory agents for patients with schizophrenia: a meta-analysis. Psychological Medicine, 2019. 49(14): p. 2307-2319.

499. Keshavan, M.S., et al., Cognitive training in mental disorders: update and future directions. Am J Psychiatry, 2014. 171(5): p. 510-22.

500. Harvey, P.D. and C.R. Bowie, Cognitive enhancement in schizophrenia: pharmacological and cognitive remediation approaches. Psychiatric Clinics, 2012. 35(3): p. 683-698.

501. De Mare, A., M. Cantarella, and G. Galeoto, Effectiveness of Integrated Neurocognitive Therapy on Cognitive Impairment and Functional Outcome for Schizophrenia Outpatients. Schizophr Res Treatment, 2018. 2018: p. 2360697.

502. Roder, V., D.R. Mueller, and S.J. Schmidt, Effectiveness of integrated psychological therapy (IPT) for schizophrenia patients: a research update. Schizophr Bull, 2011. 37 Suppl 2(Suppl 2): p. S71-9.

503. Roder V, M.A., Neurocognition and Social Cognition in Schizophrenia Patients. Basic Concepts and Treatment. 2010. vol 177(Key Issues Ment Health.): p. pp 118-144. 
504. Revell, E.R., et al., A systematic review and meta-analysis of cognitive remediation in early schizophrenia. Schizophr Res, 2015. 168(1-2): p. 213-22.

505. Medalia, A. and J. Choi, Cognitive remediation in schizophrenia. Neuropsychology review, 2009. 19(3): p. 353.

506. Wykes, T., et al., A meta-analysis of cognitive remediation for schizophrenia: methodology and effect sizes. American Journal of Psychiatry, 2011. 168(5): p. 472-485.

507. Medalia, A. and A.M. Saperstein, Does cognitive remediation for schizophrenia improve functional outcomes? Current opinion in psychiatry, 2013. 26(2): p. 151-157.

508. Medalia, A., et al., Cognitive remediation for psychological disorders: therapist guide. 2017: Oxford University Press.

509. Penadés, R., et al., Neuroimaging studies of cognitive remediation in schizophrenia: A systematic and critical review. World journal of psychiatry, 2017. 7(1): p. 34-43.

510. Reser, M.P., R. Slikboer, and S.L. Rossell, A systematic review of factors that influence the efficacy of cognitive remediation therapy in schizophrenia. Aust N Z J Psychiatry, 2019. 53(7): p. 624-641.

511. Revell, E.R., et al., A systematic review and meta-analysis of cognitive remediation in early schizophrenia. Schizophrenia research, 2015. 168(1-2): p. 213-222.

512. Vita, A., et al., Predictors of cognitive and functional improvement and normalization after cognitive remediation in patients with schizophrenia. Schizophrenia research, 2013. 150(1): p. 51-57.

513. Deste, G., et al., Effectiveness of cognitive remediation in early versus chronic schizophrenia: a preliminary report. Frontiers in Psychiatry, 2019. 10: p. 236.

514. Vita, A., et al., Effectiveness, Core Elements, and Moderators of Response of Cognitive Remediation for Schizophrenia: A Systematic Review and Meta-analysis of Randomized Clinical Trials. JAMA Psychiatry, 2021.

515. Bowie, C.R., Cognitive remediation for severe mental illness: state of the field and future directions. World Psychiatry, 2019. 18(3): p. 274-275.

516. Freeman, D., Studying and treating schizophrenia using virtual reality: a new paradigm. Schizophrenia bulletin, 2008. 34(4): p. 605-610.

517. $\mathrm{Ku}, \mathrm{J}$, et al., VR-based conversation training program for patients with schizophrenia: $a$ preliminary clinical trial. Cyberpsychology \& behavior, 2007. 10(4): p. 567-574.

518. da Costa, R.M.E.M. and L.s.A.V. de Carvalho, The acceptance of virtual reality devices for cognitive rehabilitation: a report of positive results with schizophrenia. Computer Methods and Programs in Biomedicine, 2004. 73(3): p. 173-182.

519. Kim, K., et al., Characteristics of social perception assessed in schizophrenia using virtual reality. Cyberpsychology \& behavior, 2006. 10(2): p. 215-219.

520. Adery, L.H., et al., The acceptability and feasibility of a novel virtual reality based social skills training game for schizophrenia: Preliminary findings. Psychiatry Research, 2018. 270: p. 496502.

521. d'Arma, A., et al., Social Cognition Training for Enhancing Affective and Cognitive Theory of Mind in Schizophrenia: A Systematic Review and a Meta-Analysis. J Psychol, 2021. 155(1): p. 26-58.

522. Fernández-Sotos, P., A. Fernández-Caballero, and R. Rodriguez-Jimenez, Virtual reality for psychosocial remediation in schizophrenia: a systematic review. The European Journal of Psychiatry, 2020. 34(1): p. 1-10.

523. Nijman, S.A., et al., Dynamic Interactive Social Cognition Training in Virtual Reality (DiSCoVR) for social cognition and social functioning in people with a psychotic disorder: study protocol for a multicenter randomized controlled trial. BMC Psychiatry, 2019. 19(1): p. 272.

524. Rus-Calafell, M., et al., Virtual reality in the assessment and treatment of psychosis: a systematic review of its utility, acceptability and effectiveness. Psychological Medicine, 2017. 48: p. 1-30. 
525. Dauwan, M., et al., Exercise Improves Clinical Symptoms, Quality of Life, Global Functioning, and Depression in Schizophrenia: A Systematic Review and Meta-analysis. Schizophrenia Bulletin, 2016. 42: p. 588-599.

526. Firth, J., et al., The effects and determinants of exercise participation in first-episode psychosis: a qualitative study. BMC Psychiatry, 2016. 16: p. 36.

527. Firth, J., et al., A systematic review and meta-Analysis of exercise interventions in schizophrenia patients. Psychological Medicine, 2015. 45: p. 1343-1361.

528. Malchow, B., et al., Effects of Endurance Training Combined With Cognitive Remediation on Everyday Functioning, Symptoms, and Cognition in Multiepisode Schizophrenia Patients. Schizophrenia Bulletin, 2015. 41: p. 847-858.

529. Rosenbaum, S., et al., Physical activity interventions for people with mental illness: $A$ systematic review and meta-analysis. Journal of Science and Medicine in Sport, 2014.

530. Schmitz, N., J. Kruse, and J. Kugler, The association between physical exercises and healthrelated quality of life in subjects with mental disorders: Results from a cross-sectional survey. Preventive Medicine, 2004.

531. Firth, J., et al., Aerobic exercise improves cognitive functioning in people with schizophrenia: $A$ systematic review and meta-analysis. Schizophrenia Bulletin, 2017. 43: p. 546-556.

532. Nuechterlein, K.H., et al., The MATRICS Consensus Cognitive Battery, Part 1: Test Selection, Reliability, and Validity. American Journal of Psychiatry, 2008. 165: p. 203-213.

533. Wykes, T., et al., A Meta-Analysis of Cognitive Remediation for Schizophrenia: Methodology and Effect Sizes. American Journal of Psychiatry, 2011. 168: p. 472-485.

534. Su, C.-Y., et al., The effects of aerobic exercise on cognition in schizophrenia: A 3-month follow-up study. Psychiatry Research, 2016. 244: p. 394-402.

535. Malchow, B., et al., The effects of physical exercise in schizophrenia and affective disorders. European Archives of Psychiatry and Clinical Neuroscience, 2013. 263: p. 451-467.

536. Firth, J., et al., Exercise as an intervention for first-episode psychosis: a feasibility study. Early Intervention in Psychiatry, 2018. 12: p. 307-315.

537. Kimhy, D., et al., Aerobic exercise for cognitive deficits in schizophrenia - The impact of frequency, duration, and fidelity with target training intensity. Schizophrenia Research, 2016. 172: p. 213-215.

538. Borg, G., Perceived exertion as an indicator of somatic stress. Scandinavian journal of rehabilitation medicine, 1970. 2: p. 92-8.

539. Firth, J., et al., Motivating factors and barriers towards exercise in severe mental illness: a systematic review and meta-analysis. Psychological Medicine, 2016. 46: p. 2869-2881.

540. Maurus, I., et al., Neurobiological effects of aerobic exercise, with a focus on patients with schizophrenia. European Archives of Psychiatry and Clinical Neuroscience, 2019. 269: p. 499515.

541. Erickson, K.I., R.L. Leckie, and A.M. Weinstein, Physical activity, fitness, and gray matter volume. Neurobiology of Aging, 2014. 35: p. S20-S28.

542. Malchow, B., et al., Effects of endurance training on brain structures in chronic schizophrenia patients and healthy controls. Schizophrenia Research, 2016. 173: p. 182-191.

543. Svatkova, A., et al., Physical Exercise Keeps the Brain Connected: Biking Increases White Matter Integrity in Patients With Schizophrenia and Healthy Controls. Schizophrenia Bulletin, 2015. 41: p. 869-878.

544. Black, J.E., et al., Learning causes synaptogenesis, whereas motor activity causes angiogenesis, in cerebellar cortex of adult rats. Proceedings of the National Academy of Sciences, 1990. 87: p. 5568-5572.

545. Pereira, A.C., et al., An in vivo correlate of exercise-induced neurogenesis in the adult dentate gyrus. Proceedings of the National Academy of Sciences, 2007. 104: p. 5638-5643.

546. Liu, P.Z. and R. Nusslock, Exercise-Mediated Neurogenesis in the Hippocampus via BDNF. Frontiers in Neuroscience, 2018. 12: p. 52. 
547. Ma, C.-L., et al., Physical exercise induces hippocampal neurogenesis and prevents cognitive decline. Behavioural Brain Research, 2017. 317: p. 332-339.

548. Fernandes, J., R.M. Arida, and F. Gomez-Pinilla, Physical exercise as an epigenetic modulator of brain plasticity and cognition. Neuroscience \& Biobehavioral Reviews, 2017. 80: p. 443456.

549. Voisin, S., et al., Exercise training and DNA methylation in humans. Acta Physiologica, 2015. 213: p. 39-59.

550. Kim, H.-j., et al., Increase of circulating BDNF levels and its relation to improvement of physical fitness following 12 weeks of combined exercise in chronic patients with schizophrenia: A pilot study. Psychiatry Research, 2014. 220: p. 792-796.

551. Kimhy, D., et al., The Impact of Aerobic Exercise on Brain-Derived Neurotrophic Factor and Neurocognition in Individuals With Schizophrenia: A Single-Blind, Randomized Clinical Trial. Schizophrenia Bulletin, 2015. 41: p. 859-868.

552. Kuo, F.-C., et al., Lifestyle modification and behavior therapy effectively reduce body weight and increase serum level of brain-derived neurotrophic factor in obese non-diabetic patients with schizophrenia. Psychiatry Research, 2013. 209: p. 150-154.

553. Fordyce, D.E. and R.P. Farrar, Enhancement of spatial learning in F344 rats by physical activity and related learning-associated alterations in hippocampal and cortical cholinergic functioning. Behavioural Brain Research, 1991. 46: p. 123-133.

554. Lee, H., et al., Regular Moderate or Intense Exercise Prevents Depression-Like Behavior without Change of Hippocampal Tryptophan Content in Chronically Tryptophan-Deficient and Stressed Mice. PLoS ONE, 2013. 8: p. e66996.

555. Mathes, W.F., et al., Dopaminergic dysregulation in mice selectively bred for excessive exercise or obesity. Behavioural Brain Research, 2010. 210: p. 155-163.

556. Meeusen, R. and K. De Meirleir, Exercise and Brain Neurotransmission. Sports Medicine, 1995. 20: p. 160-188.

557. Stranahan, A.M., K. Lee, and M.P. Mattson, Central Mechanisms of HPA Axis Regulation by Voluntary Exercise. NeuroMolecular Medicine, 2008. 10: p. 118-127.

558. Radak, Z., et al., Exercise, oxidative stress and hormesis. Ageing Research Reviews, 2008. 7: p. 34-42.

559. van der Stouwe, E.C.D., et al., Neural correlates of exercise training in individuals with schizophrenia and in healthy individuals: A systematic review. Neurolmage: Clinical, 2018. 19 : p. 287-301.

560. Papiol, S., et al., Polygenic risk has an impact on the structural plasticity of hippocampal subfields during aerobic exercise combined with cognitive remediation in multi-episode schizophrenia. Translational psychiatry, 2017. 7: p. e1159.

561. Pajonk, F.-G., et al., Hippocampal Plasticity in Response to Exercise in Schizophrenia. Archives of General Psychiatry, 2010. 67: p. 133.

562. Rosenbaum, S., et al., Aerobic exercise intervention in young people with schizophrenia spectrum disorders; improved fitness with no change in hippocampal volume. Psychiatry Research: Neuroimaging, 2015. 232: p. 200-201.

563. Scheewe, T.W., et al., Exercise therapy, cardiorespiratory fitness and their effect on brain volumes: A randomised controlled trial in patients with schizophrenia and healthy controls. European Neuropsychopharmacology, 2013. 23: p. 675-685.

564. Firth, J., et al., Effect of aerobic exercise on hippocampal volume in humans: A systematic review and meta-analysis. Neurolmage, 2018. 166: p. 230-238.

565. Lin, J., et al., Yoga reduces the brain's amplitude of low-frequency fluctuations in patients with early psychosis results of a randomized controlled trial. Schizophrenia Research, 2017. 184: p. 141-142. 
566. Takahashi, H., et al., Effects of sports participation on psychiatric symptoms and brain activations during sports observation in schizophrenia. Translational Psychiatry, 2012. 2: p. e96-e96.

567. Fonteneau, C., et al., Frontal Transcranial Direct Current Stimulation Induces Dopamine Release in the Ventral Striatum in Human. Cereb Cortex, 2018. 28(7): p. 2636-2646.

568. Hallett, M., Transcranial magnetic stimulation: a primer. Neuron, 2007. 55(2): p. 187-99.

569. Hasan, A., et al., Modulating neural plasticity with non-invasive brain stimulation in schizophrenia. Eur Arch Psychiatry Clin Neurosci, 2013. 263(8): p. 621-31.

570. Nitsche, M.A., et al., Transcranial direct current stimulation: State of the art 2008. Brain Stimul, 2008. 1(3): p. 206-23.

571. Peng, S., et al., BDNF as a biomarker in diagnosis and evaluation of treatment for schizophrenia and depression. Discov Med, 2018. 26(143): p. 127-136.

572. Haraldsson, H.M., et al., Transcranial Magnetic Stimulation in the investigation and treatment of schizophrenia: a review. Schizophr Res, 2004. 71(1): p. 1-16.

573. Li, J., et al., Efficacy of repetitive transcranial magnetic stimulation on auditory hallucinations in schizophrenia: A meta-analysis. Psychiatry Research, 2020. 290: p. 113141.

574. Begemann, M.J., et al., Efficacy of non-invasive brain stimulation on cognitive functioning in brain disorders: a meta-analysis. Psychological Medicine, 2020. 50(15): p. 2465-2486.

575. Jiang, Y., et al., Effects of High-Frequency Transcranial Magnetic Stimulation for Cognitive Deficit in Schizophrenia: A Meta-Analysis. Frontiers in Psychiatry, 2019. 10(135).

576. Kostova, R., et al., Targeting cognition in schizophrenia through transcranial direct current stimulation: A systematic review and perspective. Schizophrenia Research, 2020. 220: p. 300310.

577. Andrews, S.C., et al., Improving working memory: the effect of combining cognitive activity and anodal transcranial direct current stimulation to the left dorsolateral prefrontal cortex. Brain Stimul, 2011. 4(2): p. 84-9.

578. Millan, M.J., et al., Cognitive dysfunction in psychiatric disorders: characteristics, causes and the quest for improved therapy. Nature reviews Drug discovery, 2012. 11(2): p. 141-168.

579. Buckley, P.F. and B.J. Miller, Personalized medicine for schizophrenia. npj Schizophrenia, 2017. 3(1): p. 2.

580. McMahon, Francis J. and Thomas R. Insel, Pharmacogenomics and Personalized Medicine in Neuropsychiatry. Neuron, 2012. 74(5): p. 773-776.

581. FDA, FDA-NIH Biomarker Working Group. BEST (Biomarkers, EndpointS, and other Tools) in BEST (Biomarkers, EndpointS, and other Tools) Resource. 2016: Silver Spring (MD).

582. Kraus, V.B., Biomarkers as drug development tools: discovery, validation, qualification and use. Nat Rev Rheumatol, 2018. 14(6): p. 354-362.

583. Prata, J., et al., Bridging Autism Spectrum Disorders and Schizophrenia through inflammation and biomarkers - pre-clinical and clinical investigations. Journal of Neuroinflammation, 2017. 14(1): p. 179.

584. Wiecki, T.V., et al., A Computational Cognitive Biomarker for Early-Stage Huntington's Disease. PLOS ONE, 2016. 11(2): p. e0148409.

585. Neustadter, E., K. Mathiak, and B.I. Turetsky, Chapter 13 - EEG and MEG Probes of Schizophrenia Pathophysiology, in The Neurobiology of Schizophrenia, T. Abel and T. NicklJockschat, Editors. 2016, Academic Press: San Diego. p. 213-236.

586. van der Stelt, O. and A. Belger, Application of Electroencephalography to the Study of Cognitive and Brain Functions in Schizophrenia. Schizophrenia Bulletin, 2007. 33(4): p. 955970.

587. Meyer-Lindenberg, A., From maps to mechanisms through neuroimaging of schizophrenia. Nature, 2010. 468(7321): p. 194-202.

588. Penadés, R., et al., Neuroimaging Studies of Cognitive Function in Schizophrenia. 2019. p. 117-134. 
589. Linden, David E.J., The Challenges and Promise of Neuroimaging in Psychiatry. Neuron, 2012. 73(1): p. 8-22.

590. Schmitt, A., et al., Consensus paper of the WFSBP Task Force on Biological Markers: Criteria for biomarkers and endophenotypes of schizophrenia part II: Cognition, neuroimaging and genetics. The World Journal of Biological Psychiatry, 2016. 17(6): p. 406-428.

591. Oertel-Knöchel, V., et al., Discovery and development of integrative biological markers for schizophrenia. Prog Neurobiol, 2011. 95(4): p. 686-702.

592. Li, A., et al., A neuroimaging biomarker for striatal dysfunction in schizophrenia. Nature Medicine, 2020. 26(4): p. 558-565.

593. Kambeitz, J., et al., Detecting Neuroimaging Biomarkers for Schizophrenia: A Meta-Analysis of Multivariate Pattern Recognition Studies. Neuropsychopharmacology, 2015. 40(7): p. 17421751.

594. Molina, J.L., et al., Gamma oscillations predict pro-cognitive and clinical response to auditorybased cognitive training in schizophrenia. Translational Psychiatry, 2020. 10(1): p. 405.

595. Perez, V.B., et al., Mismatch Negativity is a Sensitive and Predictive Biomarker of Perceptual Learning During Auditory Cognitive Training in Schizophrenia. Neuropsychopharmacology, 2017. 42(11): p. 2206-2213.

596. Reid, R.C., From Functional Architecture to Functional Connectomics. Neuron, 2012. 75(2): p. 209-217.

597. Smith, S.M., et al., Functional connectomics from resting-state fMRI. Trends in Cognitive Sciences, 2013. 17(12): p. 666-682.

598. Andreou, C. and S. Borgwardt, Structural and functional imaging markers for susceptibility to psychosis. Molecular Psychiatry, 2020. 25(11): p. 2773-2785.

599. Baker, J.T., et al., Functional connectomics of affective and psychotic pathology. Proceedings of the National Academy of Sciences, 2019. 116(18): p. 9050.

600. Meyer-Lindenberg, A., Neural connectivity as an intermediate phenotype: brain networks under genetic control. Human brain mapping, 2009. 30(7): p. 1938-1946.

601. Viviano, J.D., et al., Resting-State Connectivity Biomarkers of Cognitive Performance and Social Function in Individuals With Schizophrenia Spectrum Disorder and Healthy Control Subjects. Biological Psychiatry, 2018. 84(9): p. 665-674.

602. Karlsgodt, K.H., Diffusion Imaging of White Matter In Schizophrenia: Progress and Future Directions. Biological psychiatry. Cognitive neuroscience and neuroimaging, 2016. 1(3): p. 209-217.

603. Kuswanto, C.N., et al., Diffusion tensor imaging findings of white matter changes in first episode schizophrenia: a systematic review. Clinical psychopharmacology and neuroscience : the official scientific journal of the Korean College of Neuropsychopharmacology, 2012. 10(1): p. 13-24.

604. Svatkova, A., et al., Physical Exercise Keeps the Brain Connected: Biking Increases White Matter Integrity in Patients With Schizophrenia and Healthy Controls. Schizophrenia Bulletin, 2015. 41(4): p. 869-878.

605. Di Biase, M.A., et al., PET imaging of putative microglial activation in individuals at ultra-high risk for psychosis, recently diagnosed and chronically ill with schizophrenia. Translational Psychiatry, 2017. 7(8): p. e1225-e1225.

606. van Berckel, B.N., et al., Microglia Activation in Recent-Onset Schizophrenia: A Quantitative (R)-[11C]PK11195 Positron Emission Tomography Study. Biological Psychiatry, 2008. 64(9): p. 820-822.

607. Penadés, R., et al., The search for new biomarkers for cognition in schizophrenia. Schizophrenia research. Cognition, 2015. 2(4): p. 172-178.

608. Vinogradov, S., et al., Is serum brain-derived neurotrophic factor a biomarker for cognitive enhancement in schizophrenia? Biological psychiatry, 2009. 66(6): p. 549-553. 
609. Power, J.D. and B.L. Schlaggar, Neural plasticity across the lifespan. Wiley interdisciplinary reviews. Developmental biology, 2017. 6(1): p. 10.1002/wdev.216.

610. Nuechterlein, K.H., et al., Enhancing Cognitive Training Through Aerobic Exercise After a First Schizophrenia Episode: Theoretical Conception and Pilot Study. Schizophrenia Bulletin, 2016. 42: p. S44-S52.

611. Jahshan, C., Y. Rassovsky, and M.F. Green, Enhancing Neuroplasticity to Augment Cognitive Remediation in Schizophrenia. Frontiers in Psychiatry, 2017. 8(191).

612. Chou, H.-H., E. Twamley, and N.R. Swerdlow, Towards medication-enhancement of cognitive interventions in schizophrenia. Handbook of experimental pharmacology, 2012(213): p. 81111.

613. Galuske, R.A.W., M.H.J. Munk, and W. Singer, Relation between gamma oscillations and neuronal plasticity in the visual cortex. Proceedings of the National Academy of Sciences, 2019. 116(46): p. 23317-23325.

614. McGorry, P.D., et al., Intervention in individuals at ultra-high risk for psychosis: a review and future directions. J Clin Psychiatry, 2009. 70(9): p. 1206-12.

615. McGorry, P.D., Early intervention in psychosis: obvious, effective, overdue. The Journal of nervous and mental disease, 2015. 203(5): p. 310-318.

616. Pukrop, R., et al., Neurocognitive indicators for a conversion to psychosis: comparison of patients in a potentially initial prodromal state who did or did not convert to a psychosis. Schizophr Res, 2007. 92(1-3): p. 116-25.

617. Riecher-Rössler, A., et al., Efficacy of using cognitive status in predicting psychosis: a 7-year follow-up. Biol Psychiatry, 2009. 66(11): p. 1023-30.

618. Glenthøj, L.B., et al., The effect of cognitive remediation in individuals at ultra-high risk for psychosis: a systematic review. NPJ schizophrenia, 2017. 3: p. 20-20.

619. Hill, S.K., et al., Neuropsychological impairments in schizophrenia and psychotic bipolar disorder: findings from the Bipolar-Schizophrenia Network on Intermediate Phenotypes (BSNIP) study. Am J Psychiatry, 2013. 170(11): p. 1275-84.

620. Ivleva, E.I., et al., Genetics and intermediate phenotypes of the schizophrenia--bipolar disorder boundary. Neurosci Biobehav Rev, 2010. 34(6): p. 897-921.

621. Schretlen, D.J., et al., Neuropsychological functioning in bipolar disorder and schizophrenia. Biol Psychiatry, 2007. 62(2): p. 179-186.

622. Goldberg, T.E., Some fairly obvious distinctions between schizophrenia and bipolar disorder. Schizophr Res, 1999. 39(2): p. 127-132.

623. Lewandowski, K., B. Cohen, and D. Öngur, Evolution of neuropsychological dysfunction during the course of schizophrenia and bipolar disorder. Psychol Med, 2011. 41(2): p. 225-241.

624. Reilly, J.L. and J.A. Sweeney, Generalized and specific neurocognitive deficits in psychotic disorders: utility for evaluating pharmacological treatment effects and as intermediate phenotypes for gene discovery. Schizophr Bull, 2014. 40(3): p. 516-522.

625. Barnes-Scheufler, C.V., et al., Transdiagnostic comparison of visual working memory capacity in bipolar disorder and schizophrenia. Int J Bipolar Disord, 2021. 9(1): p. 12.

626. Owen, M.J. and M.C. O'Donovan, Schizophrenia and the neurodevelopmental continuum:evidence from genomics. World Psychiatry, 2017. 16(3): p. 227-235.

627. Tamminga, C.A., et al., Bipolar and schizophrenia network for intermediate phenotypes: outcomes across the psychosis continuum. Schizophrenia bulletin, 2014. 40 Suppl 2(Suppl 2): p. S131-S137.

628. Kim, E.J., et al., Current Status of Cognitive Remediation for Psychiatric Disorders: A Review. Frontiers in Psychiatry, 2018. 9(461).

629. Leppanen, J., J. Adamson, and K. Tchanturia, Impact of Cognitive Remediation Therapy on Neurocognitive Processing in Anorexia Nervosa. Frontiers in Psychiatry, 2018. 9(96). 